\title{
The Insecurities of Service: Airport Check-In Workers
}

By

\author{
Ellen Rosskam * \\ Andrew Drewczynski ** \\ Renzo Bertolini ***
}

\begin{abstract}
Authors of the study:
* Ellen Rosskam, Ph.D., MPH, Senior Work Security Specialist, Socio-Economic Security Programme, International Labour Office, Geneva, Switzerland

** Andrew Drewczynski, MSc, Ergonomist, Canadian Centre for Occupational Health and Safety, Hamilton, Ontario, Canada

*** Renzo Bertolini, Ph.D., Researcher, Canadian Centre for Occupational Health and Safety, Hamilton, Ontario, Canada
\end{abstract}

This study was conducted with the collaboration of the International Transport Workers' Federation (ITF), the Canadian Labour Congress (CLC), the Canadian Auto Workers' Union $(C A W)$, representing check-in workers in Canada and which is affiliated to the ITF, and the trade unions representing check-in workers in Switzerland-Syndicat des Services Publique (SSP) and Personnel Union SAIR Holding (PUSH). Employers at each study site were equal, and encouraging participants in the research process.

For further information on the study, contact Ellen Rosskam, Senior Work Security Specialist, Socio-Economic Security Programme, International Labour Office, 4, route des Morillons, CH1211 Geneva, Switzerland, email:Rosskam@ilo.org; tel. direct: (41)22-799-8815; fax: (41) 22799-7123. For additional copies of this report, contact Julie Lim, ILO Socio-Economic Security Programmelimj@ilo.org),or download copies off ourwebsite (www.ilo.org/ses). 



\section{Table of Contents}

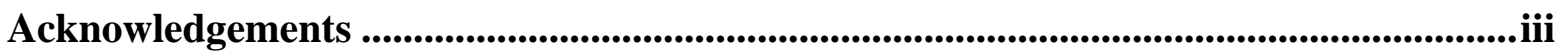

Abstract

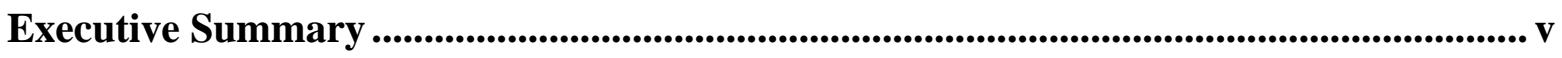

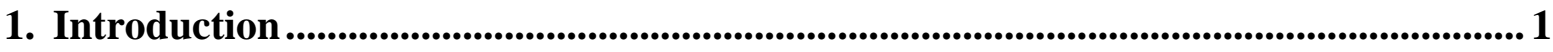

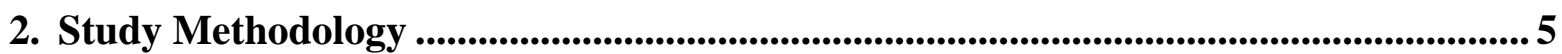

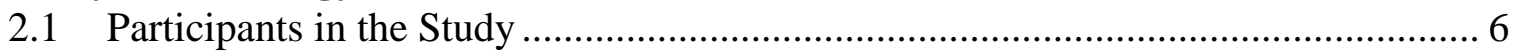

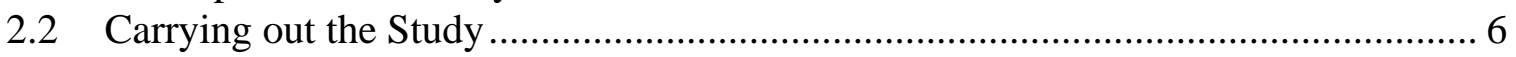

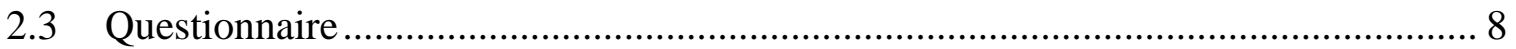

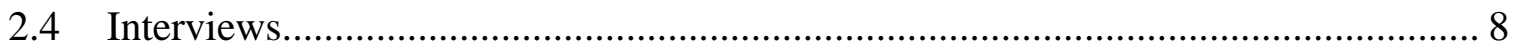

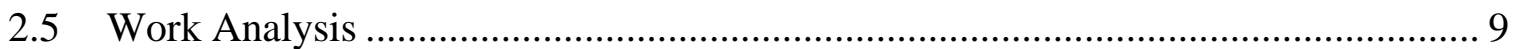

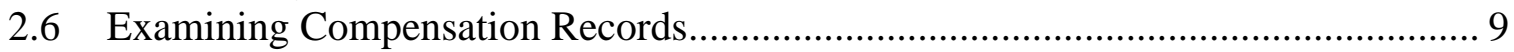

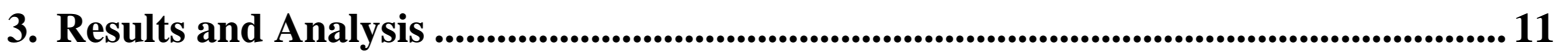

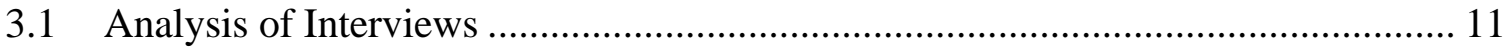

3.2 Summary of Results from Workstation Analysis ............................................. 15

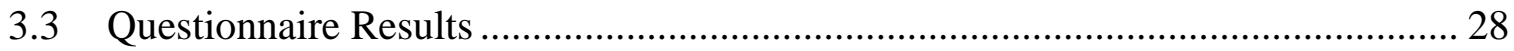

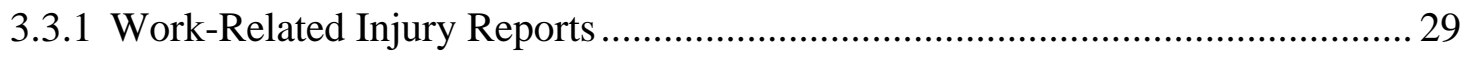

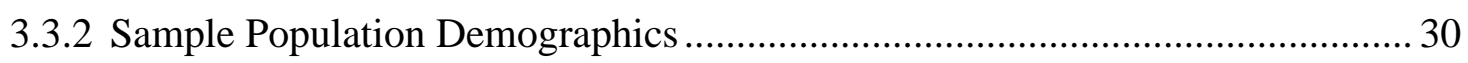

3.3.3 Workplace Environmental Factors............................................................... 31

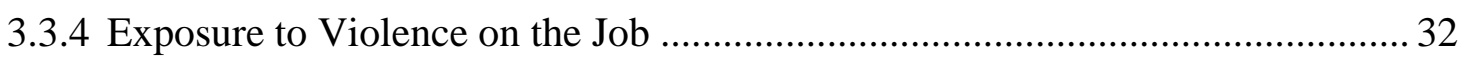

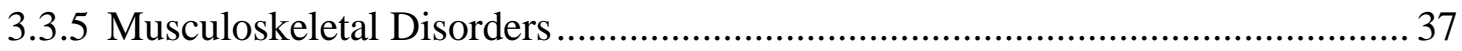

3.3.5.1 Neck and Shoulder Pain........................................................................ 41

3.3.5.2 Elbow, Wrist/Forearm and Hand Pain ..................................................... 41

3.3.5.3 Upper and Lower Back Pain and Foot Pain ........................................... 42

3.3.5.4 Distribution of Reported Musculoskeletal Pain ....................................... 43

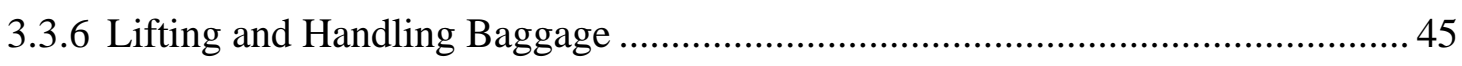

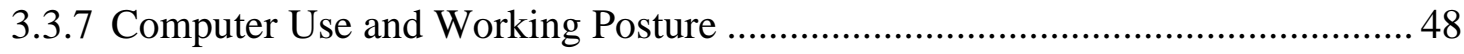

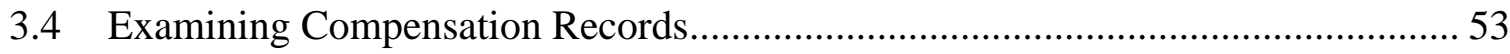

3.5 Cost of Fully Mechanized Baggage System ...................................................... 54

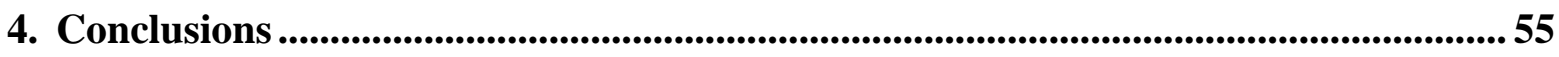

4.1 General Conclusions: Violence and MSDs ............................................................ 55

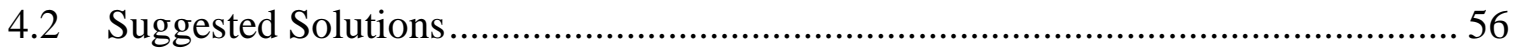

4.2.1 Suggestions for Workers and Trade Unions ................................................... 59

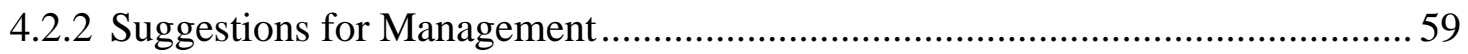

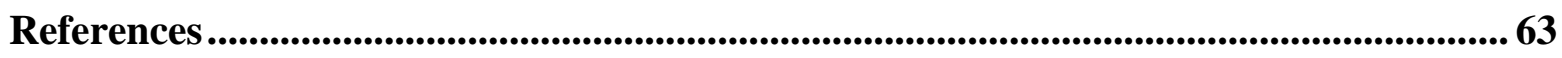

Appendix A: Use of the Study Results to Date ................................................................ 65 



\title{
Acknowledgements
}

This study was conducted within the Social and Economic Security Programme, International Labour Office (ILO), Geneva, together with the Canadian Centre for Occupational Health and Safety (CCOHS), Ontario, Canada. The study was headed by Ellen Rosskam, Social and Economic Security Programme, ILO, and carried out together with Andrew Drewczynski and Renzo Bertolini of the CCOHS.

The investigators extend their personal appreciation to the following individuals for their insight and support during this study: University of Lausanne, Switzerland (Alexander Bergmann, Dean, School of Management); Canadian Centre for Occupational Health and Safety (Len Hong, President and CEO, P.K. Abeytunga, Vice-President and Director-General, and Anne Gravereaux); International Transport Workers' Federation (Shane Enright, Head, Civil Aviation Section, Ingo Marowsky, Civil Aviation Section); Canadian Labour Congress (Jean-Claude Parrot, former Executive Vice-President, Brian Mallon, former Project Coordinator, International Affairs Department); Canadian Auto Workers' Union (Cathy Walker, Director of Health and Safety); International Labour Office (Richard Anker, former Head, Statistical Task Force, Ullrich Flechsenhar, former Deputy Director, Bureau for Workers' Activities, Tom Netter, Department of Communications, and Damien Riunaud, Department of Communications).

Gratitude is extended to Wilma Graham Jordan for her work transcribing interviews, to Tracy Murphy and Julie Lim for their editorial support on the report, and to Evis Kabili for assistance with data entry and analysis. Special thanks are extended to Laszlo Zsoldos for creating the charts and formatting the text.

Finally, the investigators wish to thank all the check-in workers around the world who have shared details of their working and non-working lives as part of this study. Their personal stories have provided a great deal of insight into the issues surrounding check-in work, and jobs performed predominantly by women.

This study has been supported by the International Transport Workers' Federation, the Canadian Labour Congress, and the International Labour Office (Bureau for Workers' Activities).

\author{
Guy Standing \\ Director \\ Socio-Economic Security Programme \\ International Labour Office \\ August, 2003, Geneva
}




\begin{abstract}
Airport check-in work, an increasingly de-professionalized occupation largely performed by women, characterized as high work demand with low worker control, has been not studied, until now. We examine the occupational health and safety issues together with the impact of current management practices and work organization, on check-in workers' health. Check-in workers face numerous obvious as well as less apparent hazards. High rates of musculoskeletal injury result from frequent lifting/handling of baggage and prolonged standing while operating a computer in a very constrained space. Other hazards include violence, work scheduling, environmental conditions, and uneven workload distribution. This report identifies that quick turnaround policies, work intensification, lack of training, lack of autonomy and of a voice in workplace decision-making have significant negative impacts on check-in workers. This twocountry study, conducted in Canada and Switzerland, examined check-in workers and employer injury/lost work time data at three types of airports representative of airport designs worldwide. Results show MSDs are common among check-in workers, may lead to temporary or permanent disability, and disrupt sleep and non work activities. Injury risks associated with semimechanised baggage systems are comparable to those of industrial workplaces, far from the glamourous image of check-in work. Frequent bending, awkward postures, prolonged sitting, and pulling baggage provoke MSDs even at fully mechanized check-ins. Ground rage and passenger violence are widespread, while protective management policies are rare. Current trends to reduce costs using less experienced, younger workers diminish job security while less attention is paid to working conditions. Adjustable workstations, change in management practices, skills development, increased worker participation and voice are recommended to make improvements for check-in workers.
\end{abstract}




\section{Executive Summary}

Examination of airport check-in workers is timely in an industry undergoing major change and characterized by worsening conditions of work. Highlighting airport check-in workers is perhaps even more appropriate following the events of September 11, 2001, when world attention is now focusing on ways to prevent disruptive passengers or terrorists from getting onto airplanes. Media attention today is focusing more on airport security workers and flight attendants. Attention could also be given, however, to the positive role that check-in workers can play in identifying potentially dangerous passengers, and the actions they can take to help ensure the safety and security of all on board aircrafts. For a group of workers that has been relatively in the background in air transport, a re-focusing of roles would require management strategies aimed at empowering check-in workers, policies, training, and organizational recognition of the preventive role in air transport safety that check-in workers can play. Perhaps a look at airport check-in workers' working conditions is a first step to bringing them into focus as a worker group with a larger role to play in public safety.

This study is the very first examination of the working conditions of airport check-in workers. Key findings indicate that musculoskeletal disorders (MSDs) are prevalent and severe among airport check-in workers and may lead to temporary or permanent disability. Over half the workers in the study live with neck pain, $49 \%$ have shoulder pain, and 1 out of 2 workers lives with lower back pain. In the past year nearly $16 \%$ lost work time due to neck pain, three out of every twenty-five (12.5\%) workers lost time at their professional activity from shoulder disorders, and nearly $20 \%$ were absent from work due to lower back pain. A substantial number of check-in workers performed their job functions despite significant neck, shoulder and/or back pain (defined as a level that interferes with the ability to perform one's job or which interferes with sleep). Nearly $75 \%$ of check-in workers experienced neck pain that interfered with their ability to work, and over two thirds experienced shoulder pain and/or lower back pain to a degree that interfered with work performance.

Over half of the workers had lower back pain in the past year painful enough that it interfered with their sleep. Chronic sleep loss due to pain interferes with one's ability to perform optimally at work, reduces resistance to stressors on the job and outside work, and can catalyse a cycle of physician visits, treatments, medications, and time off work, all with cost implications to workers and their families, particularly when no link to working conditions is suspected. These findings would indicate airport check-in work as having clear hazards associated with the job, an occupation likely to cause severe musculoskeletal disorders.

Awkward posture, lifting, carrying and tagging baggage, plus non-adjustable computer workstations, or an adjustable workstation that has not been adjusted for the individual worker, as well as static posture throughout a work shift are all factors in check-in work that appear to cause, or contribute to neck, shoulder, back, leg and wrist pain. The results related to MSDs suggest to management that there could be significant costs savings through lowered absence and improved performance levels if the workplace problems identified in this report are addressed.

Findings in this study reveal a picture of pain among check-in workers, at both semi-mechanized and fully mechanized baggage handling systems. While check-in work is a predominantly female occupation at the three study sites, results show that male check-in workers keep their female counterparts company in suffering from the gamut of MSDs, particularly with neck and lower 
back pain. The strain of lifting and carrying baggage, awkward postures and excessive sitting appear to know no gender bias, although proportionately more women are affected due to their greater numbers in the occupation, compared to men.

The cost of lost work time and diminished productivity indicates the need for workstation and work process re-design, in particular installing a fully mechanized baggage handling system where one does not exist. Ergonomic features should include the possibility for workers to alternate between sitting and standing throughout their work shift, and to adjust their table and chair heights.

Results indicate that pain which disrupts sleep, and non-work related activities, and which interferes with the ability to carry out job functions at optimum level of performance, has negative effects on productivity and efficiency. It also results in disruption to workers' lives beyond the workplace, interfering with quality of life, sometimes intermittently, other times longterm. The level of disabling and non-disabling injuries self-reported by check-in workers is significantly higher than those registered with their employers. A high level of underreporting of injuries is likely, although improvement in reporting can be addressed through various means.

Check-in work-related factors presenting the greatest risk for MSDs were found to involve:

?? fixed and constrained postures that are frequently awkward, uncomfortable and maintained for too long a period;

?? forceful hand movements and cyclical repetition;

?? an externally imposed pace of work; for example a high volume of passengers, and a high pace of work with quick turnaround policies dictating pace of work.

Expediting a passenger's baggage involves some different demands, but the same in external work rate. At airports with semi-mechanized baggage handling systems check-in workers have to lift and carry manually every piece of baggage checked-in. The resulting workload and the risk for MSD, especially low back injury, is comparable to an industrial workplace with heavy manual lifting. A fully mechanized baggage handling system obviates manual lifting only in principle, given that workers still manipulate bags regularly. The risk of injury is compounded by frequent bending, twisting, squatting, and other awkward postures adopted while tagging baggage.

Violence from aggressive passengers was found to be a serious issue facing check-in workers as well. One in twenty check-in workers in this study has been physically assaulted on the job, over $80 \%$ have been subjected to verbal abuse from passengers, and over $20 \%$ have been threatened by passengers.

Management policies engendering a high level of demand with a low level of control by workers, which characterizes check-in work, are shown to cause negative effects on workers' health. A lack of worker voice, autonomy and participation in workplace decision-making, as well as the lack of participation in work organization and workstation design are equally shown to adversely impact workers' health.

It is hoped that the findings from this study will be used to create improved working conditions, to redress deficiencies, and to improve overall conditions for check-in workers. 


\section{Introduction}

The airline industry is transforming. Growing international competition, mergers, alliances, and cost-efficiency strategies are increasing pressure, all with direct or indirect impact on the jobs and conditions of work for workers in the industry. Adding to what already has been an extremely complex industry, the social effects of liberalization are not making conditions better for workers in civil aviation, with impacts including low growth and a deterioration in the quality of existing occupations, in terms of employment security, atypical employment patterns and longer working hours (Boyd \& Bain, 1999). In general, airline industry workers are experiencing increased insecurity on all fronts. Airport check-in workers are no exception.

Research on workers' health tends to be concentrated on injuries and illnesses that cause lost work time and which have a clearly defined cause. This results in research generally focusing on a number of traditional male jobs, which tend to be associated with high levels of workers' compensation. The potential hazards of many occupations are not examined scientifically because many jobs are perceived as being 'clean' or 'safe', or present situations which are difficult to quantify or describe, particularly jobs largely undertaken by women. This perception does not mean that the workers do not face a variety of risks on the job.

Airport check-in workers are mostly, but not exclusively, women. While dramatic, easily identified, dangers are rare in the types of jobs usually assigned to women, nonetheless many jobs performed by women present a multitude of issues affecting their basic social and economic security, and their well-being. The 'feminized' image of check-in work combined with the perception of check-in work as 'safe, clean' work are key factors explaining why check-in workers have not been included previously in work-related health, or social and economic security studies, prior to this investigation.

There are a number of obvious hazards inherent in check-in work, and a variety of what may be less visibly apparent, but no less harmful hazards to the health of the workers. Check-in workers face a clear set of risk factors which place them at high risk of musculoskeletal injury, in particular frequent lifting and handling of baggage and operating a computer while standing or sitting for prolonged periods of time. Other obvious hazards include work scheduling, environmental conditions such as noise, ambient temperature, humidity, lighting, and uneven workload distribution. Other issues affecting check-in workers include work intensifying management policies and practices, stressful work that has a high level of demand but is associated with little worker control over the work organisation, employment and income insecurity, the precarious nature of many jobs, non access to skills development, and the lack of possibility to express one's voice. And any or all of these may impact the existence of and severity of musculoskeletal disorders (MSDs), and other ill-health outcomes.

The professional commitment of check-in workers is continuously undermined in the civil aviation industry: sufficient recognition is not accorded to the professional skills of check-in workers, the role of safety professional on the ground has not yet been widely linked with checkin work despite the natural placement for this expanded function, management policies increasingly target those workers with seniority, generally having higher salaries, encouraging them to leave their jobs, enabling management to hire younger workers, usually paid lower wages, often accompanied by less attractive benefits, and sometimes with worse working conditions (such as exclusively performing check-in work throughout an entire work shift, versus 
combining check-in work with other tasks). Low wages, work rate, and increase in short-term contracts, or increasingly flexible timing laws may contribute as reasons for check-in workers to turn over more quickly now in some areas, looking elsewhere for better paying jobs, or better working conditions. Turnover, however, does not mean that conditions improve for newly hired workers. In areas where employment opportunities are limited, workers may accept poor working conditions, reluctant to make demands or requests for improved conditions, for fear of losing their job. Similarly, management may use economic cycles as an excuse for not making improvements to working conditions.

A key risk of worker turnover in any industry where physical work is involved (particularly manual lifting), or where workstations are poorly designed, is that injuries, such as musculoskeletal disorders, which can be cumulative in nature with continued exposure over time, will not appear until later. An injury can be easily identified as work-related when there has been a sudden trauma. But daily low-level exposure, even over as little as one or two years, can weaken the musculoskeletal system, leaving a worker more susceptible to an injury in the future. The effect of stress is also likely to contribute to the existence of MSDs. With rapid turnover, it is difficult for workers and employers to associate work exposures with eventual adverse health outcomes. In terms of compensation, workers may be left without any recourse, while employers are spared their burden of costs, as well as their social, legal and ethical responsibilities for protecting workers' health.

Check-in workers do not appear typically to receive training for skills development, job enrichment, or for worker protection, including training in ergonomics, safe lifting techniques or for self-protection against aggressive passengers. For the workers in this present study, the only training received focused on use of the computer software needed to perform the check-in job.

In the area of psychosocial health, management practices are shown to be both direct and indirect causes of ill-health in workers. The spillover effect into workers' personal lives from disempowering management practices cannot be disassociated from working life (Chanlat, 1990). The link between direct and indirect causes of work-related ill health and the resulting impacts on private life is revealed among check-in workers, where important numbers of workers in the study reported that pain from MSDs interferes with sleep and causes them to stop activities outside of work. Management at airports around the world would do well to realise that workers need to be able to set parameters in the workplace, and that increased autonomy and worker voice are associated with increased benefits for both workers and management (Smith, 1981, 1997; Stratham and Bravo, 1990). Flexibility in managerial attitudes is a rational and positive start toward participation in organizational decision-making.

Check-in workers are the first point of contact with passengers. They have to perform their job functions no matter what emotional state passengers may display prior to travel, which can prove highly stressful for many people. Yet even with the multitude of skills check-in workers display in performing their job, they are seldom part of an established system of established measures and procedures designed to assure passenger, crew, and aircraft safety from aggressive or potentially dangerous passengers.

In the face of what can be difficult working conditions, check-in workers demonstrate positive attitudes towards their job, and give their best to ensure that passengers get off to their flights safely and contentedly. Check-in workers mostly report that they enjoy the work they perform, enjoy working with the traveling public, enjoy working in airports, and often express a great 
sense of commitment to doing their best on the job. Check-in workers may well be a group of heroes in civil aviation.

\section{Air and Ground Rage}

Violence against check-in workers from aggressive, disruptive or unruly passengers is a real and growing phenomenon (ITF, 2000). Compounding the already stressed and nervous state of many passengers upon arrival in an airport, airlines today use a variety of promises made through marketing to compete for loyal customers. This contributes to customer demands and entitlements expressed at the check-in counter, the first point of encounter between traveling passengers and airport staff.

The problem of aggressive or disruptive passengers traveling by air has markedly increased in the past several years, including threats, verbal abuse and physical abuse from disruptive passengers (IATA, 1998). Frustration at lack of progress on this growing problem prompted the International Transport Workers' Federation (ITF) to launch in 2000 and 2001 a worldwide campaign against air rage to protect cabin crew. The ITF estimates there has been a fivefold increase in incidents from 1994 (1,132 incidents) to 1997 (5,416 incidents), and the US Aviation Safety Reporting System shows that reports of aggressive passengers increased by about 800\% between 1997 (66 incidents) and 1999 (534 incidents). These rates of increase may reflect increased reporting, but also may reflect underestimates, because reporting typically included only actual violence but seldom addressed threatening behavior. As a result of lobbying by trade unions in the USA, in March 2000 the US government increased the maximum fine for disruptive passenger behavior offences from $\$ 1,100$ to $\$ 25,000$ (ITF, 2000).

There is a need for multi-level action to combat the problem of workplace violence against workers, including check-in workers and other ground staff. Action is needed at individual, group and organization-wide levels (Dickson et al, 1993, 1994; Leather et al, 1998), including prevention, intervention and rehabilitation. Organizational support helps to diminish the negative effects of violence against workers when incidences do occur by buffering the negative effects in a way that support from family and friends does not provide (Leather et al, 1998).

An employer attitude of zero-tolerance of work-related violence is a necessary organizational focus, which should be communicated to and by Human Resources Departments. Policies and procedures, security, crisis management teams and employee assistance programmes as well as educating workers and managers about work-related violence are the necessary components of an organizational approach aimed at zero-level work-related violence (Chenier, 1998).

Employers intending to develop and maintain productive and healthful work environments must protect themselves, their workplaces, and workers to minimize risks from potentially hostile sources. Airports around the world would do well to address the rapidly changing employment arena by establishing and implementing workplace violence prevention plans, and devising related training for all employees. Today, and even more since the events of September 11, 2001 in the United States, it is crucial that workers responsible for public safety be specially trained, particularly in airports and other public transport facilities.

Airport check-in workers, the first in contact with traveling passengers, having a wide range of skills that can be used in the role of safety professional, are a logical first line of defense for public safety in airports. It is important that check-in workers have the confidence, commitment and authority to deal with aggressive and disruptive passengers (ITF, 2000). Given the necessary 
training and management support to empower them to take on this critical role, check-in workers are well placed to identify potentially aggressive or threatening passengers, and to catalyse a chain of actions aimed at preventing disasters, or aggressive behavior towards check-in and other air transport workers. Recognition of the positive and important role that check-in workers can play as safety professionals on the ground would be a natural means of broadening their skill base, providing well-deserved recognition to the professional job performed, and could serve to offset the cyclical, repetitive nature of some of the job tasks.

"If airports, handling agents and airlines don't treat their staff as safety professionals, it can hardly come as a surprise that passengers don't do so either. The management of unruly or disruptive behaviour can best be achieved where passengers recognize the safety role of staff, are willing to accept their authority, and will comply with their instructions. Unfortunately, the marketing of aviation very often explicitly undermines this staff role: crew and passenger handling staff are all too often portrayed as compliant service providers, willing and able to meet the individual requirements of passengers. Service with a smile, delivered by young, attractive and usually female staff is the standard approach when promoting airline brands. Such images promote in the mind of passengers the notion that crew and ground staffs exist to meet passenger demands alone, rather than to enforce and deliver passenger safety" (ITF, 2000, p.12).

Check-in workers are well placed to assess the weight of bags, ensure that carry on baggage is of the correct weight, size and number, identify passengers who are under the influence of alcohol at time of check-in (before they become a potential problem on board an aircraft), and to identify passengers with mood problems (also before they become a potential problem on board an aircraft), all of which are factors identified as potential causes of air rage. Such skills are key means of preventing passenger rage on the ground or in the air.

"Unless airlines and passenger handling agencies actively promote and reinforce the safety professional role of employees in the minds of passengers, such staff will less easily be able to enforce their authority or get passengers to comply with their instructions. The active promotion of staff as safety professionals is an essential precondition to their empowerment..." (ITF, 2000, p.12). 


\section{Study Methodology}

To look at the complex set of occupational health and safety issues among airport check-in workers in a variety of countries, the International Labour Office (ILO) and the Canadian Centre for Occupational Health and Safety (CCOHS) (both tripartite organizations, whose constituents consist of governments, trade unions, and employers' organisations), carried out the present study in Canada and Switzerland, consisting of surveying by questionnaire, interviews, work analysis, and discussions with workers, employers, and airport authorities. The results of this study could be used to determine whether further research would be justified, using a number of countries to provide information for a multiple country comparative analysis.

The present study was conducted in three airports, to evaluate the working conditions of check-in workers. The selection of the three airports was based on the size of the airport and the system used for handling baggage, to elicit a view of the range of baggage check-in systems, from manual to mechanized:

?? Airport A is a small, regional airport in Canada with a semi-mechanized system for handling baggage. The semi-mechanized baggage system requires check-in workers to manually lift and carry every piece of checked baggage from the baggage scale up to the main conveyor, which then carries baggage further along to the area where it is loaded into the airplane cargo hold.

?? Airport B is a large, international airport in Canada with a fully mechanized baggage system, where check-in workers can alternate working in a sitting or standing position. The fully-mechanized baggage system includes a segment of conveyor connecting the baggage scale to the main conveyor, meant to eliminate the need for check-in workers to carry baggage manually.

?? Airport $\mathrm{C}$ is a medium sized, international airport in Switzerland with a fully mechanized system for handling baggage where check-in workers work exclusively in a sitting position.

The evaluation of work-related hazards was carried out under four major categories:

?? literature review;

?? examining compensation records;

?? surveying and interviewing workers and supervisors; and

?? work analysis.

To examine compensation records we looked at published national statistics and requested airlines to provide their own statistical data on injuries resulting in lost work time. To survey workers we distributed a questionnaire to all check-in workers among the three airports. Structured interviews were also carried out to obtain additional and more detailed information. Work analysis was carried out by observing tasks and jobs, by assessing workstation layout, and by videotaping workers. 


\subsection{Participants in the Study}

Participatory Action Research (PAR) was applied as the study methodology, selected to allow for participation by the unions and employers involved, and the desire for the research to lead to positive change (De Koning and Martin, 1996; Hall, 1975). This method allowed us to include a consultation mechanism in the study, for conveying the study results back to both the unions and the employers at the various study sites. Research based on Participatory Action Research establishes a means of providing empirical data to collective bargaining agents, as well as providing employers of check-in workers with a picture about the experiences of this group of workers. Discussions with unions at local, national and international levels helped bring to the surface various issues, helping to orient us to some of the intricacies of airport and check-in worker life, which would otherwise be difficult for researchers to know.

The study was designed in cooperation with the ITF and the Canadian Auto Workers Union (CAW represents check-in workers in Canada and is affiliated to the ITF). The ITF gave importance to, and encouraged the study, identifying it as priority issue for the international union. The local level unions at the three study sites helped to put us in contact with the key management people in human resources at the study sites. Following these links, we were able to discuss and agree with management and union on the various steps of the study, how best to implement the questionnaire, conduct interviews, and create a feedback mechanism. Management at the various study sites provided us with other key contacts, such as individuals who could provide us with information on the cost of installing and maintaining a fully mechanised baggage check-in system, and on recorded work-related injuries and lost work time.

At the initial stage of outlining the study design, the ITF helped to define a logical blend of study sites for the initial exploratory study, and a cross-sectional mix of countries and airports for a larger study, if one were to be undertaken in future. It was agreed to examine a semi-mechanised baggage check-in system, a fully mechanised system where workers operate in a fixed position throughout their work shift, and a fully mechanised system where workers have postural flexibility. We used these criteria to identify three airports of varying sizes, to provide a broad picture of check-in conditions. We conducted our own outreach to obtain management permission, and local level union support to conduct the study at the various sites.

\subsection{Carrying out the Study}

The problems faced by check-in workers were first identified by the ITF, but had not been quantified or studied in a comparative manner between several airports. Our literature review revealed that no previous studies had been conducted on check-in workers. The experience and knowledge of check-in workers and their representative unions and employers, including the Human Resource Departments, was relevant and guiding to the issues and the study overall. Input from all groups helped to shape the study design, while research objectivity was carefully maintained.

A workshop was held at the 1999 ITF health and safety conference, to discuss with global affiliates the issues they considered of priority importance with regard to check-in workers. Participants mainly included ground staff from various countries. Responses were enthusiastic, with spirited engagement in discussion.

We defined the research questions, and adapted to check-in work the research instruments necessary to measure the various aspects. Appropriate means of evaluating health and safety hazards among check-in workers, and evaluating lost work time due to injuries and work-related 
illness due to check-in work were identified. The following four research questions were defined:

?? Airport check-in work exposes workers to occupational hazards.

?? Workstation design, work organization, and management policies cause MSDs among airport check-in workers.

?? Check-in workers at semi-mechanised baggage check-in systems experience more adverse health outcomes than workers at fully mechanised systems.

?? Workstation design, work organization, and management policies cost employers of check-in workers reduced productivity, lost work time and workers' compensation costs, with higher levels of lost work time and workers' compensation among workers at semi-mechanized systems.

The process of investigation was initiated with the support of management at the three study sites. Discussions with the various employers enabled us to obtain management perspectives on issues such as the various factors thought to contribute to violence toward check-in workers, management interpretation of worker-reported MSDs as compared with employer records on injuries and lost work time, mechanization of baggage check-in systems versus non mechanization, training, skills development, empowerment of check-in workers, and systems of work organization. Similar discussions were held with the ITF, the national level trade unions, and local level unions, to obtain trade union perspectives on the issues. Management representatives expressed strong interest in using the study results to identify gaps in information and to identify areas needing improvement; unions expressed similar wishes, in addition to the ITF's stated intention to incorporate the study findings into their international media campaign against air rage, as appropriate, for the protection of check-in workers against passenger violence.

Preliminary testing of the questionnaire and interview schedule was performed at Airport A in Canada. Overall, the questionnaire yielded the required and desired information at all three study sites, despite the differing baggage check-in systems and workstation designs. Some questions in the questionnaire appeared to be unclear initially, particularly about lifting and carrying baggage. In analyzing the results, we found that even after refining these questions, there was still some lack of clarity depending on the baggage check-in system used by respondents. The questionnaire was distributed across three airport sites, and interviews conducted of workers and supervisors at each airport. Data were analyzed with unions and management providing input on interpretation of the preliminary findings. The final phase of the study also involved writing up the study in a report for both the unions and management, and communicating the key findings back to the unions and management.

At the 2001 ITF health and safety conference, another lively discussion resulted from presentation of the preliminary findings of the study, this time with a group consisting mainly of cabin crew. We discussed with the group whether the affiliates and the international union felt that a larger study was justified, based on the preliminary findings. Many of the affiliates indicated the need now for a larger study, covering more countries. Competing priorities were also discussed, however, such as the increasing problem of air and ground rage for ground staff and cabin crew, and diminishing air quality inside aircraft. It was agreed to make use of the findings of the present study as far as possible, while the ITF would explore avenues for research to be developed on these other priority issues. 


\subsection{Questionnaire}

The questionnaire used consisted of seventy-two open and closed-ended questions concerning work history, such as years in the profession; medical history including MSDs; physical work environment, for example, frequency of lifting; and psychosocial work environment, including violence at work.

We distributed the questionnaire to all check-in workers, in 2000, through management at the three airports. Questionnaires were voluntarily and anonymously completed and returned by workers. We used a distribution cycle, calculated with the management to cover all shifts and capture as many workers as possible, including those cycling back to work after vacation periods. Boxes for workers to pick up and return questionnaires were set up in central locations at the study sites. This system was established to ensure respondents' anonymity (which was important due to the personal nature of some of the questions, such as experience with violence, disclosure of MSD symptoms, severity of symptoms and whether these impacted the ability to perform one's job, and due to the fact that management distributed the questionnaire). Management representatives at the central locations were engaged to remind workers to pick up and return the questionnaire, with the hope of increasing the response rate and highlighting to workers management's support for the study.

Questionnaires were distributed in one round, to ensure confidentiality and protect workers' anonymity, a consequence of which was a lower response rate than might have been achieved with repeated surveying. We accepted the response rate in order to ensure anonymity and to maintain an un-pressured environment for workers' and managers' input to the study. In particular, it did not seem advisable to put pressure on management to engage in a second round of questionnaire distribution. However, the questionnaire distribution period was extended by an additional two weeks at Airport $\mathrm{C}$, in an effort to increase the number of responses.

Questions pertaining to perceived workload, working conditions and musculoskeletal complaints were based on benchmarking of variables and risk factors by NIOSH, variables noted in the literature, and questionnaires used by CCOHS and ILO. Questions addressing work-related violence were taken from the questionnaire used in an ILO study of work-related violence, taking into consideration ITF guidelines on air rage (Chappell and Di Martino, 2000).

A body map was integrated into the questionnaires so that respondents could indicate on outlines of the front and back of a human body exactly where they experienced pain from MSDs, if pain was present. The body maps completed by the questionnaire respondents helped to identify the extent of MSDs experienced by check-in workers, revealing many workers living with pain in multiple body sites at once (De Koning and Martin, 1996). The results of the body maps are statistically represented in Section 3.

\subsection{Interviews}

Interviews with 15 check-in workers (five at each airport, including at least one male at each site) and three supervisors (one at each airport) were guided with structured questions linked to the questionnaire. Workers were selected randomly, invited to a face-to-face interview, but decided themselves to participate in interviews. We had interview access to workers on all shifts. Personal interviews allowed us to collect information relating to work-related health and safety aspects of the job, training, effectiveness of communication with employer, work scheduling, expectation of length of employment, and any other concerns. Interviews were based on openended questions, such as: 
?? Do you have any health and safety concerns about your job? If so, what are they?

?? Do you receive training on lifting?

?? Is the joint health and safety committee effective? If not, why?

?? Is the workload the same throughout the shift?

?? Do you feel that you have open communication with your employer?

(Selected interview comments are found throughout the text of this Report.)

\subsection{Work Analysis}

We used direct observation of check-in workers performing their job functions, and the positions they adopt while performing job tasks to understand the precise duties of check in workers at all three study sites. Workstation layout was assessed through observation, ergonomic assessment, and by videotaping workers performing their jobs, focusing on check-in workers' main task: checking-in passengers and their baggage. Through observation, work analysis and videotaping workers performing their jobs, the principal components of check-in work were identified as: checking security and identification information, processing a passenger's ticket to generate a boarding pass, and expediting a passenger's baggage for loading onto the aircraft. No matter how similar these tasks may be at various airports, they can present very different workloads for the individuals performing them. Variations can be found in the design of the computer workstation, the baggage handling system, the volume of passengers, the quality of environmental conditions (lighting, noise, temperature) at any given airport, stress associated with aggressive passengers, and management practices.

\subsection{Examining Compensation Records}

In order to examine published compensation records, national statistics in Canada were examined, with the same attempt made in Switzerland, but without much success. Additionally, individual airlines consenting to participate in the study were requested to provide their own statistical data of injuries resulting in lost work time. As individual airlines are the employers of check-in workers at the two Canadian study sites, their consent was needed for participation in the study. In Switzerland, management consent was through the two ground handling companies at Airport $\mathrm{C}$, which are the employers of the check-in workers (as opposed to the airlines, who are the employers at the two study sites in Canada).

We wanted to examine Canadian and Swiss workers' compensation records in order to compare the national data with the airline or airport management company records. We wanted to obtain a picture of lost work time due to injuries among check-in workers, and types of work-related injuries that were compensated, particularly work-related MSDs. One could then compare the national figures with the airline/management records to know how check-in workers' reported injury rates and lost work time rates compared with other similar groups. This part of the study proved to have a number of limitations, and some unforeseen circumstances.

At present, workers' compensation records in each of Canada's provinces and territories are the most valuable sources of statistical information on work time lost due to work-related injuries and illnesses. These statistics are difficult to access and evaluate however, because of variation 
in classification systems and lack of standardization between provinces and territories. Each of the 13 Canadian jurisdictions has individual occupational health and safety act and regulations. Each jurisdiction also has its own legal process for injury and disease claims. Between Canadian provinces, workers' compensation programmes differ in benefits payable, administration practices, and in the compilation of statistics. There is no uniformity or consistency since different workers' compensation boards use different classification methods based on their particular needs. We were only able to obtain statistical data about Canadian airport personnel in general, as there is no specific code for reporting injuries resulting in lost work time among check-in workers specifically, in Canada.

Compensation information related to check-in workers in Switzerland was difficult to obtain for reasons similar to those described for check-in workers in Canada, with one additional major circumstance - the unanticipated collapse of Swissair, which was the national airline of Switzerland at the time. Although Swissair was not the direct employer of check-in workers in Switzerland, it was the major employer of the ground handling company employing the majority of check-in workers at Airport C, and its demise affected collection of data for check-in workers in Switzerland. In Switzerland, workers' compensation data are centralized with the Swiss National Insurance Fund (SUVA). Despite goodwill on their part, the airport ground handling companies were not in a position to request this information from SUVA because of the impending bankruptcy of the national airline. The ground handling companies were fully occupied due to the airline's financial crisis, and did not seem to be in a position where they felt they could approach SUVA, on behalf of the researchers.

Adding to the difficulty of obtaining workers' compensation data for the two countries studied, neither Swiss nor Canadian workers' compensation data include a category for MSDs. This makes it virtually impossible to identify work-related MSDs among any group of workers, even if one were able to obtain the compensation data from the central insurance fund or compensation board. 


\section{Results and Analysis}

\subsection{Analysis of Interviews}

In general, responses to interview questions were similar from all workers. Some of the major concerns reported included heavy workloads and poor environmental conditions. Workers and supervisors were asked how they perceived their workload. If the answer indicated heavy or stressful workload, a further question was asked regarding any management measures to address heavy workload. In general responses indicated that a heavy workload is characteristic of the job, causing stress, with a very high volume of baggage to handle, with many peak and few slack periods, and where passengers as well as management practices push the workers to work faster. One management practice at Airport $\mathrm{C}$ was noted for managing heavy workloads. Workers at this airport try to follow the rule of having no more than 1 passenger in line for first class, 3 in line for business class, and 7 in line for economy. Auxiliary and part-time workers can be brought in during peak periods. Common complaints included stuffy air, uneven air temperature between check-in areas (some areas too cold, others not cool enough, some areas comfortable), poor lighting, and persistent noise from the baggage conveyor (Airports B and C).

Addressing some basic health and safety issues, the following comments were made:

"The workstation is not very safe, it has a lot of zig-zag pointy corners. The first part of the belt is zig-zag, but the second part is smooth. The whole belt should be zig-zag" (worker, Airport C).

"I am concerned about the cleanliness of the counters, the keyboard and the passengers. Last year we requested vaccinations, but we were refused" (worker, Airport B).

And highlighting health and safety concerns, and lack of communication with management:

"Management doesn't explain how health and safety is protected for the workers. I asked for information, but never got any answers. I have back problems. Suitcases fall down, even with the zig zag carpet because there is no bar. I have to pick up the bags and put them back on the conveyor belt. The chairs are not good, there's no full back support and they're not comfortable. The new chairs are not fully adjustable. The employer bought these without consulting some workers. On one side of the airport, the temperature is $O K$, but on the other side, nearer to the doors, it's too cold. There's a lot of noise, and it's tiring. The boarding pass printer makes noise and there is general noise all around. The lighting is very bright everywhere. The health and safety committee exists, but it's not that effective dealing with health and safety issues. At the beginning of this year, a worker was killed on the tarmac by a high-loader going backwards. It was noisy so the worker could not hear it coming. This should have gotten more attention than it did. It didn't change anything" (worker, Airport C).

A general picture of check-in workers emerged from the face-to-face interviews, consistent at all study sites. In general, check-in work is the workers' and supervisors' job of choice. Check-in workers enjoy working with the public, are proud to wear the airline uniforms, and are committed 
to do their best at all times. While perceptions about the effectiveness of communication with management differed among workers at the various airports, notwithstanding, workers expressed a general attitude of willingness to work in cooperation with management.

At the end of the interview, workers and supervisors were asked if they had any other concerns they wanted to mention. We note here several 'other concerns' that were mentioned.

"Pushing wheelchairs with obese people through the snow, outside the airport in winter, is really hard" (worker, Airport A).

One Airport $\mathrm{C}$ worker was concerned about having to work a shift beginning before 07:00, obliging her to pay for a taxi to get to work since there is no bus at that hour. "If my schedule starts before 07:00, I have to pay for a taxi. This is a problem because the taxi fare is really expensive for me."

One worker from Airport A and two from Airport B commented on the need to receive some training on handling passengers in wheelchairs. One Airport $C$ worker summed up the major qualitative changes she noticed over time in her job and in the industry in general,

"I don't learn anything here. Only the computer system is used here, tag a bag, then explain things to people. Before, there were challenges, motivation, but not any longer. The ambiance changed. People who were here for 10-15 years are now leaving, and the pay cuts are demoralizing. The human touch is lost now. Making more money in less time is now the only important point."

Yet, in direct contrast with this comment, another worker at Airport C stated,

"I find the job quite interesting. It's up to the individual to make the job interesting. If you don't like it, better leave it."

While the following health and safety-related comment may be rather particular to Canada, it highlights the range of issues that check-in workers have to face:

"I had a beef (no pun intended) with hunters bringing in their bloody trophies.

I am a vegetarian. I wasn't sure if this was healthy and safe, for example it made the floor slippery. I was told by management not to deal with those passengers and to have another agent help them" (worker, Airport B).

These noted points punctuate the need for worker participation in work organization, and for effective use of workers' voice.

When asked about the effectiveness of the joint health and safety committee, both workers and supervisors at each airport made various comments:

"I don't know if the health and safety committee is effective or not" (supervisor, Airport C).

"The health and safety committee is, for me, non existent. It exists in fact, but it doesn't function" (worker, Airport A). 
"I'm satisfied with the health and safety committee, but there's only so much they can do, due to infrastructure problems" (worker, Airport B).

"I know that the health and safety committee is trying to change some ways of doing our job” (worker, Airport B).

"I can be very involved in raising issues. I wrote a letter that the whole group signed, about the workstations. I did this because I had severe muscle pain from lifting bags. I wanted something done about the conveyor belt set up and the twisting we had to do. I discussed the problem with the supervisor and then got the petition letter going. I copied the letter to the health and safety committee with a couple of injury reports, but they never used it. I don't know who is the health and safety committee representative" (worker, Airport A).

And two different workers at Airport B expressed concern about new scanners that had been introduced. Management had sent out a letter regarding the introduction of this new technology.

"I'm concerned about the new scanners we got. We received a letter from management, but I don't believe them. I'm aware that this concern is with the health and safety committee. The cleanliness of the counters and keyboards is a problem. The health and safety committee was informed about this, but no action was taken" (worker, Airport B).

"I'm concerned about the new laser unit we got to scan boarding passes. The health and safety committee was approached about this, and a letter was sent out by management saying there was no danger, but some passengers told me the contrary" (worker, Airport B).

Some comments recorded during interviews indicated mixed perceptions about communication with management. We note here some examples of comments from different individuals at each airport:

"Pretty much there is open communication between management and workers" (worker, Airport A).

"I have almost never talked [about health and safety concerns] with my supervisor. I'm not very outgoing to report anything, and I'm not sure if there is any sense complaining” (worker, Airport B).

"There's no fixed communication, it comes up as necessary. Supervisors meet every week" (supervisor, Airport C).

"I think there's good communication between workers and management" (worker, Airport C).

"Communication between workers and the employer is up to the individual. You have to get a lot of information on your own. If a worker is quiet, you may not have good communication" (worker, Airport C).

"There has been a lot of staff turnover - about 25 people left recently. The employer wants to have people stay a maximum of 2 years in order not to pay 
higher wages. So senior people leave. They put pressure on senior staff to leave. Communication between workers and employer doesn't flow at all. The employer doesn't involve workers when communicating. My supervisor is very understanding. Not all supervisors are like this, not all will have the answers to your questions. You have to chase them usually to get your answers" (worker, Airport C).

Workers at Airports A and B remain on the job longer, on average, than those at Airport C, or at least longer than those workers employed by one of the two employers at Airport C. When asked about their expectation for remaining on the job, responses from several workers at Airport A point to their long-term vision for remaining on the job: "I guess I will stay on this job until my retirement" (worker, Airport A). "This is pretty much a career job for me" (worker, Airport A). "I will probably do this job for 12 more years" (worker, Airport A). While working conditions appear worse at Airport $\mathrm{A}$ than at $\mathrm{C}$, some factors appear to override the negative conditions, motivating Airport A workers to stay up to 10 years on the job, and still express enjoyment with their work. Notwithstanding, personal interviews reveal individual differences, demonstrated by the following comments made by two workers at Airport B: "I hope not to be doing this work for too much longer. I preferred being a flight attendant - there were less aggressive passengers" (worker, Airport B). "I guess I will do this job as long as I can. It's convenient for making some money” (worker, Airport B).

Remarks made by five different workers at Airport $\mathrm{C}$ revealed a lack of long-term expectation of remaining on the job. Some workers explained the reason(s) for their dissatisfaction:

"I've been doing this job for 3 years, and think I'll do this only until I find something else. I need more challenging work. This is a good job for part-time people and students. It's not a good job for full-time people" (worker, Airport C).

"I've been here 4 years and will stay another 2 years. I was told that a normal passenger should take 40 seconds to check-in. I used to be able to take more time with passengers. I want more contact time with passengers, to have them leave happy, not to be a 40-second per passenger machine" (worker, Airport C).

"I've been on the job for one and a half years. I'm thinking about quitting now because the conditions are not good. I don't get the hours I want, the supervisor doesn't come to tell her issues to me, instead she goes to the unit head. They go behind my back instead of coming to me personally" (worker, Airport C).

"When I was hired 5 years ago, I expected it to be for life. Now I think 3-7 years is best. I might stay on past 7 years, but I doubt it” (worker, Airport C)

"I am leaving in one month" (worker, Airport C).

Again highlighting individual differences, one Airport $\mathrm{C}$ worker expressed contentment with the job, "I've been working here for 2 years. No idea how long I'll be doing this job. It suits me well now, it matches with my private life and gives me a lot of free time" (worker, Airport C). 
Shoes constitute part of a check-in worker's uniform and therefore must conform to uniform regulations. At Airport A, workers are provided with an allowance of Canadian $\$ 70$ per year for the purchase of shoes. Workers reported that the allowance is inadequate for the three pairs of shoes (on average) they typically wear out per year. Shoes wear out quickly due to excessive standing on a hard surface, walking in the airport and on the tarmac, and from lifting and carrying baggage, the weight of which places wear and tear on the soles of shoes. To stretch their shoe allowance Airport A workers purchase low cost shoes (in both price and relative quality). During the interviews, some Airport A workers indicated that they intended to raise the issue with the health and safety committee.

Perhaps, the most significant finding from interviews of both workers and supervisors was the unanimous confirmation of the lack of any ergonomics or safety training on either manual materials handling or computer use. Direct outcomes of the lack of basic knowledge about properly designed and adjusted workstations, and of proper work techniques include:

?? work in awkward positions that expose workers to discomfort, with a higher risk for injuries;

?? compromise improvements of working conditions as a consequence of lack of awareness of better ways of working.

\subsection{Summary of Results from Workstation Analysis}

\section{Check-in duties:}

Checking-in, the core task of the check-in worker, is a complex one, involving a series of various activities that require a variety of skills. Activities are cyclically repetitive. The typical sequence of activities to serve a single passenger is as follows:

?? welcoming a passenger

?? obtaining security information

?? receiving an air ticket

?? processing the ticket electronically

?? printing and issuing a boarding pass

?? informing a passenger about his/her seat on the plane

?? checking the weight of the baggage

?? printing a baggage tag

?? attaching the tag to the baggage

?? lifting and carrying baggage (often extremely bulky, heavy and unwieldy) from the scale to the conveyor belt

?? activating the conveyor belt

?? making sure that the baggage moves along smoothly

?? picking up baggage when it falls off the conveyor and putting it back on the belt

Additional regular tasks of check-in workers may include:

?? handling special baggage

?? unloading unclaimed baggage from baggage carousels and lining up bags on the floor to clear carousels for in-coming flights 
?? gate duties, including lifting and carrying bags that cannot be hand carried onto airplanes by passengers and which have to be specially checked at the gate. Often such bags are heavy and check-in workers have to carry these to the airplane tarmac.

Both sitting and standing present their own unique problems, even at workstations that allow workers to alternate between sitting and standing, for flexibility of working postures. For instance, considering that all work activities except for lifting and carrying baggage could be done in a sitting position, Airport A check-in workers nevertheless work predominantly in a standing position (Photo 2).

The impact of check-in work on the individuals performing it can be diverse, depending on the design of the check-in counter and the baggage handling system. Factors that can influence the workload include the design of the computer workstation, the baggage handling system, the volume of passengers and the regularity at which they arrive, the number of flights to check in per work shift, and the environmental conditions (particularly air quality, noise, and temperature) at each airport.

It is unclear to what extent each of these factors impacts the workload for any individual worker, and whether each factor has equal impact. However, the baggage handling system and the design of the computer workstation appear to have significant impact on workload, perhaps playing a more influential role than the other factors with regard to adverse health outcomes.

It appears that airlines' quick turnaround policies also exercise a significant influence on workload. Work demand (exerted by the speed of work), the number of flights each day, and pressure exerted on workers to ensure that passengers are checked-in quickly, while maintaining a polite and friendly manner, contribute to a heavy daily workload. The work shift length, plus number of bags handled per day (which fluctuates according to day and work shift) are additional indicators of workload.

Damaging workloads are indicated by the high rates of MSD-related symptoms, revealed by workers at both semi-mechanized and fully mechanized check-ins, and among workers at very poorly laid out workstations (Airport A), as well as at better-designed workstations. Sitting for 68 hours, and lifting or generally handling baggage, even where there is a fully mechanized system, plus twisting in an awkward posture to tag bags, in the absence of any training on proper lifting technique, appear to be hazardous combinations for workload levels and for worker health.

Workers and supervisors at all three airports commented on the absence of training on safe lifting technique and the need for such training.

"I've never had any training on lifting” (supervisor, Airport C).

"I never had any training on lifting. I don't even know if the employer has a policy on manual handling! I know we are allowed to lift 70 pounds, with the maximum allowed 100 pounds" (worker, Airport A).

"I never had any real training on lifting, just I was told to bend my knees. I am careful when I have to lift baggage, to avoid back problems. I have a good idea just by looking at the size of a bag of the actual weight" (worker, Airport B). 
"I was supposed to attend a training seminar on safe lifting, but it was cancelled several times. I have no idea of any safe lifting limit” (worker, Airport B).

"I never had any training on lifting, and we need this. Bags fall over behind my desk, and I have to ask passengers to help me lift them, because they are too heavy" (worker, Airport C).

"I know there is a company policy of 70 pounds. I think I can safely lift up to 50 pounds" (worker, Airport A).

"I've never had any training on lifting. If a big bag falls off, I'll ask someone else to pick it up" (worker, Airport C).

"I never had any training on lifting, and I think there should be training on proper lifting” (worker, Airport C).

To investigate whether length of work shift contributes to check-in workers' MSDs, we examined the number of workers having pain and those workers not having pain, cross-tabulated with the length of their respective work shifts (see later in Figure 15). The findings show that at Airport A, where the work shift is more than $11 \frac{1 / 2}{2}$ hours long, all workers have MSD pain. At Airport B, significantly more workers on a 71/2-hour shift have MSD-related pain compared with those on a roughly 6-hour shift.

While further research should be conducted before drawing firm conclusions, these findings may indicate a relative tolerable limit of body load for a check-in worker, after which point musculoskeletal pain begins to appear. Approximately 6 hours of check-in work may be the 'safe' limit, at a fully mechanized workstation that allows for both sitting and standing. One and a half hours more work time under the same conditions appears to result in a significant increase in the number of workers experiencing MSD pain.

For workers lifting and carrying baggage all day long (Airport A), there is likely no 'safe' exposure limit under such conditions. Here too, further investigation of workers at semimechanized systems working various shift lengths would be necessary to draw more firm conclusions. What is evident, however, is that workers employed under conditions similar to those found at Airport A are extremely likely, if not certain, to develop MSDs. For check-in workers operating under conditions similar to those at Airport $\mathrm{C}$ (fully mechanized baggage system, sitting down throughout the entire shift), MSDs are also likely to develop, largely due to excessive static posture combined with various awkward movements, even when the work shift is under 7 hours.

If the cumulative effect of various factors over a given period of time causes a breaking point in a worker's physiology, then physical characteristics of a worker (notably relative strength) are likely to be irrelevant, and most workers might end up with some sort of health problem, given sufficient exposure level and frequency. Full mechanization of baggage check-in systems alone is not sufficient to eliminate MSDs from check-in workers, as demonstrated by significant rates of MSDs among workers at Airports B and C.

There is a noted difference between Airport C, and Airports A and B. Two independent management companies operate at Airport $\mathrm{C}$, with check-in workers employed by one of the two 
companies. One of the two employers has a policy of not allowing check-in workers to perform exclusively check-in work, so that workers perform multiple functions as part of their job, including a variety of passenger service duties, consisting of working at the gate, assisting passengers in wheelchairs, assisting elderly passengers and passengers with any type of disability, and assisting VIP passengers. The results, plus discussions with workers, indicate that while in principle, check-in work is meant to make up only part of the overall job, for those Airport $\mathrm{C}$ workers employed with such management policy, often this is not the case, with those workers still performing check-in functions exclusively. Task variety is not built into the job of check-in workers employed by the other management company at Airport $\mathrm{C}$, where workers perform check-in work exclusively. Due to data aggregation, plus questionnaire anonymity, it cannot be determined which respondents are employees of which management company at Airport C.

\section{Workstation layout:}

Detailed study of the workstation layout at all three study sites revealed a number of points in common among all check-in workstations. The worktables at check-in work areas are of a fixed height, and are not adjustable even though they have to be used by a variety of workers, of different sizes. Computer keyboards and screens also are at fixed heights, even though they have to be used by workers of any size. Chairs may or may not be adjustable but have to be used by workers of any height and size. The workstation is designed for work in a standing or sitting position, depending on the design. Heat and humidity in summer, and chilly drafts in winter aggravate the physical stress on workers' bodies at all three sites.

A summary of the findings by each Airport is presented below.

AIRPORT A: Small, regional airport with semi-mechanised baggage system requiring workers to lift and carry every bag checked-in.

The check-in workers' work area is fixed, that is, non-adjustable, and is designed for sharing among a number of workers, on various shifts. The workstation is designed for work in a standing or sitting position at the discretion of the worker, and consists of the following:

?? a check-in counter the surface of which is typically occupied by a computer monitor, keyboard, printer, telephone, scale display, and a labelling/tagging device (Photo 1)

?? a tall sit/stand chair (non-adjustable for most workers)

?? the baggage weigh scale (Photo 2)

?? the baggage conveyor belt 


\section{Photo 1}

Check-in workstation surface and computer, Airport A

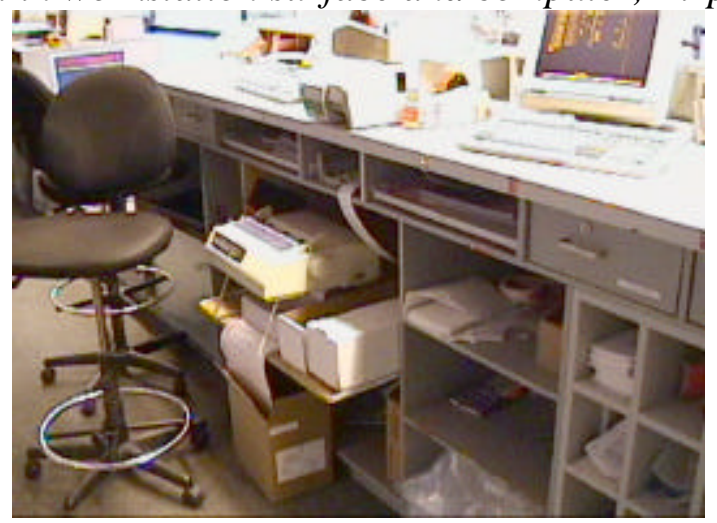

Photo 2

Working in standing position at check-in, Airport A

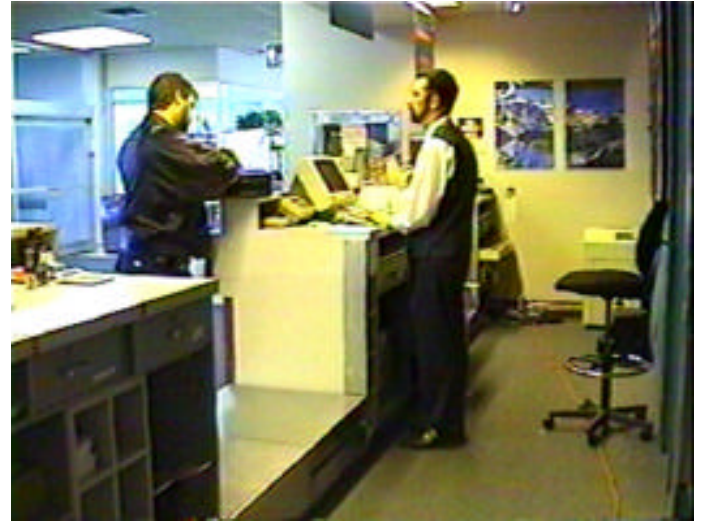

Photo 3

Working in sitting position at check-in, Airport A

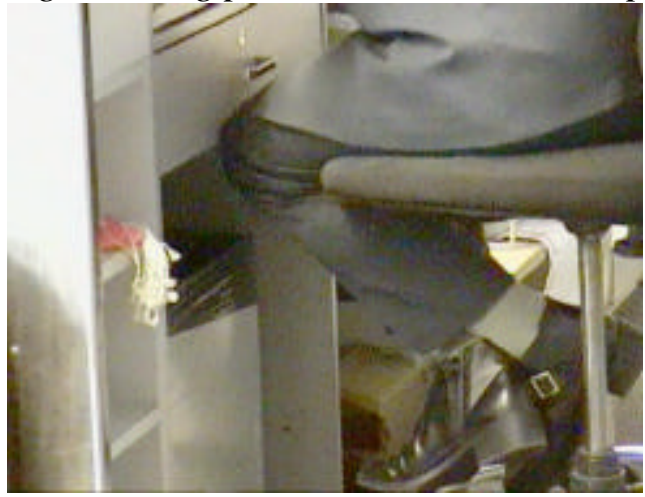

Operating computers practically all day long at a workstation lacking height adjustability and sufficient leg clearance contributes to a strained and uncomfortable body posture, regardless of whether a check-in worker chooses to work standing or sitting. Manual lifting is a major source of discomfort and hazard for low back injury. Workers at Airport A bend low and reach forward to grasp and lift the baggage from where a passenger left it on the scale, most of the time using only one hand, then haul baggage to the conveyor behind their workstation.

"We operate around 1 flight per hour, which is a rapid air schedule. We often have to pull bags off the in-coming baggage belt, which can be as much as a 
whole flight load of bags that have to be pulled off. I am the only one who will ever call for help or shut down the belt moving to get the bags off. Many of the bags are very heavy, plus they pull against a moving belt" (worker, Airport A).

Repetitive lifting, twisting and carrying, plus the heavy weights, put check-in workers at risk of various musculoskeletal injuries, low back injury in particular. The environmental conditions at Airport A aggravate the physical stress on the workers' bodies, with temperature extremes ranging from too hot to too cold, too much noise, and poor levels of lighting.

Airport A check-in stations are near the entrance to the airport. There is one set of automatic doors between workers and the outside. Each time the doors open in winter, cold blasts of air hit the workers directly. In summer, the opposite problem occurs, with air conditioning inside the airport, and hot, humid air brought in from outside each time the doors open and close.

In principle, work can be performed from a sitting or standing position, although workers spend nearly two thirds of their work shift standing. Workers prefer to stand, even for extended periods, due to the complete lack of legroom under the check-in counter. The lack of legroom results in workers hitting their knees and shins against drawers or other hard surfaces when they work sitting down. Uncomfortable chairs are also obstacles to working from a seated position. The chairs are in poor state of repair, with some chairs broken, unstable and unsafe. In addition, the unsuitably laid-out work surface, which necessitates over-reaching, excessive bending and stretching, also discourages workers from carrying out their jobs from a seated position. From a seated position, workers are unable to get sufficiently close to the counter and computer screen due to the complete lack of space under the counter. The only means of reaching the computer in a relatively comfortable manner is to stand up and bend forward over the counter. Workers therefore generally prefer to stand during their work shift. Due to these conditions, over $70 \%$ of workers at Airport A reported feeling that they work in a constrained posture (see later in Figure 17).

\section{Photo 4}

\section{Lifting and carrying large baggage from the baggage scale to the conveyor, Airport A}

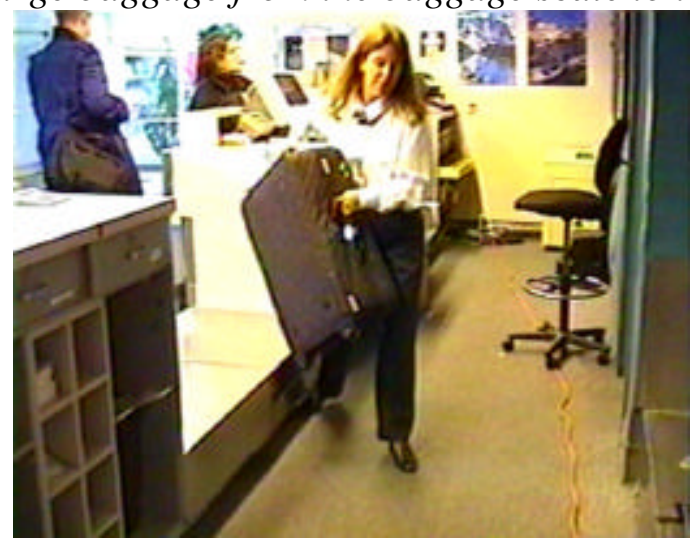


Photo 5

Getting baggage to conveyor, Airport A

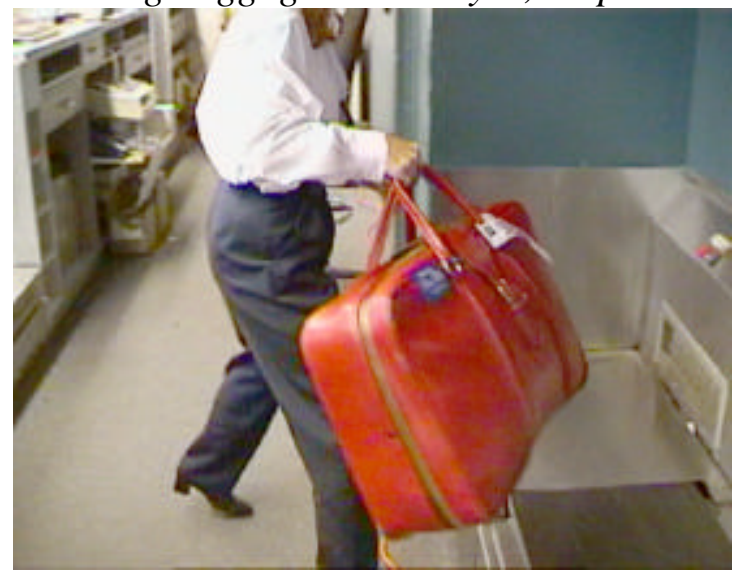

Photo 6

Mustering strength to haul a heavy bag from the baggage scale to the conveyor, Airport A

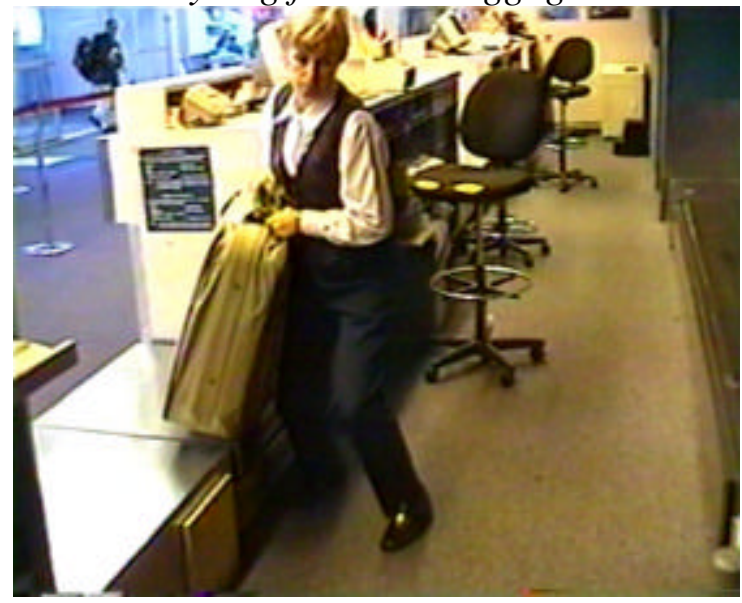

AIRPORT B: Large, international airport with fully mechanized baggage system where workers have option to work either sitting or standing.

\section{Workstation layout:}

The check-in counter at Airport B appears similar to the one at Airport A with the following differences: the baggage handling system has an additional conveyor belt connecting the baggage scale with the main conveyor, the computer workstation has a height-adjustable keyboard tray and there is sufficient leg clearance under the counter (Photo 8).

A number of features of the design and layout of the check-in counter at Airport B provide some degree of protection to check-in workers against aggressive passengers. These features include:

?? the chest-high check-in counter;

?? the fairly narrow opening for the baggage scale;

?? the short stretch of the moving conveyor. 
Photo 7

Check-in workstation, Airport B

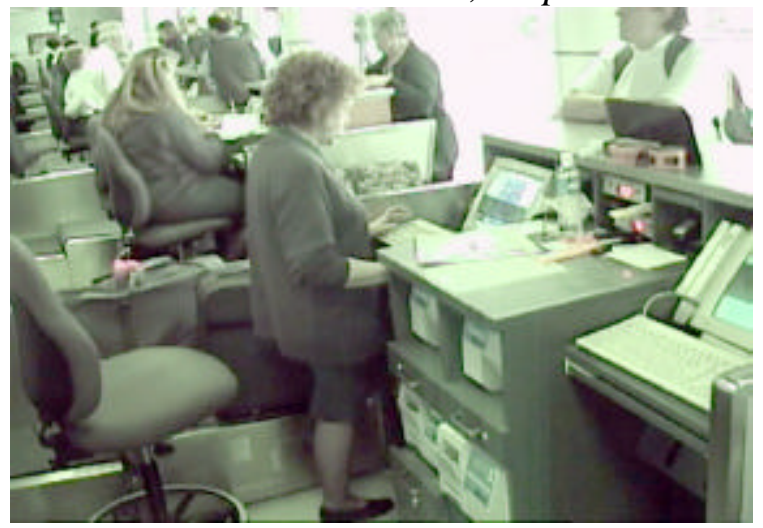

Photo 8

Leg clearance under check-in workstation, Airport B

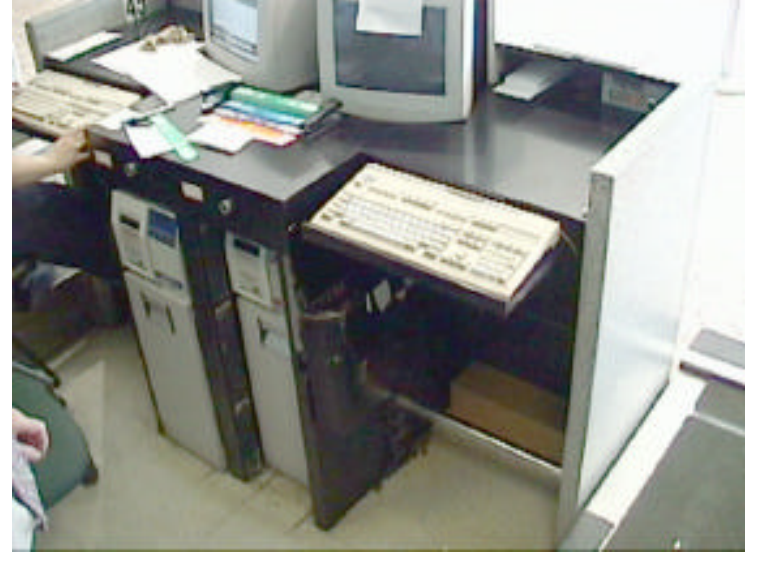

Photo 9

Baggage jammed on the conveyor, Airport B

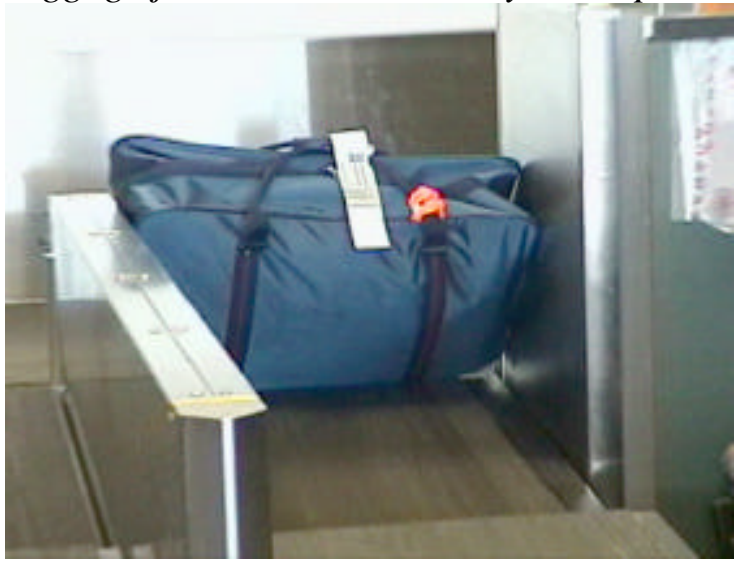


Photo 10

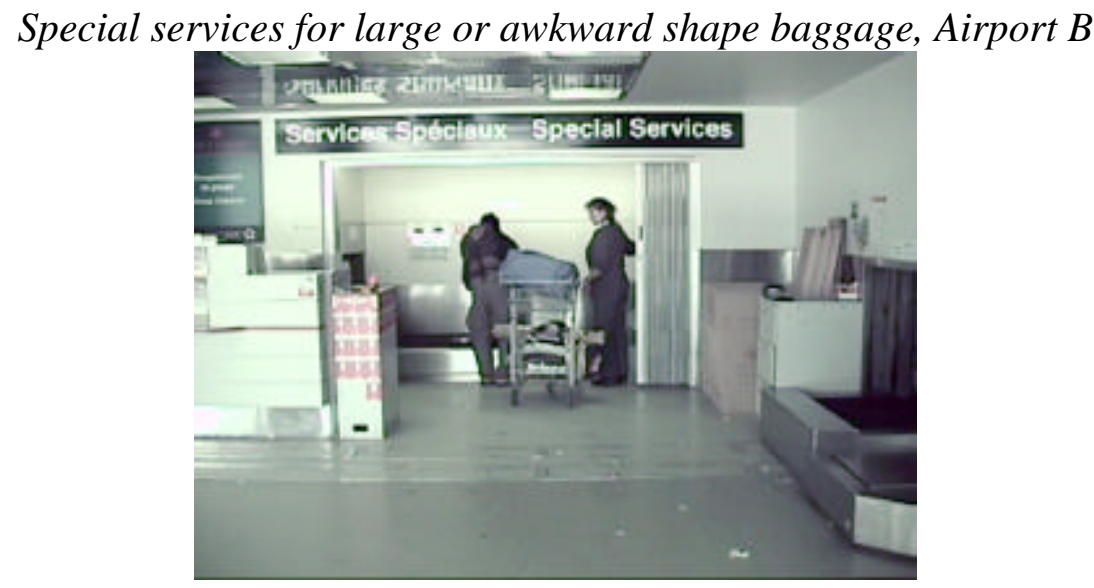

Check-in workstations at Airport B include a mechanical conveyor belt connecting the baggage weigh scale with the main conveyor. The conveyor system transporting baggage straight from the baggage weigh scale mechanizes the baggage handling system completely. This system is designed to speed up the check-in process. It has the further advantage of eliminating, in principle, the need for workers to lift and carry every bag checked-in. However, this is not always the case, for example when bags get jammed on the conveyor, workers must un-jam the bags by pulling, tugging, lifting, and carrying bags. "We don't have to do much lifting of bags as such, but a lot of "un-jamming" of baggage" (worker, Airport B). Similarly, when bags fall off the conveyor, workers pick up the bags and place them back on the conveyor (Photo 9). As well, workers often lift and turn over bags as they are placed on the weigh scale, to situate bags in the correct position for tagging. Check-in workers also intervene manually in the case of special baggage being checked-in, which are defined as pieces of baggage of large size or awkward shape (Photo 10).

The fully mechanized baggage handling system appears to decrease the workload, or the perception of workload, among check-in workers, yet despite the minimal need for manual lifting and carrying of baggage, Airport B check-in workers are still at risk for physical fatigue and postural discomfort. Tagging baggage, whether performed from a standing or sitting position, requires considerable awkward body movements, such as bending, twisting, squatting and reaching. In order to pick up the tag from the printer a check-in worker has to twist the body (Photo 12); then to attach the tag to the baggage the worker has to bend over the piece of baggage at around and sometimes below knee level, constituting awkward postures, repeated many times each day. "We have to do a lot of twisting and stretching at the workstation" (worker, Airport $\mathrm{B})$. "We have very little room to work. We do a lot of stretching, like reaching to get the passenger's ticket, and twisting to get the baggage tags. I remember one time that after a particularly stressful day, I had neck pain for 2 days" (worker, Airport B). 
Photo 11

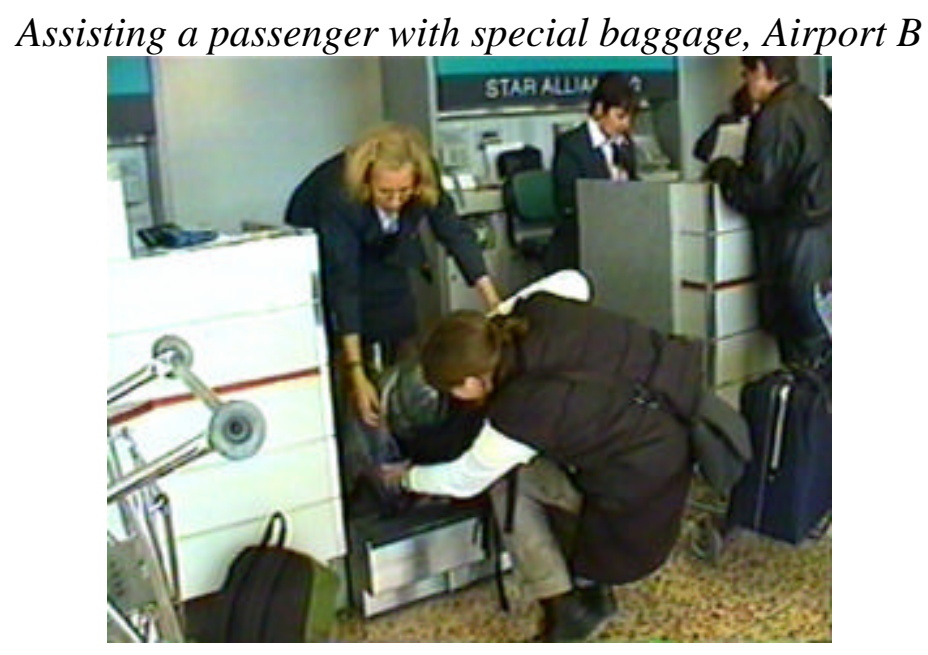

Photo 12

Twisting body to pick up a baggage tag from the printer, Airport B

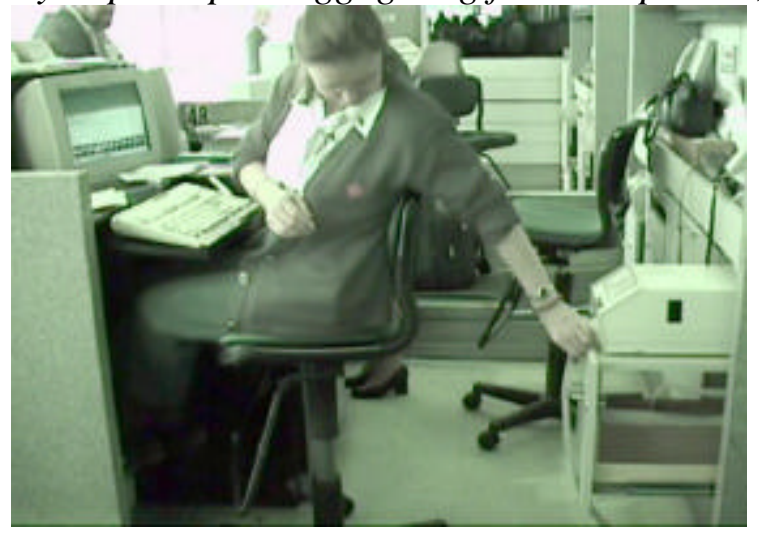

The computer workstation has a height-adjustable keyboard tray and sufficient leg clearance under the counter (Photo 14). Workers are provided with chairs, although observation revealed that the chairs provided are not fully adjustable nor are they sufficiently ergonomic in design. "We got new chairs with inclined seats, but no foot rest. I have low back problems and do not like these new chairs, they are not comfortable for me" (worker, Airport B). Check-in workers take advantage of the existence of a chair to sit for half of their working shift (Table 3), which is recommended to decrease body load over the work shift, to increase blood circulation in the body, and generally increase comfort.

Use of the computer throughout an entire work shift at a workstation lacking height adjustability can contribute to strained and uncomfortable body posture regardless of whether workers choose to work standing or sitting. Not all workers at Airport B appear to know the keyboard tray is height adjustable and therefore do not adjust it for their height needs, which could be easily rectified with information dissemination and training.

Airport B workers reported that of the two check-in areas studied at Airport B - International and Domestic - check-in workers strongly favour the Domestic area. While differences in workstation design between these two work areas are relatively minor, workers favour the Domestic check-in over the International due to worse environmental conditions, particularly thermal conditions and noise, and more difficult baggage handling at the International check-in. These conditions cause fatigue to check-in workers faster than in any other area at Airport B. 
"The International flight area is too warm" (worker, Airport B); "The noise is worse in the International area and you get more tired there" (worker, Airport B); "It is very warm in the International flight area (87 degrees)[Fahrenheit]” (worker, Airport B).

Heat and humidity seem to build-up faster at the International check-in area due to the low ceiling. Higher noise levels at the International area may be also due, in part, to the lower ceiling, which captures sound closer to the workers, as well as due to the more dense crowds associated with international travel.

The baggage of international travellers is oversized and heavy more often than domestic baggage. Larger 'international' bags cause more frequent jams on the conveyor belts, thus forcing the check-in workers to intervene directly and physically to unplug the jams. Other challenges of the job, such as dealing with difficult or aggressive passengers, and operating a computer terminal for long hours, remain similar to the challenges faced by check-in workers in the other study site airports.

\section{Photo 13}

Bending to tag a bag, Airport B

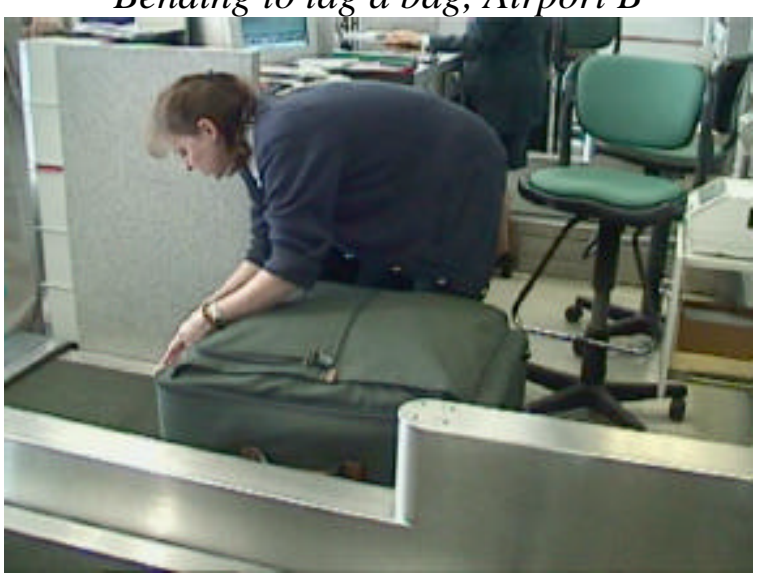

Photo 14

Sitting at the check-in, Airport B

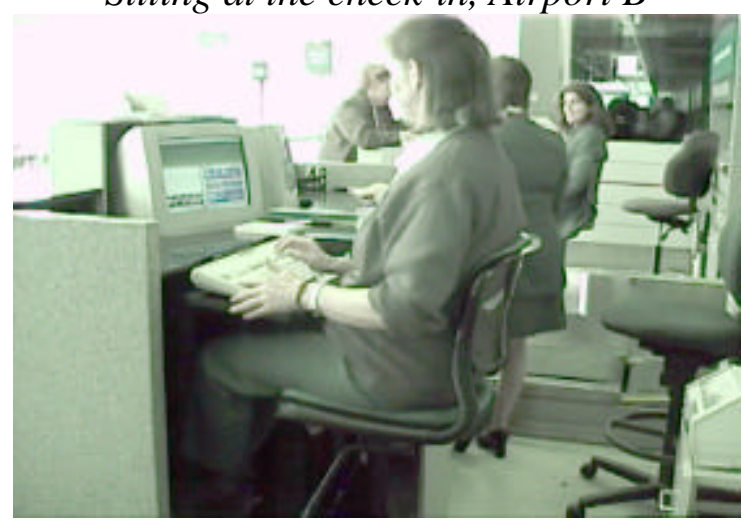

Full mechanization of baggage handling combined with alternating work positions reduces postural discomfort at the workstation $(82.6 \%$ of Airport B check-in workers indicate that they do not suffer from postural discomfort at work (see later in Figure 18).

AIRPORT C: Medium sized, international airport with fully mechanized baggage system where workers sit down throughout their entire shift. 
Of the two ground handling companies operating at Airport $\mathrm{C}$, one offers the possibility of parttime work, attracting students, paying lower wages than the other employer, and with many workers indicating they did not intend to remain on the job for more than two years. In contrast, workers employed by the other employer work full-time, are more likely to see their work as a career job, and remain longer on the job.

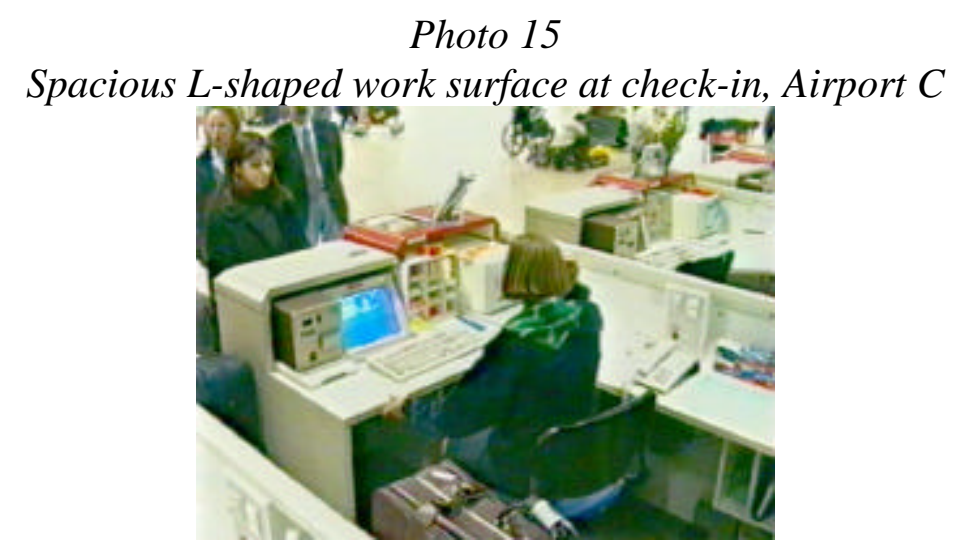

Photo 16

Baggage scale and work equipment within easy reach, Airport $C$

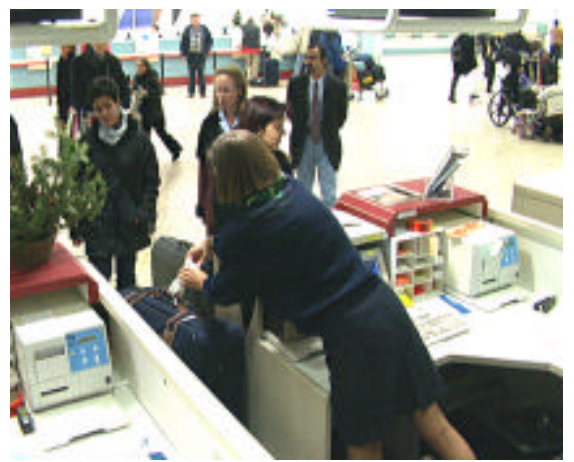

The check-in workstation at Airport $\mathrm{C}$ is designed for workers to perform their job functions from a sitting position during the entire work shift. Spacious L-shaped work surfaces (Photo 15) allow check-in workers to locate all their work equipment (computer monitor and keyboard, baggage tag and boarding pass printers) within easy reach (Photo 16). Adequate counter space at arm level allows workers room to perform their job functions, however, workers commented that the amount of space at the top of the counter was insufficient, particularly when checking in a group of passengers or a family at the same time. Airport $\mathrm{C}$ workers are able to view the baggage scale display without twisting their head, neck or any other part of their body. Semi-adjustable chairs allow workers to sit relatively comfortably, particularly if they have adjusted the chair for individual height needs. The baggage conveyor delivers baggage at the height and distance suitable for attaching tags without requiring workers to leave their chair.

Airport $\mathrm{C}$ workers do not have to lift bags that are checked in. As a result the check-in operation, with the exception of sporadic baggage jams, can be done from a sitting position, with check-in workers spending nearly $90 \%$ of their work shift in a sitting position (see later in Figure 17). However, sitting and operating a computer for an entire work shift are a significant hazard for postural discomfort and potential MSD. More than half of Airport C check-in workers feel that 
the job forces them to sit for too long (see later in Figure 18). With only sporadic need to lift and carry baggage, and with all work functions within reach from a seated position, there is minimal objective need to adopt different working postures. The only opportunity to change from a sitting position occurs when the worker welcomes incoming passengers and while attaching tags to the baggage (Photo 18).

The tops of the Airport $\mathrm{C}$ check-in counters meet approximately chest level on an adult passenger. Check-in workers, from their seated position, reach up and forward to exchange documents with passengers. The counter height together with the worker's seated position places workers below the height of standing passengers. Counters at Airports A and B are lower in height, with passengers able to lean forward across the top of the counter, coming relatively close to the face of the workers while checking-in. The higher counter at Airport $\mathrm{C}$ provides some degree of worker protection against potentially aggressive passengers, although it is unknown whether this was the reason behind the design.

Temperature fluctuations and noise were found to be a problem at Airport C. Significant numbers of workers at Airport $\mathrm{C}$ reported ambient temperatures that are either too hot or too cold (85.9\% and 58.7\% respectively, see later in Figure 4). Temperature extremes appear to result from poor temperature control in the check-in area, as well as from incoming draughts of hot air in summer, and incoming draughts of cold air in winter. Draughts are caused by the frequent opening and closing of the automatic doors to the airport, which face the check-in workstations. Uncontrollable variations in temperature cause discomfort to the workers. Nearly $80 \%$ of the check-in workers reported noise as a severe problem as well (see later in Figure 4). Sources of noise include crowds in the airport, which may be made worse by the acoustics at the check-in areas, plus the mechanized baggage conveyor behind the check-in workstation, which is a source of constant background noise for workers. Other challenges of the job, such as dealing with difficult or aggressive passengers, and operating a computer terminal for long hours remain similar to the challenges faced by check-in workers in the other study site airports.

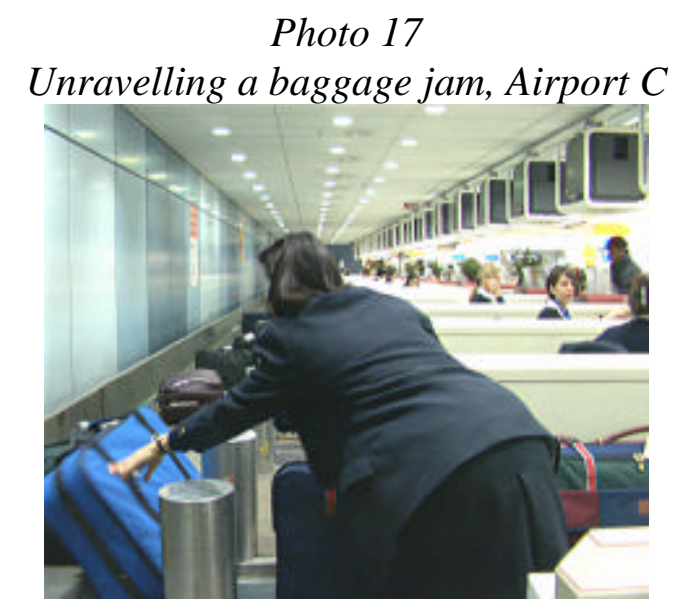


Photo 18

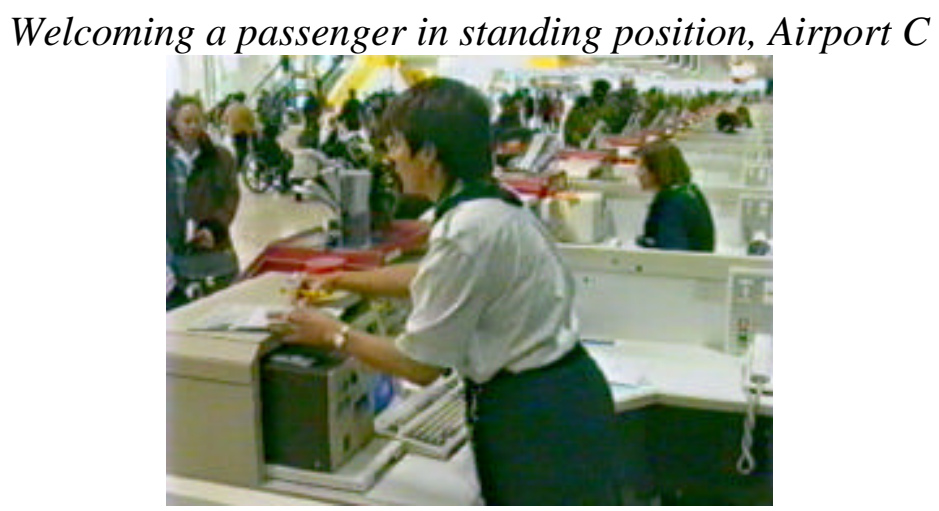

A fully mechanized baggage handling system combined with a computer workstation designed exclusively for work in a seated position may reduce physical effort requirements, particularly compared with a semi-mechanized system. However, the lack of postural flexibility accorded by this design creates conditions for postural strain due to prolonged sitting. A workstation designed to allow both sitting and standing work, as well as easy adjustability for workers of different sizes, is preferable. Additionally, the fully mechanized system does not eliminate the need for workers to pull and push bags when they jam on the conveyor, or to lift bags off the floor when they fall off the initial check-in conveyor.

In sum, the workstations at Airport $\mathrm{C}$ appear, at first glance, to be much better in design than those at Airports A and B. Workers at Airport A have no leg room, and are practically obliged to work standing entirely, with only a semi-mechanized system at their disposal. Workers at Airport $\mathrm{B}$ can alternate their positions, but the placement of the tagging device requires awkward twisting, with pushing/pulling bags a common feature of the job, as at Airport C.

\subsection{Questionnaire Results}

Questionnaires were voluntarily completed and returned by 132 check-in workers:

?? Airport A: response rate $50.0 \%$ (8 workers of a total 16)

?? Airport B: response rate $9.1 \%$ (32 workers of a total 350 )

?? Airport C: response rate $18.0 \%$ (92 workers of a total 504).

Differences in response rates may be due to several factors. Airport A was used as the preliminary testing site for the questionnaire and interview schedule. A small airport, with only 16 check-in staff, we were able to meet more of the workers personally during both preliminary testing and full launching of the questionnaire and interviews, than at the larger two airports. The response rate obtained may have been in part due to the particular work shifts that met with the presence of the researchers.

We believe the response rate from Airport $\mathrm{C}$ was better than that of Airport $\mathrm{B}$ due to a two week extension of the response period, intended to increase response numbers. The local presence of one of the researchers may have had some degree of positive influence as well, proximity enabling us to go numerous times to speak with management, supervisors, and workers.

Airport B is located in a province of Canada far from the base of any of the researchers. Travel to this study site was limited due to funding. Extending the response period from Airport B, as we 
did at Airport C, may have increased the response rate, however, requesting further intervention from management may have been perceived as burdensome at the time.

Because not all respondents answered all questions in the questionnaire, the numbers of answers versus questions are not the same. The percentage for each question was calculated according to the number of answers rather than the total number of questionnaires received.

\subsubsection{Work-Related Injury Reports}

The ground handling companies at Airport $\mathrm{C}$, and the airline employing check-in workers at Airport B, provided us with an injury report for check-in workers. Figure 1 summarizes injuries reported by check-in workers employed at Airports B and C for the period January 1998 to December 1999. In 1998 there were 30 non-disabling and 20 disabling injuries, which resulted in 280 lost work days. In 1999, there were 26 non-disabling injuries and 14 disabling injuries, causing 181 lost work days. None of the employer-provided injury reports distinguish MSDs from other injuries, making it impossible to know if MSDs caused any of the lost work time reports, or whether MSDs resulted in workers' compensation claims. Statistics were not available for Airport A.

Figure 1: Check-In Workers Injury Report (data provided by employers)

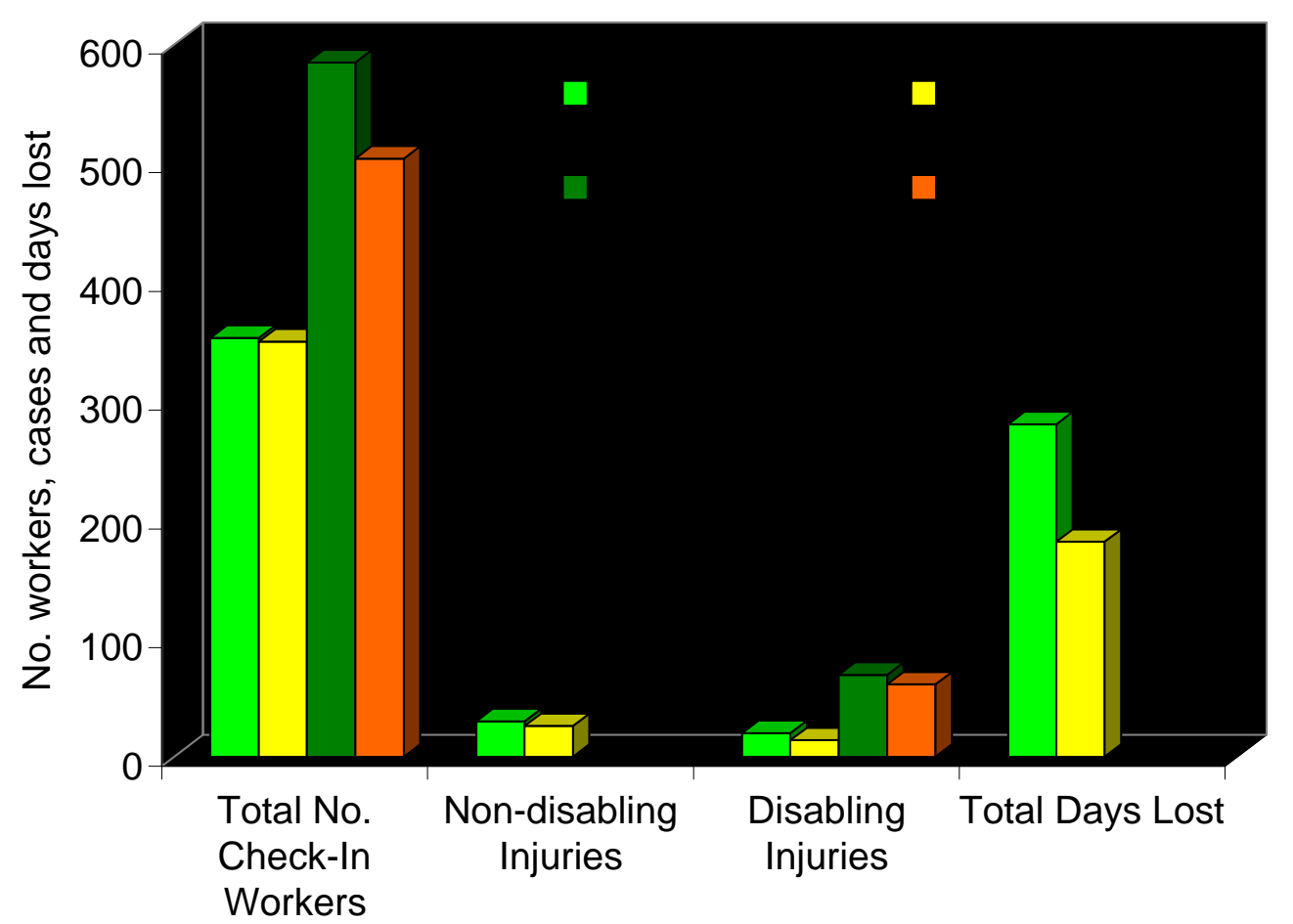

The need to investigate the real costs to employers and workers caused by poorly-designed work processes, work organization, work design and management practices is punctuated by the significantly different lost work time injury reports provided by the two different employers of check-in workers at Airport C. The difference in reporting appears to result, in part, by the fact that one employer encourages the hiring of very young, inexperienced workers, paying lower wages than the other employer, accepting a high turnover of workers on the job and short employment duration. This means that workers are likely to leave the job before MSDs appear. 


\subsubsection{Sample Population Demographics}

Demographic factors (Figure 2) demonstrate that check-in work in Canada and Switzerland, is predominantly, but not exclusively, a job performed by women. In 2000, of the 504 check-in workers at Airport C, $80 \%$ were women and $20 \%$ men. Of the 16 check-in workers at Airport A, there were 15 women and 1 man. Women constituted $72 \%$ of all check-in workers at Airport B. Questionnaire responses were obtained from a 7:1 ratio of women to men at Airport A; a 28:4 ratio at Airport B; and an 80:12 ratio of women workers to male workers at Airport C. $87 \%$ of the workers involved in the study were women. Their age ranged from 31 to 46 years. Length of employment ranged from 4 to 10 years on the job (Figure 3). The lower end of the range of employment duration is thought to be a factor of one of the two employers at Airport $\mathrm{C}$ offering worse conditions of employment than the other, which may logically be accompanied by a higher degree of worker turnover.

Figure 2: Demographic Factors of Respondents: Gender Distribution

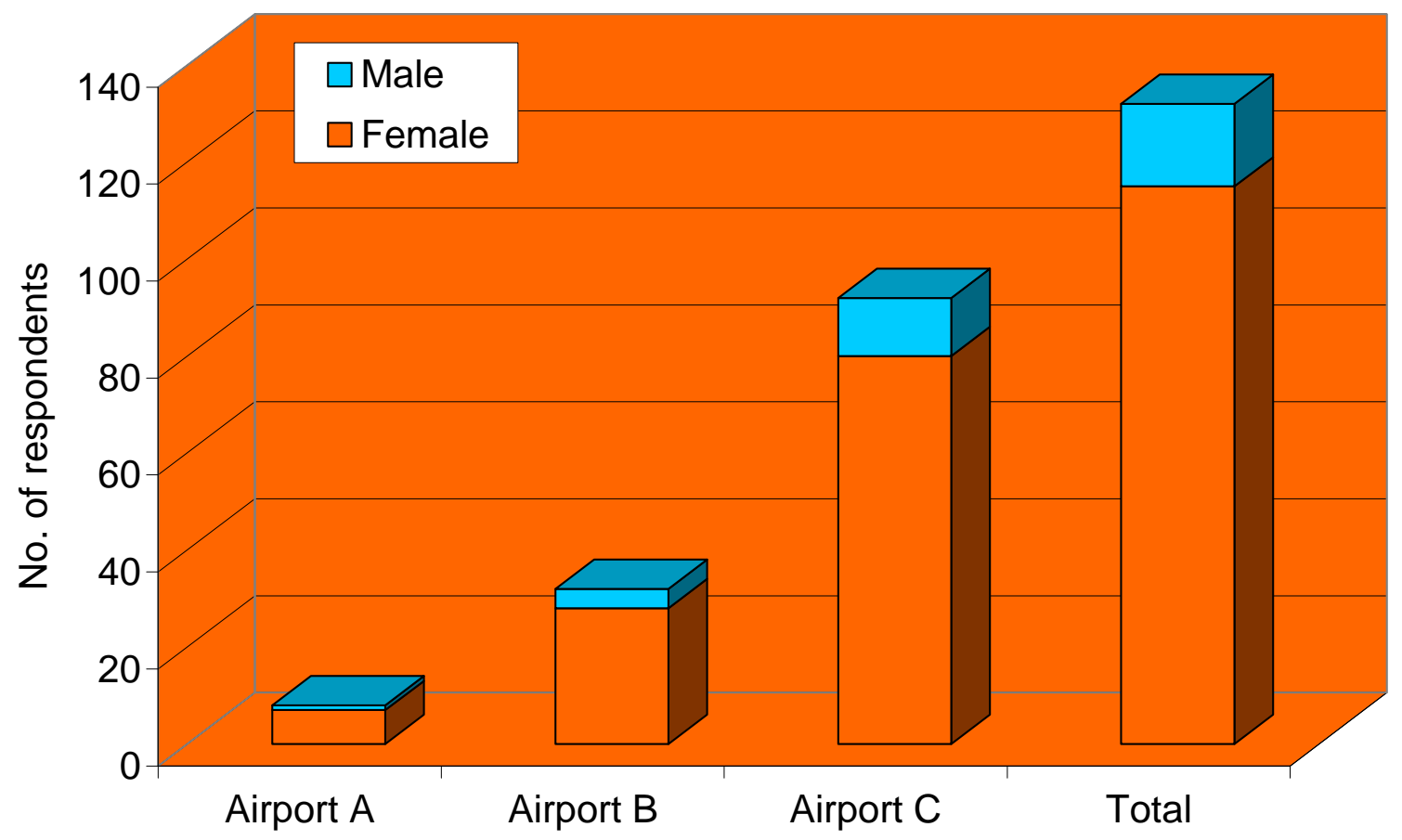

$\mathrm{n}=132(8,32,92 ;$ Airport A, B, C respectively $)$ 
Figure 3: Average Age and Average Length of Employment

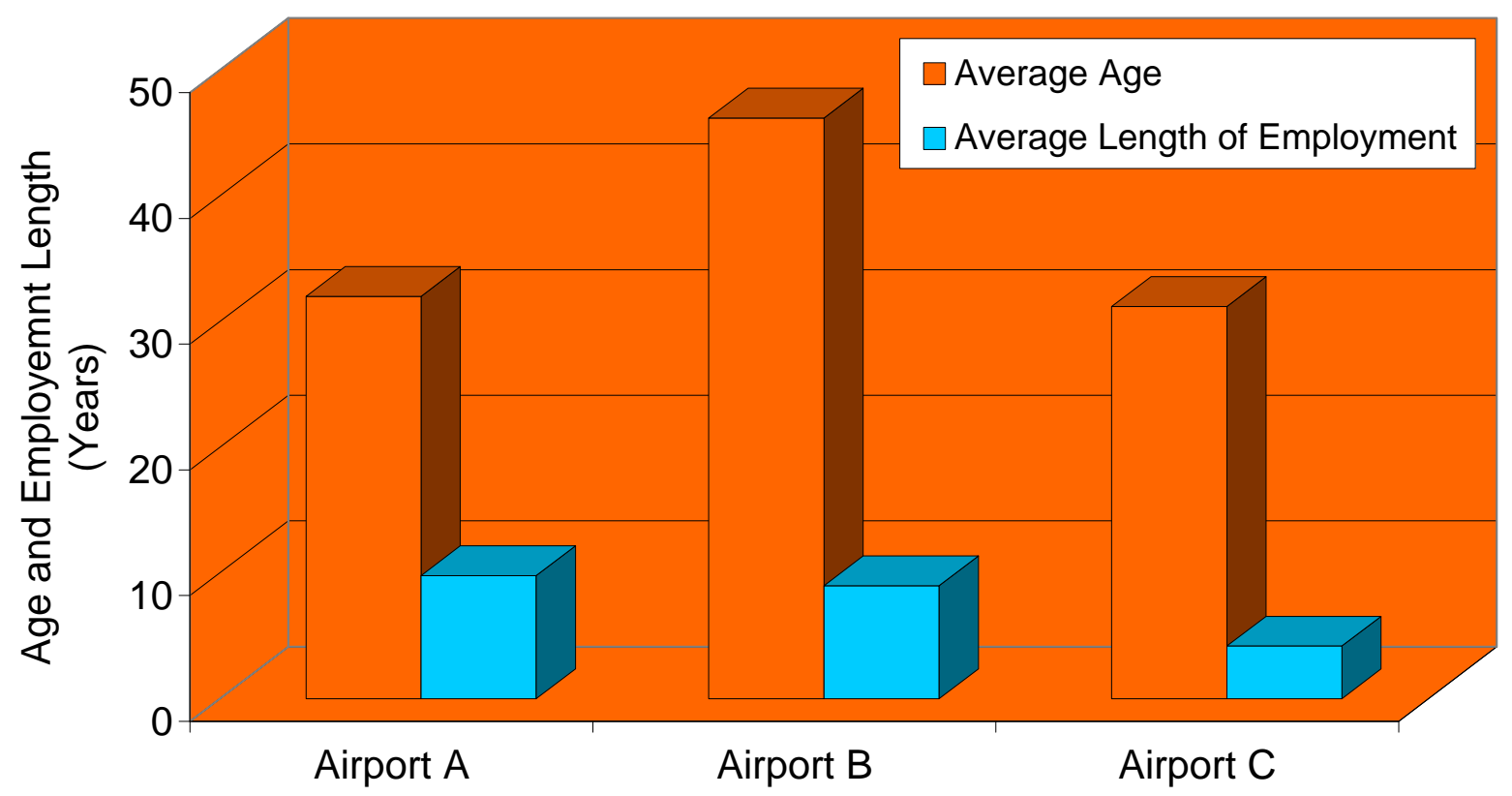

$\mathrm{n}=132(8,32,92 ;$ Airport A, B, C respectively $)$

\subsubsection{Workplace Environmental Factors}

Check-in workers at all study sites work on computers throughout their entire work shift, a task that requires sufficient and appropriate lighting. Direct overhead lighting reflecting down on the computer screen makes it difficult for workers to see the information on the screen. Glare (such as from overhead lights or sun) can cause computer workers to squint and contort the body in order to view the screen. Twisting the body all day long to view a computer can rapidly lead to musculoskeletal pain, particularly in the neck and shoulders. More than $22 \%$ of respondents indicated that lighting was poor or inadequate in their work environments.

"The air is stuffy in the airport and the building is dirty. The lighting is really poor. Twice I had to go home with migraines from the lighting, it's fluorescent, compounded by the 12-hour shift. I hate the 12-hour shift, but the majority of the group prefer it" (worker, Airport A).

Over $90 \%$ of workers indicated that their work area was too hot some of the time, while $65 \%$ reported that their work area was too cold some of the time (Figure 4). Both central heating systems and central air conditioning systems can be hard to regulate in large spaces with high ceilings, and with automatic sliding doors at the airport entrance creating regular temperature fluctuations. Varying external climatic conditions, artificially regulated indoor temperature, and the combination of regular exposure to extremes of both heat and cold are all part of the daily work experience for many check-in workers. 
Figure 4: Environmental Conditions

(\% respondents selecting specified condition)

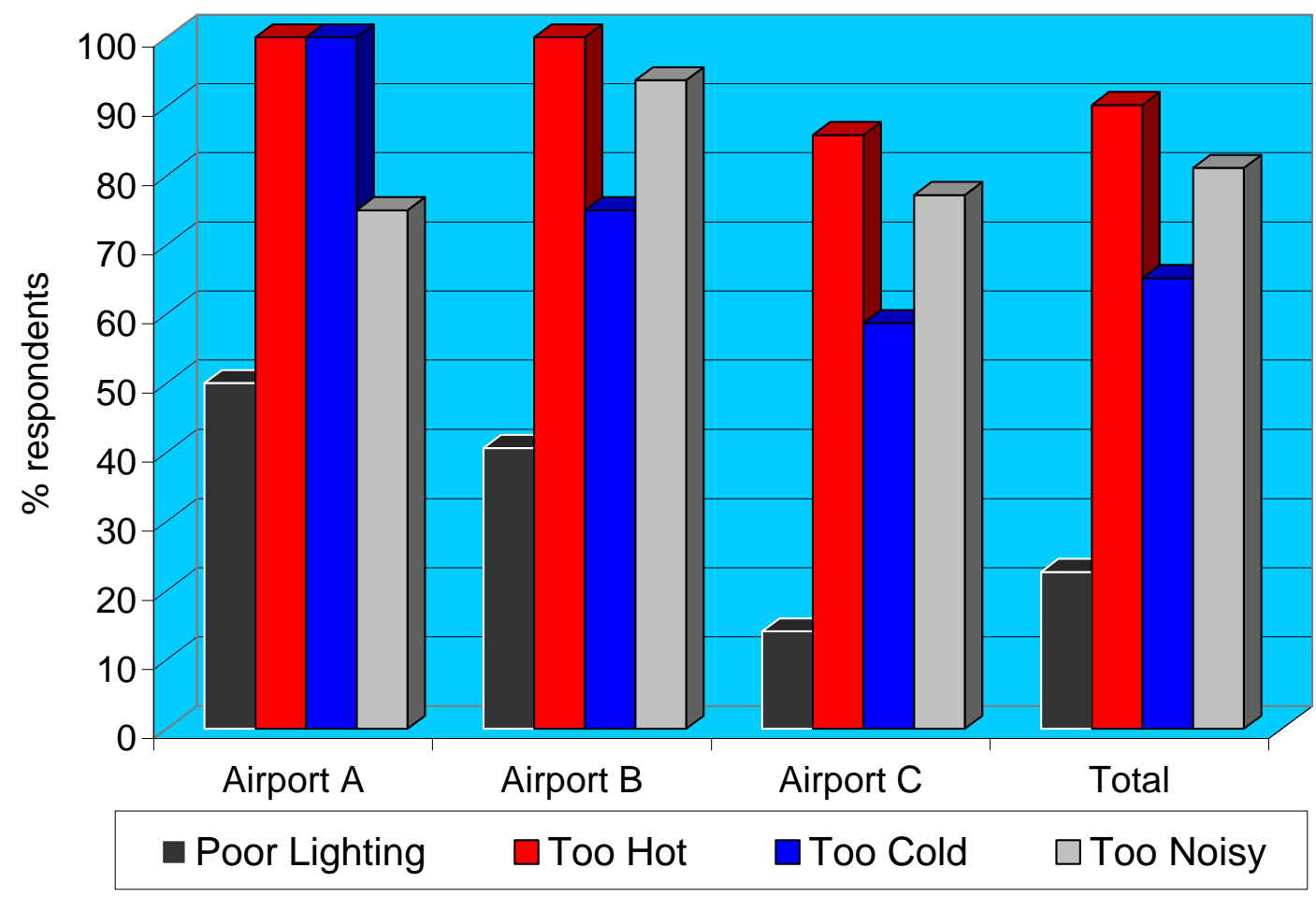

$\mathrm{n}=132(8,32,92 ;$ Airport A, B, C respectively)

Noise at the check-in workstation is another reported disturbance. Over $80 \%$ of workers said that their work area is too noisy and that noise interferes with the ability to perform the job properly and comfortably. A variety of noise sources were identified including noise generated by passengers checking in, passengers' family and friends accompanying them to the airport, the general ambient environment in the airport, airport public address systems, by neighbouring check-in workstations, the conveyor for checking in baggage, the conveyor that takes baggage to the airplane loading area, and the boarding pass printer. Constant noise on the job, such as noise generated by the conveyor that takes baggage to the airplane loading area, can add to fatigue and be considered an important work-related stressor.

"The air quality in the airport is poor, there is a smell of diesel. Also, it is very dusty - to the point where some of the check-in agents got conjunctivitis. It is a very noisy environment - maybe acoustic tiles could improve the situation" (worker, Airport B).

\subsubsection{Exposure to Violence on the Job}

Four questions related specifically to a lifetime experience of violence at work:

1. Have you ever been subjected to verbal abuse at work?

Yes: Daily; Monthly/No

2. Have you ever been physically threatened while working?

Yes/No; If yes, how often 
3. Have you ever been physically assaulted or attacked while working?

Yes/No; If yes, please describe

4. Do you consider that violence at your job represents:

Low Risk/Medium Risk/High Risk

The findings are revealing, both in terms of types of violence experienced by check-in workers and the level of perceived risk of facing aggressive or violent passengers (Figure 5). "In the international flight area, passengers have easier access to us, so there is more danger with aggressive passengers" (worker, Airport B). "When I have to deal with abusive passengers, I call for a supervisor, but if I have to deal with an abusive co-worker, I probably would not report it" (worker, Airport B). Interviews and focus group workshops confirmed verbal abuse, and violence in general, as primarily a passenger-related problem.

Figure 5: Experience with Violence (\% respondents having experienced specified type)

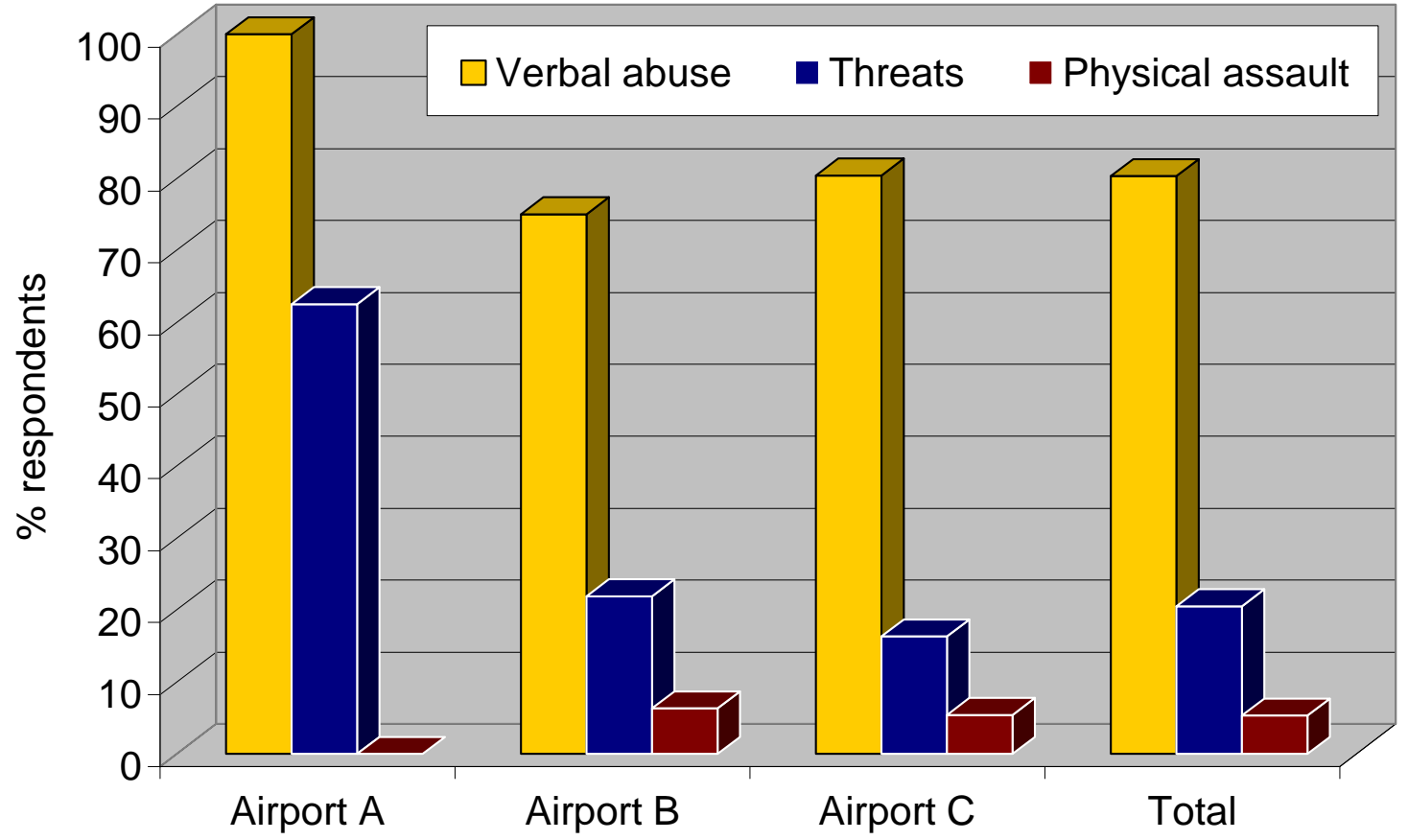

$\mathrm{n}=132(8,32,92 ;$ Airport A, B, C respectively $)$

Workers at all three airports reported having been subjected to at least one form of abuse from passengers. Among 132 check-in workers, over $80 \%$ have been subjected to verbal abuse from passengers, over $20 \%$ have received threats from passengers, and more than 1 out of every 20 check-in workers $(5.3 \%)$ have been physically assaulted on the job. These figures are for incidents experienced during workers' employment as a check-in worker. Very few check-in workers indicated how often they had such experiences. Several workers at the three study sites mentioned the difficulty of dealing with aggressive passengers and the associated stress, highlighting that they did not receive support from management: 
"It is hard to handle the difficult passengers, and you don't really get help" (worker, Airport A).

"Abusive passengers are hard to deal with. I have approached my supervisor about this, but didn't get any support” (worker, Airport B).

"If you witness violence, or if you're the victim of violence, the supervisor on the floor will be called. They call in security when the situation gets worse. Dealing with angry or disgruntled passengers, like when a flight is cancelled or overbooked, is really stressful. We go out for a smoke to deal with the stress" (worker, Airport B).

In addition to the act of verbal or physical violence, the perception of the potential, or perceived risk of being exposed to work-related violence is revealing (Figure 6). Over 50\% of the workers consider violence a low risk at their jobs, more than one third perceive that their jobs present a medium level of risk, and 5.3\% perceive their jobs as placing them at high risk of work-related violence. Taking together the results for medium and high risk levels, nearly half of the workers $(\mathbf{4 6 . 2 \%})$ perceive a substantial risk of violence in their work. Thus the perceived risk of violence is significant in this occupation (Hoel et al, 2000).

Figure 6: Perceived Level of Risk Related to Violence

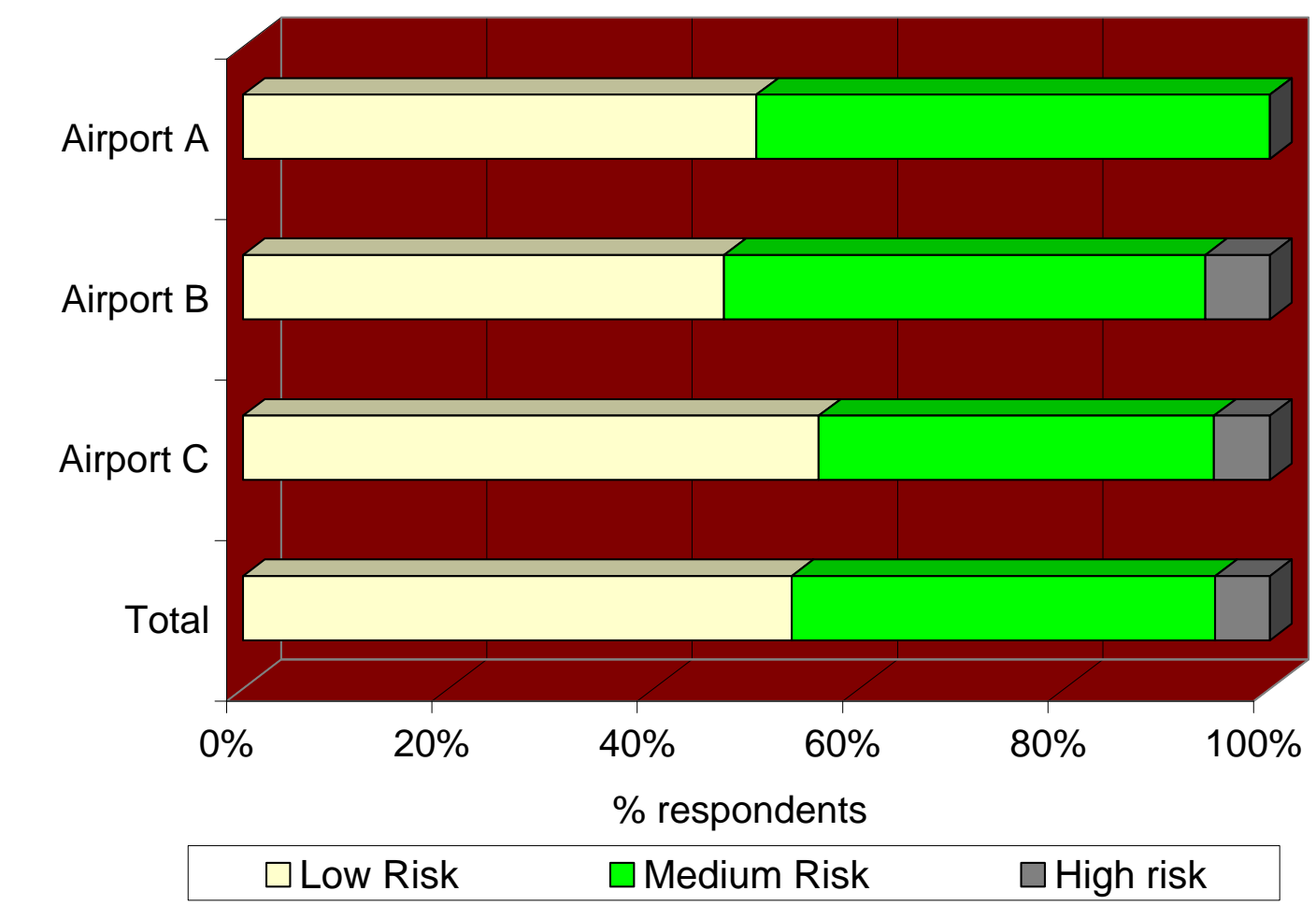

$\mathrm{n}=132(8,32,92 ;$ Airport A, B, C respectively $)$

These findings are alarming, and should be considered in the context of workers performing a job everyday with the stress of knowing that past experiences with violent passengers can be repeated at any time with new passengers. Left un-addressed, this stressor has the potential to engender a feeling of victimization among workers whose job status and training do not empower them with tools to deal adequately with violent, or potentially violent situations. 
The finding that over $80 \%$ of workers (male and female) had personally experienced verbal violence and over $5 \%$ had been physically assaulted by passengers, leads us to presume that many more workers have witnessed violence against check-in colleagues, even if they themselves were not the target of the aggression.

The ITF, workers, and management at all three airports reported that aggressive passenger behaviour is increasing, both in the air and on the ground. Taking a proactive approach to the problem, in 2000, management at Airport C (including both employers at Airport C) initiated a $2 \frac{1}{2}$-day training seminar on dealing with aggressive passengers, obligatory for all check-in workers and managers. "Aggression training is new this year, it's a response to this problem increasing. Ten people attend a 2.5 day course at a time" (worker, Airport C). The seminar provides workers and managers with tools for dealing with aggressive passengers and empowers and authorizes check-in workers to say "no" to aggressive passengers under certain situations, even though saying "no" to passengers is against airline policy. Implementation of this kind of seminar, with mandatory participation by both workers and managers, constitutes a proactive management technique, and is an important means of helping to pre-empt incidents of aggressive behaviour in the air, where the consequences can be more far-reaching.

The root causes of passenger violence against check-in workers are likely multiple in nature, but have not been studied. Some factors suggested by unions and management as key contributors include: alcohol, drugs, stress, time pressure, delayed, cancelled or missed flights, fear of flying, sense of entitlement due to airline advertising and competition policies, increased numbers and type of people travelling in the general public, and experience on board aircrafts in extremely confined spaces for long periods of time. There may be other, less obvious contributing factors as well.

Management at one of the three airports suggested that the overriding factor causing passenger aggression is the competitive policy of airlines, aimed at obtaining customer loyalty by making various promises through advertising and publicity. Consequently, passengers feel entitled to demand what was "promised" to them, making such demands to check-in workers. 
Figure 7: Experience with Violence, by Gender (\% respondents having experienced specified type)

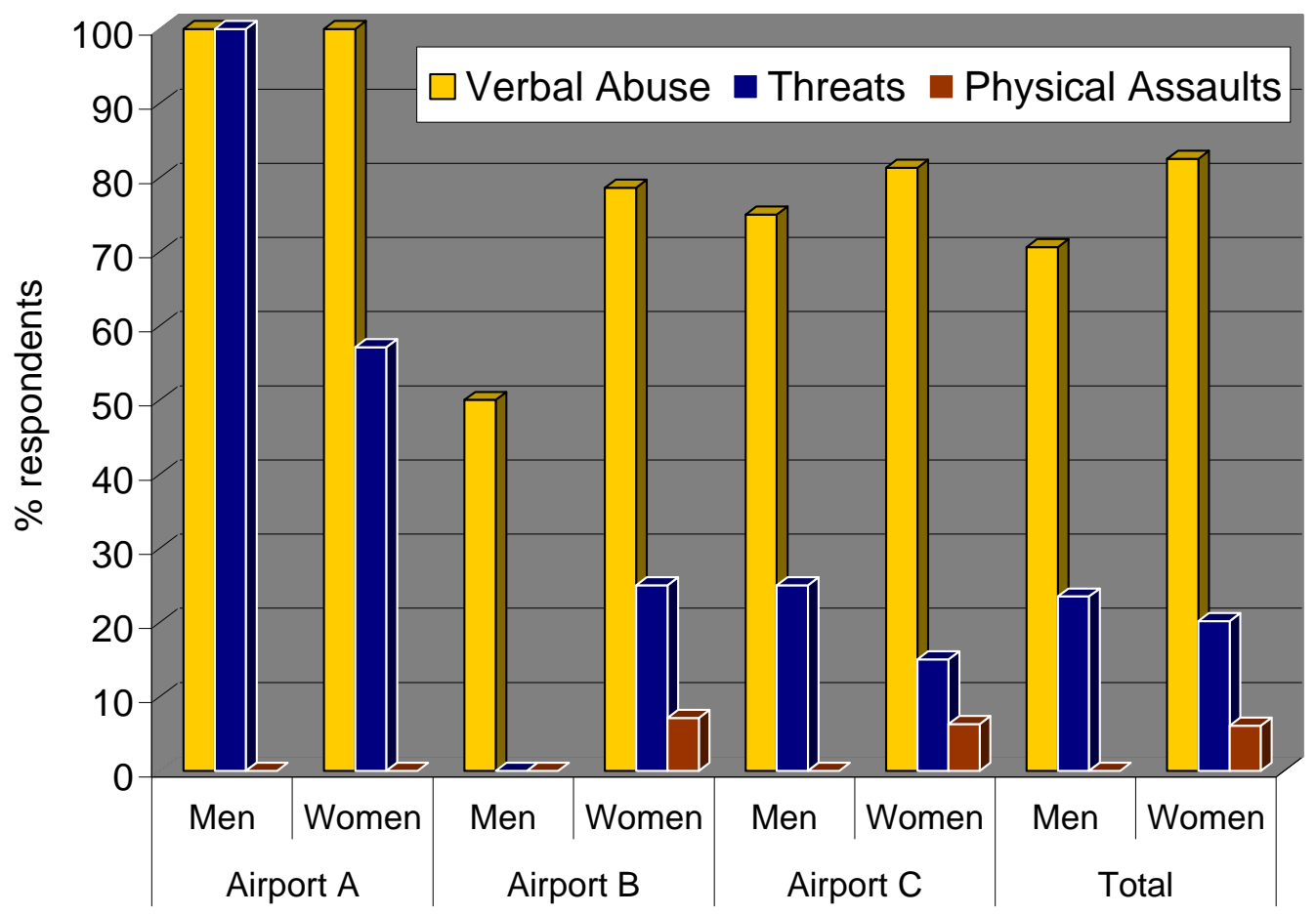

$\mathrm{n}=132(8,32,92$; Airport A, B, C respectively)

Figures 7 and 8 present check-in workers' experience with violence, by gender. The small number of male check-in workers means that we cannot draw any firm conclusions about men or women being more exposed to one type of violence or another. It is clear from the findings, however, that men as well as women report experiencing verbal abuse and threats. No men in the sample experienced physical assault by passengers. In service sector work overall, women are more likely to be victims of physical assault than men. Male check-in workers from all three airports see check-in work as exposing them to a degree of risk of violence. Some male workers consider check-in work low risk, while others consider that it exposes them to a significant risk of violence. The fact that violence was experienced by check-in workers at three different airports, in two different countries, both known for rather peaceful civilian life, leads us to conclude that this is a problem likely knowing no social, economic, or cultural boundaries. 


\section{Figure 8: Perceived Level of Risk Related to Violence, by Gender}

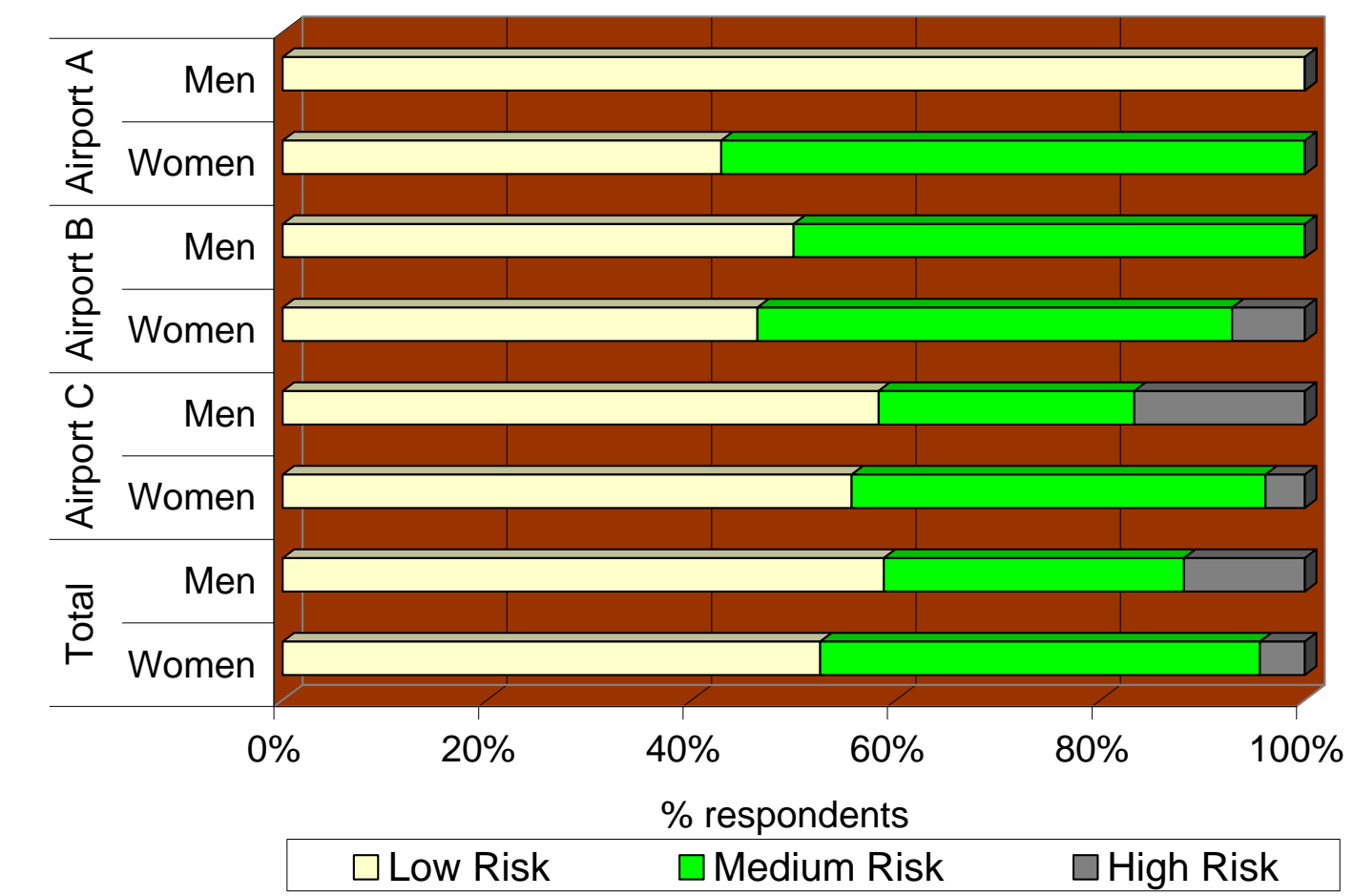

$\mathrm{n}=132(8,32,92 ;$ Airport A, B, C respectively $)$

\subsubsection{Musculoskeletal Disorders}

This study reveals that musculoskeletal problems are common among airport check-in workers and can lead to temporary or permanent disability. Among the respondents more than $70 \%$ indicated that neck pain affected work performance, and nearly $16 \%$ reported temporarily leaving their professional activity because of neck pain.

Reporting of symptoms was subjectively based on the feelings and perceptions of the workers. The significant number of workers reporting living with MSD pain compared with the relatively low number of lost work days due to injury or pain (results obtained by combination of questionnaire, interview and official lost work time reports) indicates that many check-in workers consider musculoskeletal pain to simply be "part of the job."

A number of workers indicated having to stop non work-related activities as a result of MSDs, ranging from 4 days to 1 year due to pain in one or several parts of the body. Some workers had pain in more than one part of their body at the same time, with one worker having pain in 7 different parts of the body, necessitating a cessation of non-work activities for 2 months due to neck, shoulder and elbow pain, and a stoppage of activity for 1 year due to wrist, hand, upper back and lower back pain. These data reveal a serious negative impact on workers' lives outside work, as a result of musculoskeletal pain, indicating work exposures contributing to, or as the direct cause of MSDs.

Often workers do not report MSDs to their employer. Official figures may therefore show zero non-disabling or disabling work-related injuries in a given year. Yet when workers are asked about pain and suffering in an anonymous questionnaire, they reveal the existence of significant 
pain that interferes with work as well as sleep and life outside of work, caused by their working conditions.

Even when musculoskeletal pain interferes with the ability to perform the job, disrupts sleep or other life activities, check-in workers do not appear to lose much work time due to their pain. The contrast between the percentage of workers losing work time compared with the percentage reporting pain is significant: for example, nearly $80 \%$ of workers experiencing upper back pain reported that the pain interfered with their ability to work, while only $18 \%$ lost work time in the past year due to upper back pain. Similarly, $80 \%$ report that elbow pain interferes with work, while only $20 \%$ took time off work due to elbow pain.

These findings can be interpreted in a number of different ways: a) because pain is the norm at the check-in workplace, workers simply keep going to work despite their pain; b) at a certain level, the pain is manageable. Those workers taking time off work may suffer to a worse degree than other workers, and/or may have a lower individual pain threshold; c) workers may receive subtle or overt messages from employers "encouraging" them not to take time off under workers' compensation due to cost implications for the employer; d) workers may not take time off under workers' compensation because they do not connect the particular pain to job exposures; e) check-in workers are a dedicated group of workers and for the most part enjoy their jobs, which motivates them to go to work, even while living with pain. 
Figure 9: Pain at Work and Its Consequences

Neck Pain
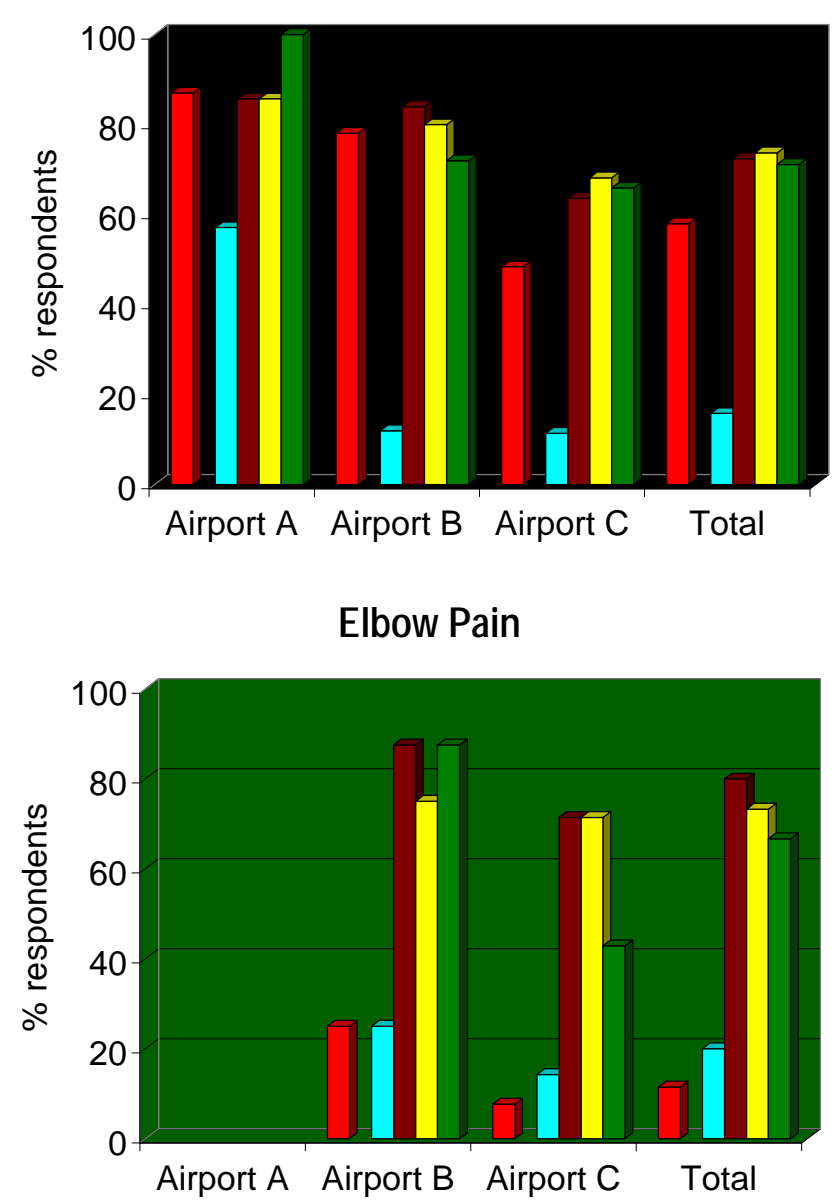

Shoulder Pain

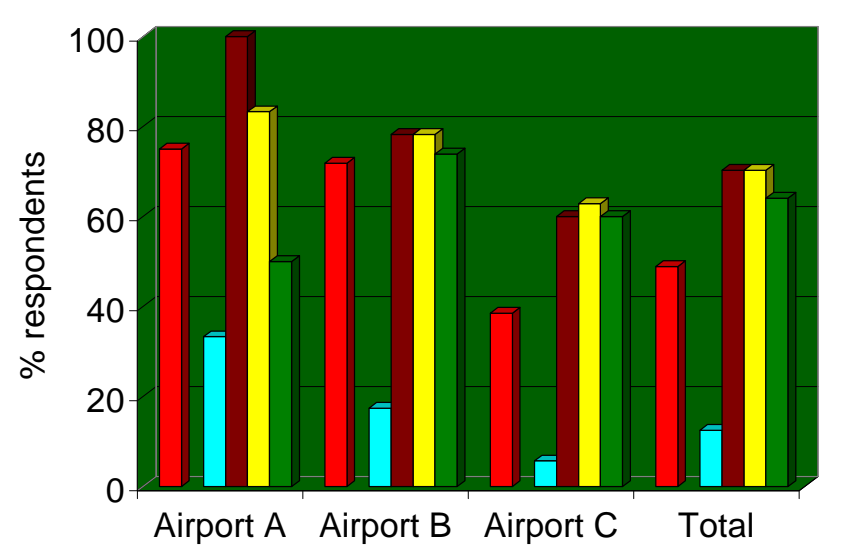

Wrist/Forearm Pain

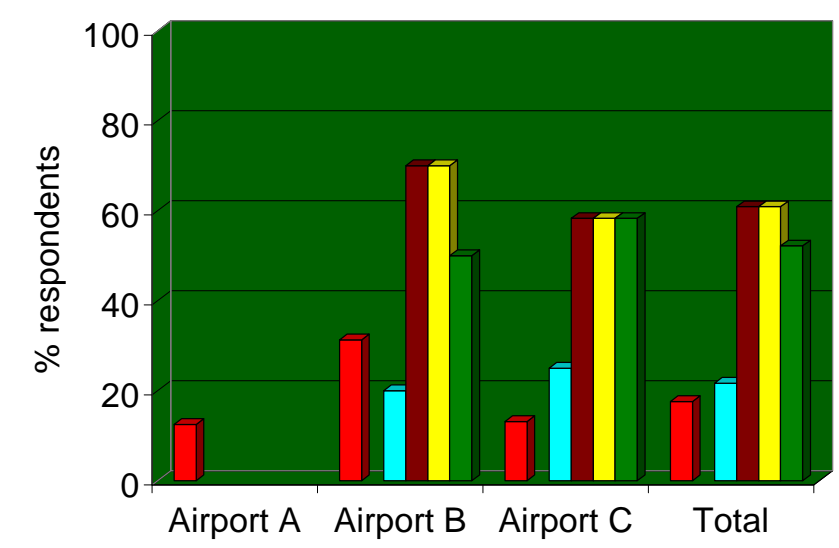

$\square$ Frequency

$\square$ Causes Time Off

$\square$ Interferes with other activities
- Interferes with work performance

$\square$ Interferes with sleep 
Figure 9: Pain at Work and Its Consequences (continued)

Hand Pain

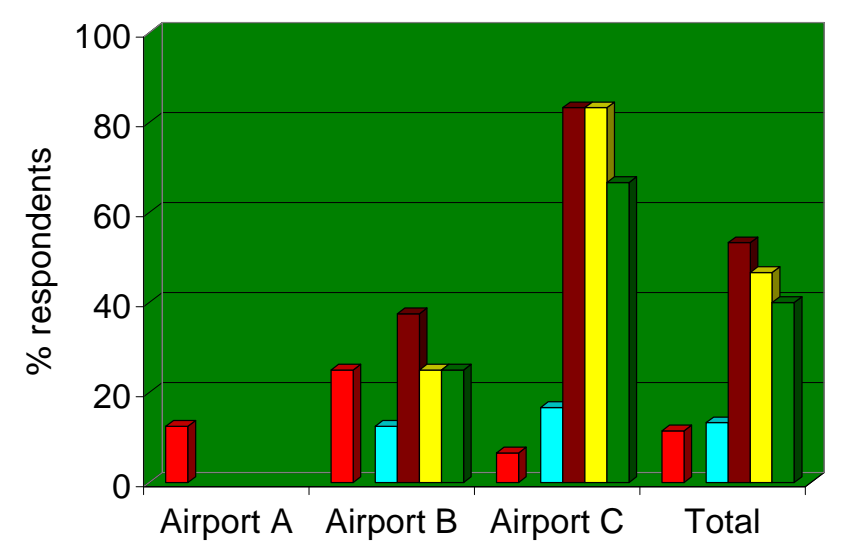

Lower Back Pain

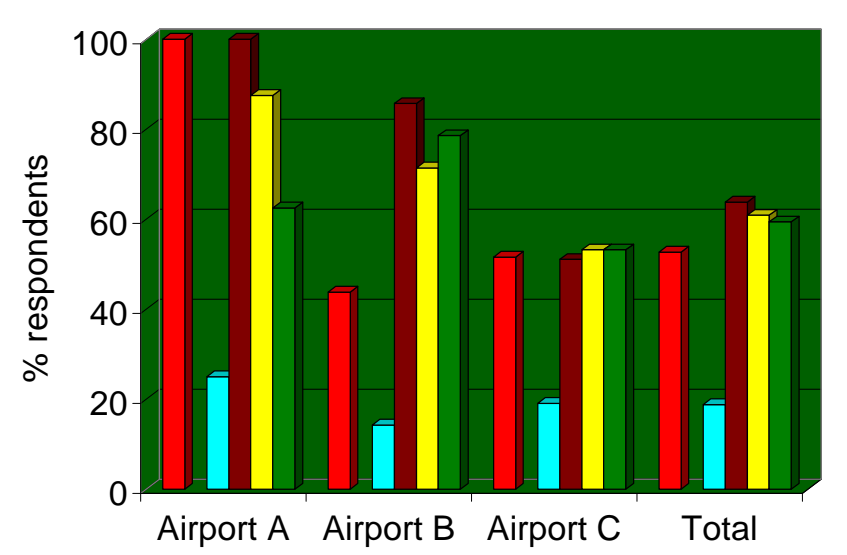

Upper Back Pain

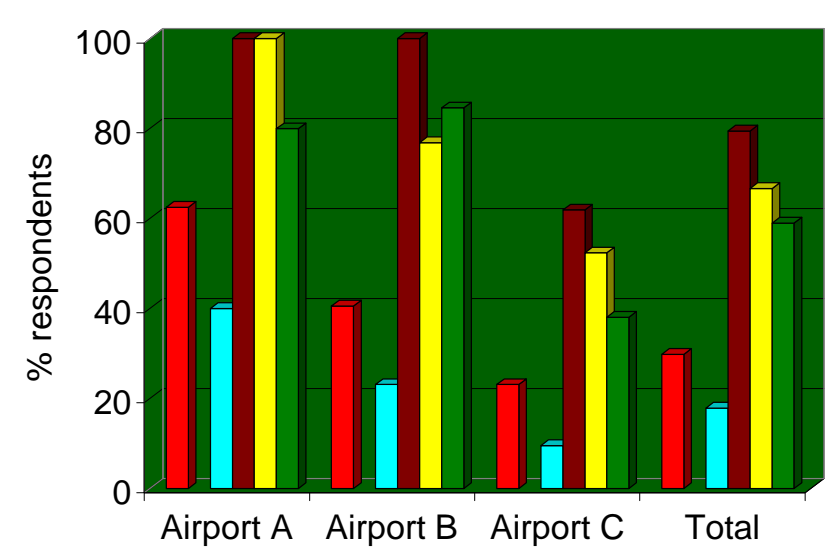

Foot Pain

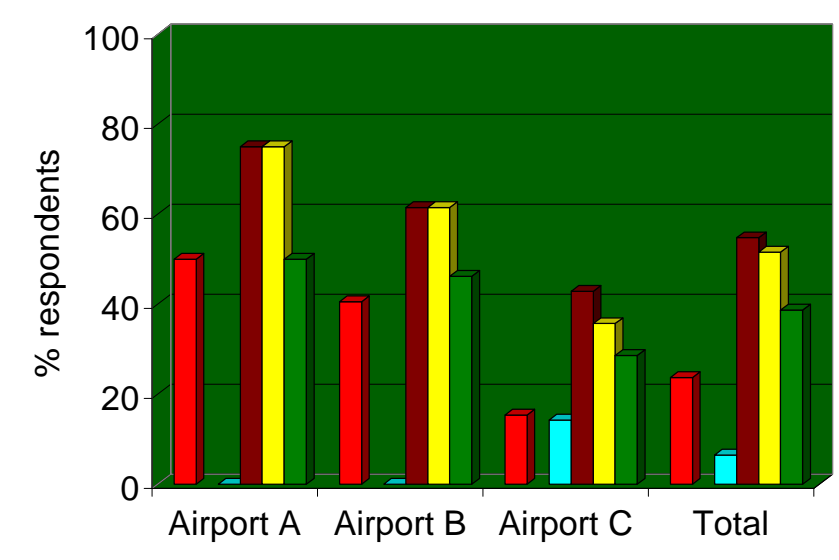

$\square$ Frequency

$\square$ Causes Time Off

- Interferes with work performance

$\square$ Interferes with other activities

$\square$ Interferes with sleep

$\mathrm{n}=131(8,32,91$; Airport A, B, C respectively $)$ 


\subsubsection{Neck and Shoulder Pain}

Musculoskeletal disorders are cumulative over time. Higher average age and mean length of employment at Airport B compared with Airports A and C, may explain greater numbers of Airport B workers losing work time due to shoulder pain. This is not, however, a consistent trend for the other forms of musculoskeletal pain: 9 workers at Airport C, for example, lost work time due to lower back pain, compared with 2 workers from each of the other two airports. This outcome is likely to be associated with prolonged sitting on the job, combined with awkward postures. Twisting to tag baggage, plus frequent pulling and pushing of bags, are key sources of back strain for Airport $\mathrm{C}$ workers.

Shoulder pain is a direct outcome of lifting and carrying baggage (particularly at Airport A), from twisting and leaning to tag bags (particularly at Airports B and C), from computer work performed at workstations which are not adjustable for the workers (Airports A, B, C), as well as from lengthy shifts performing only check-in work for most workers at Airports A and B and some of the workers at Airport C.

Shoulder pain appears to have a significant and negative impact on work life and non-working life: over $70 \%$ of workers experienced shoulder pain to a degree that interfered with their work, more than $12 \%$ had to take time off work due to pain ( 8 workers), over $70 \%$ reported that pain interfered with non work-related activities, and nearly $65 \%$ said that shoulder pain interfered with their sleep. Of the 8 workers who lost work time due to shoulder pain, half work at Airport B. " $I$ had tendonitis, bursitis, shoulder and neck pain" (worker, Airport B). "Sometimes I have pain in my upper body and arms..." (worker, Airport B).

Neck pain is a direct outcome of lifting heavy bags (particularly at Airport A), and static posture or prolonged work at a computer workstation lacking adjustability. Lack of adjustability in the angle of the computer screen can also lead to painful neck strain, particularly among workers who may wear corrective lenses.

Of the nearly $60 \%$ of workers experiencing neck pain, a greater proportion work at Airport A. Over $70 \%$ (55 workers) indicated that neck pain interfered with their work performance, while 12 workers (nearly $16 \%$ of the workers with neck pain) had neck pain serious enough to cause them to take time off work. Over $70 \%$ (54 workers) experienced neck pain that interfered with their sleep, and $74 \%$ (56 respondents) had neck pain that interfered with activities outside of work. More of the severe neck pain reports came from workers at Airport A than from Airports B and $\mathrm{C}$, which is significant given that Airport $\mathrm{A}$ is where the most lifting is performed regularly, indicating that the constant lifting of heavy baggage causes damage to workers' necks (Figure 9).

\subsubsection{Elbow, Wrist/Forearm and Hand Pain}

Elbow, wrist/forearm and hand pain in check-in workers are likely caused by repetitive computer work at a keyboard surface that keeps the arms elevated too high, from lifting heavy baggage, and from general baggage manipulation.

Hand pain is reported less frequently than other types of pain, however, when it does occur, particularly at Airport $\mathrm{C}$, where over $11 \%$ reported hand pain, it is severe in consequence: over $80 \%$ of Airport $\mathrm{C}$ workers with hand pain report interference with job performance, $83 \%$ report disruption to non work-related activities, and nearly $70 \%$ report sleep loss due to hand pain. One worker at Airport C and 1 worker at Airport B lost work time due to hand pain, 2 Airport B 
workers had hand pain severe enough to interfere with non work-related activities with the same 2 workers reporting sleep loss due to hand pain. Pain in the hand causing interference with sleep, disruption to non work activities, and interfering with job performance could be an indication of tendonitis, or a severe, potentially debilitating MSD, such as carpal tunnel syndrome. At the very least such symptoms indicate the need for medical attention.

Computer users' wrists should be held in a straight position during keyboard use. The correct wrist position can be difficult, even impossible to maintain when the workstation is not height adjustable. The preponderance of suffering due to hand pain at Airport $\mathrm{C}$ is most likely caused by the prolonged use of a computer keyboard placed on a table too high for most workers. The high table surface leads to an overextension of the wrist, which can cause repetitive strain injuries of the wrist, arm and shoulder. The variation between sitting and standing work at Airport B may explain the difference in hand pain rates at these two airports.

An additional key risk factor for hand, wrist, and arm injury is repeated lifting of heavy baggage. Work observation revealed that check-in workers at Airport A lift and carry bags with one hand most of the time, placing additional strain on the wrist, elbow and arm.

More workers report wrist and forearm pain than elbow pain: 23 workers have wrist and forearm pain, and over $20 \%$ lost work time due to the pain. $60 \%$ said it interfered with job performance, the same number (14) said wrist/forearm pain interfered with non work-related activities, and over $50 \%$ (12 individuals) said the pain disturbed their sleep. Airport $\mathrm{C}$ wrist/forearm sufferers experience pain to a degree that interferes with work performance, non work-related activities, and with sleep. This is cause for attention since Airport $\mathrm{C}$ workers work intensively at the computer, in a fixed sitting posture throughout their entire work shift. Wrist/forearm pain does not appear to be a widespread problem among workers at Airport A, with only one worker reporting this problem.

Elbow pain seems to be experienced less frequently than neck and shoulder pain, but among those workers experiencing elbow pain, the intensity of the pain appears to be quite disruptive: 15 workers experienced elbow pain, with $80 \%$ saying the pain interfered with work, over $70 \%$ said elbow pain interfered with non work-related activities, and over $66 \%$ said elbow pain interfered with sleep. Elbow pain was not reported among workers at Airport A (Figure 9).

\subsubsection{Upper and Lower Back Pain and Foot Pain}

Lower back pain is common among workers who have to lift or pull heavy weights or who lift frequently, even if the loads are not heavy. It is also common among workers who sit for prolonged periods at work operating computers, and among workers adopting awkward postures, particularly twisting and bending. These exposures are found at all three airports, and would explain the prevalence of lower back pain discovered.

Prolonged sitting and lifting cause more pressure on the lower back (lumbar region) than on the upper back. Upper and lower back pain exist at all three airports, although lower back pain is less at Airport B, probably due to the flexibility of working from both sitting and standing positions. When upper and lower back pain occur, they are severe: among Airport A and B workers, $100 \%$ of upper back pain sufferers said the pain interferes with job performance, over $66 \%$ said the pain interferes with non work-related activities, and nearly $60 \%$ lost sleep due to pain. These findings indicate the existence of a severe problem. 
More than half of the check-in workers live with lower back pain, with $100 \%$ of workers at Airport A suffering from this MSD. Where lower back pain occurs among check-in workers, it is severe: nearly $64 \%$ of lower back pain sufferers say the pain interfered with job performance (Figure 9), 60\% of lower back pain sufferers say the pain interferes with non work-related activities, and nearly $80 \%$ from Airport B, over $60 \%$ at Airport A, and more than half from Airport $\mathrm{C}$ said lower back pain interrupts their sleep. Lower back pain causes some check-in workers to lose work time, but not at a rate proportional to the number of workers living with pain: 19\% (13 individuals) lost work time due to lower back pain - 9 out of 13 were workers at Airport C. Severe lower back pain at Airport C is likely due to prolonged sitting in a static position, combined with, and probably aggravated by, awkward postures associated with baggage tagging.

Prolonged standing, particularly on hard surfaces, causes foot pain among some workers. "Sometimes I have pain in my upper body and arms, and swollen feet" (worker, Airport B). Fatigue and pain in the feet, caused by standing for long periods, is made worse by regular lifting and carrying of heavy bags, which exerts significant pressure on the legs and feet. Prolonged periods of standing combined with regular lifting of bags are the most likely major factors explaining the foot pain experienced by Airport A workers. Foot pain causes check-in workers sleep loss, interferes with job performance and with activities outside of work. Where the chairs provided to workers are uncomfortable, or where there is a lack of legroom while sitting, workers are more likely to stand, contributing to foot pain. Adding a cushioned mat to the floor surface is a simple, low cost means of increasing comfort while standing.

\subsubsection{Distribution of Reported Musculoskeletal Pain}

It is not uncommon for check-in workers to suffer from MSD pain in more than one place on their body at the same time (Figure 10). Four workers had pain in 8 different points on their body simultaneously, indicating pain all over. All over pain was found at all three study sites, is not dependent on the type of baggage handling system, and occurs among many workers. 
Figure 10: Total Number of Musculoskeletal Pains Reported (\% respondents reporting specified number of pains)

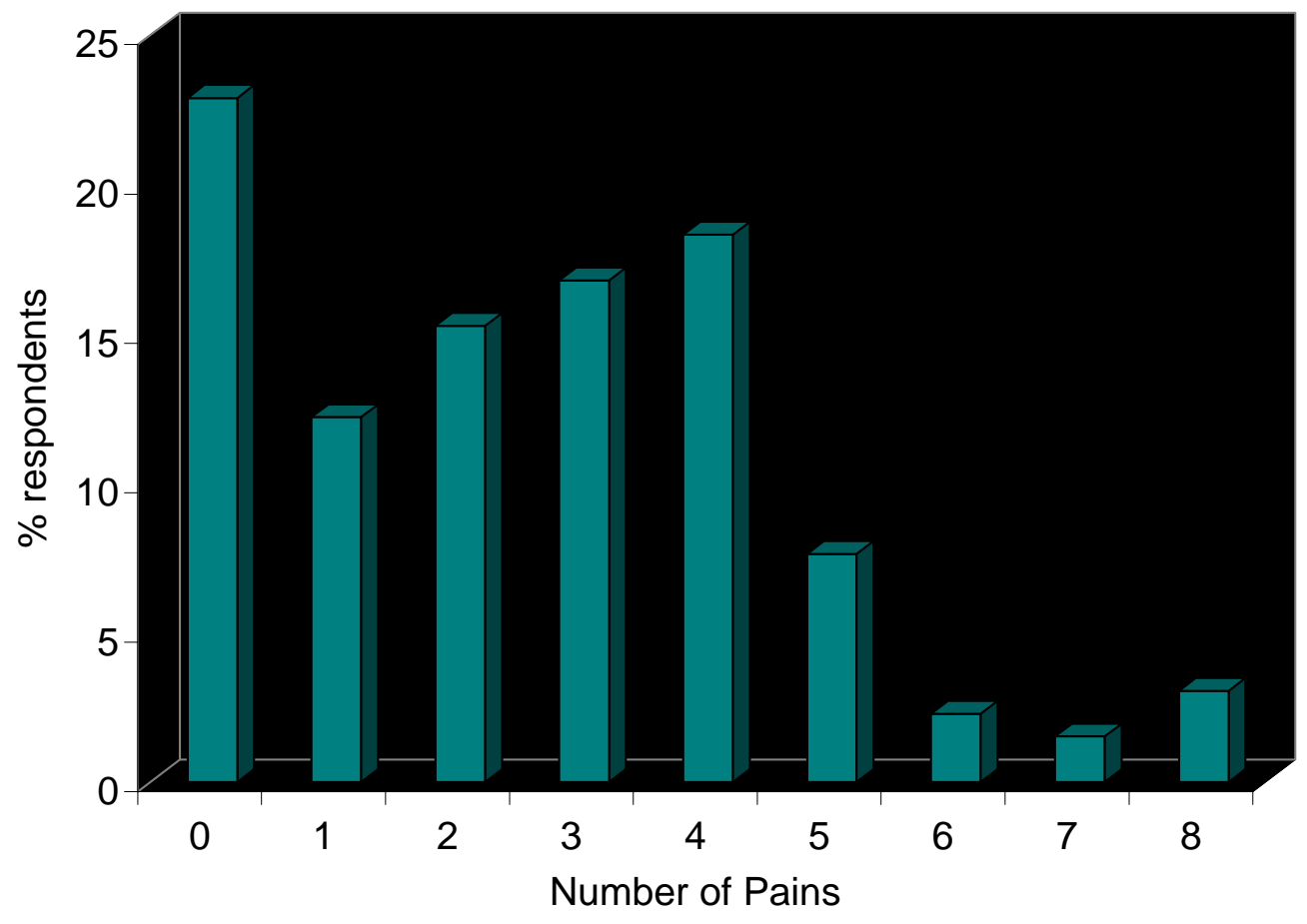

$\mathrm{n}=131$

One might consider that the self-reporting of MSDs could lead to symptom exaggeration by respondents, consequently leading to an overestimation of prevalence. We found consistency in the responses about musculoskeletal problems and symptoms among workers at the three airports (Figure 11). It would seem, therefore, reasonable to treat the results with respect to subjective complaints as an accurate method for evaluating work-related health hazards and symptoms among check-in workers. Indeed workers may experience musculoskeletal pain that is induced by non work-related activities, and which may worsen, even to the level of a disabling injury, due to work-related factors. The reverse can be equally true, where job factors can trigger a problem that could become aggravated by non work-related activities. However, length of time spent on the job, cyclical repetition involved in the work, and regularity of daily exposures normally add up to more exposure time, and in many cases more body load, than exposures caused by most off the job activities. This chicken-egg problem is what makes the diagnosis (and compensation) of work-related MSDs so tricky. 
Figure 11: Distribution of Musculoskeletal Symptoms (\% workers reporting specified type of pain)

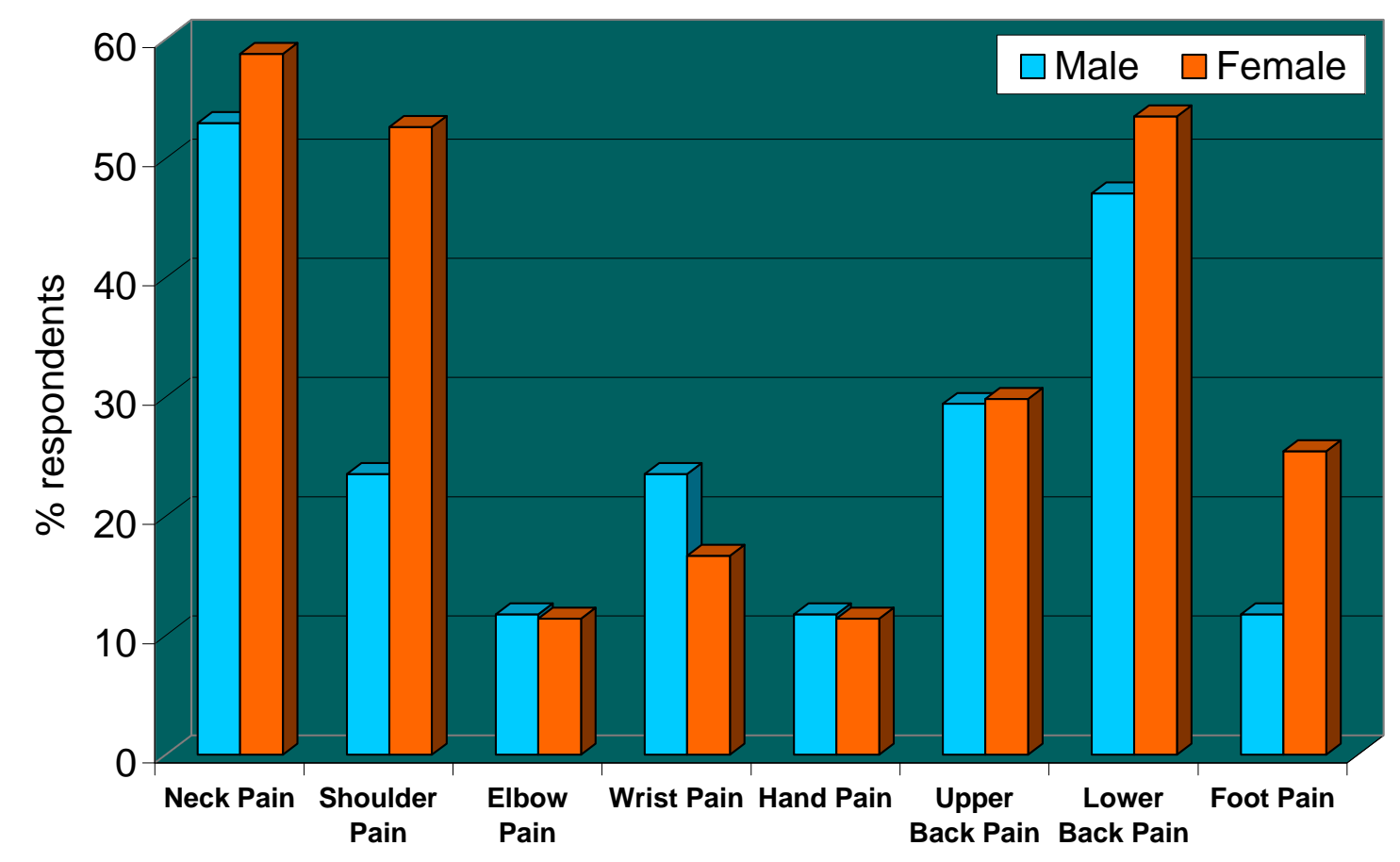

$\mathrm{n}=131$

The discrepancy between the MSDs reported by workers, compared with the injury reports provided by their employers indicates that often workers do not report their MSDs to their employer. Official figures may, therefore, show zero non-disabling or disabling work-related injuries in a given year without reflecting the reality of workers' experiences.

\subsubsection{Lifting and Handling Baggage}

The formulation of several questions in the questionnaire did not seem to differentiate sufficiently between manual lifting and carrying baggage, and handling baggage during typical operations such as sorting out baggage jams. Pain and MSDs among Airport B and C check-in workers appear to result, at least in large part, from prolonged sitting or standing and awkward body movements, rather than from constant manual lifting of passengers' baggage, except for lifting and carrying fallen bags, and un-jamming the conveyor.

Workers manually handle baggage at all three airports, albeit to different degrees: all Airport A workers manually lift baggage often (Figure 12). In spite of the fully mechanized baggage checkin systems, nearly $80 \%$ of Airport B workers and $61 \%$ of Airport C workers lift baggage manually, but with less frequency than Airport A workers (Figure 13). 
Figure 12: Whether Baggage Lifted or Generally Handled

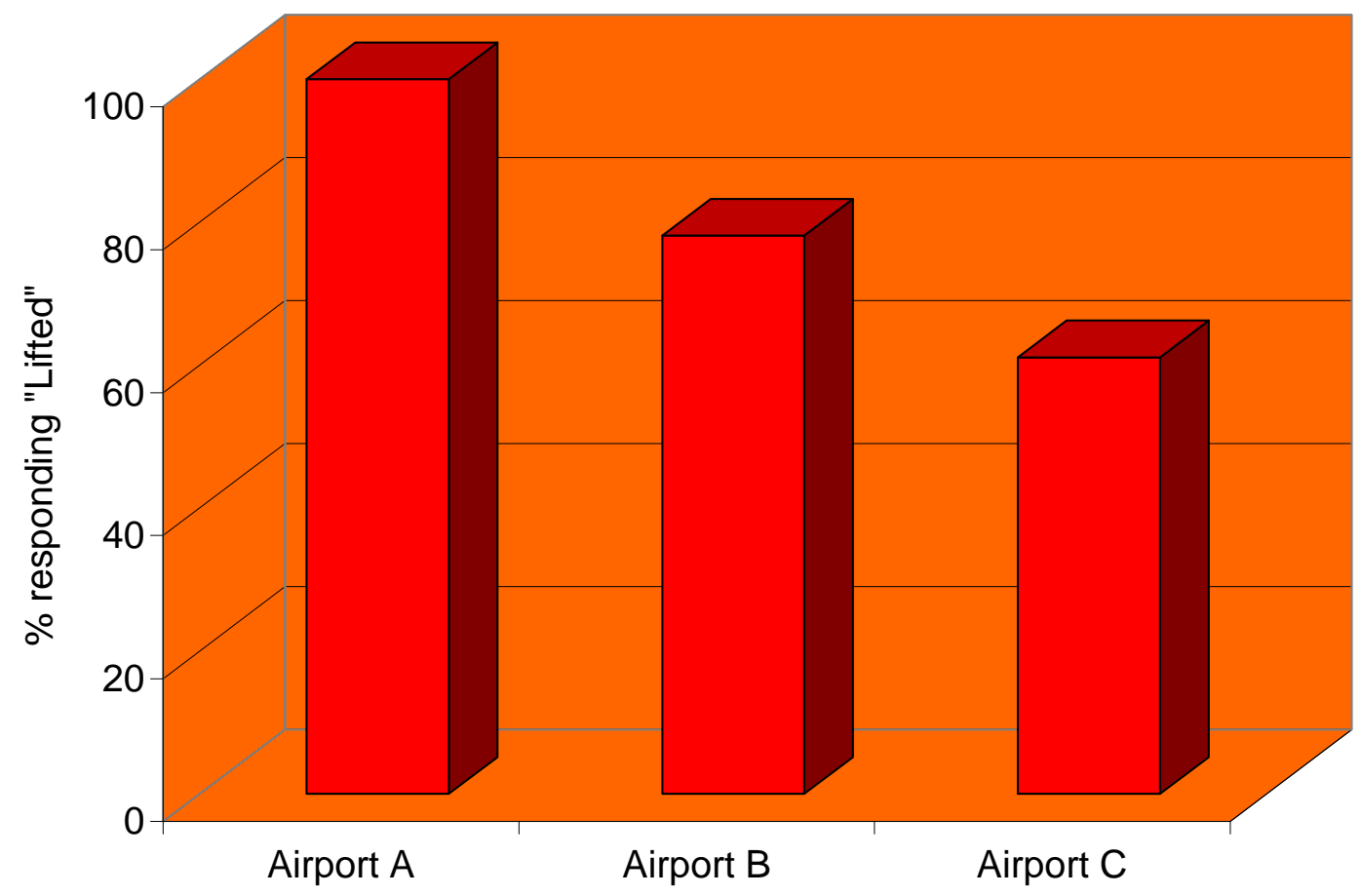

$\mathrm{n}=130(8,32,90 ;$ Airport A, B, C respectively $)$

Figure 13: Frequency of Handling Baggage

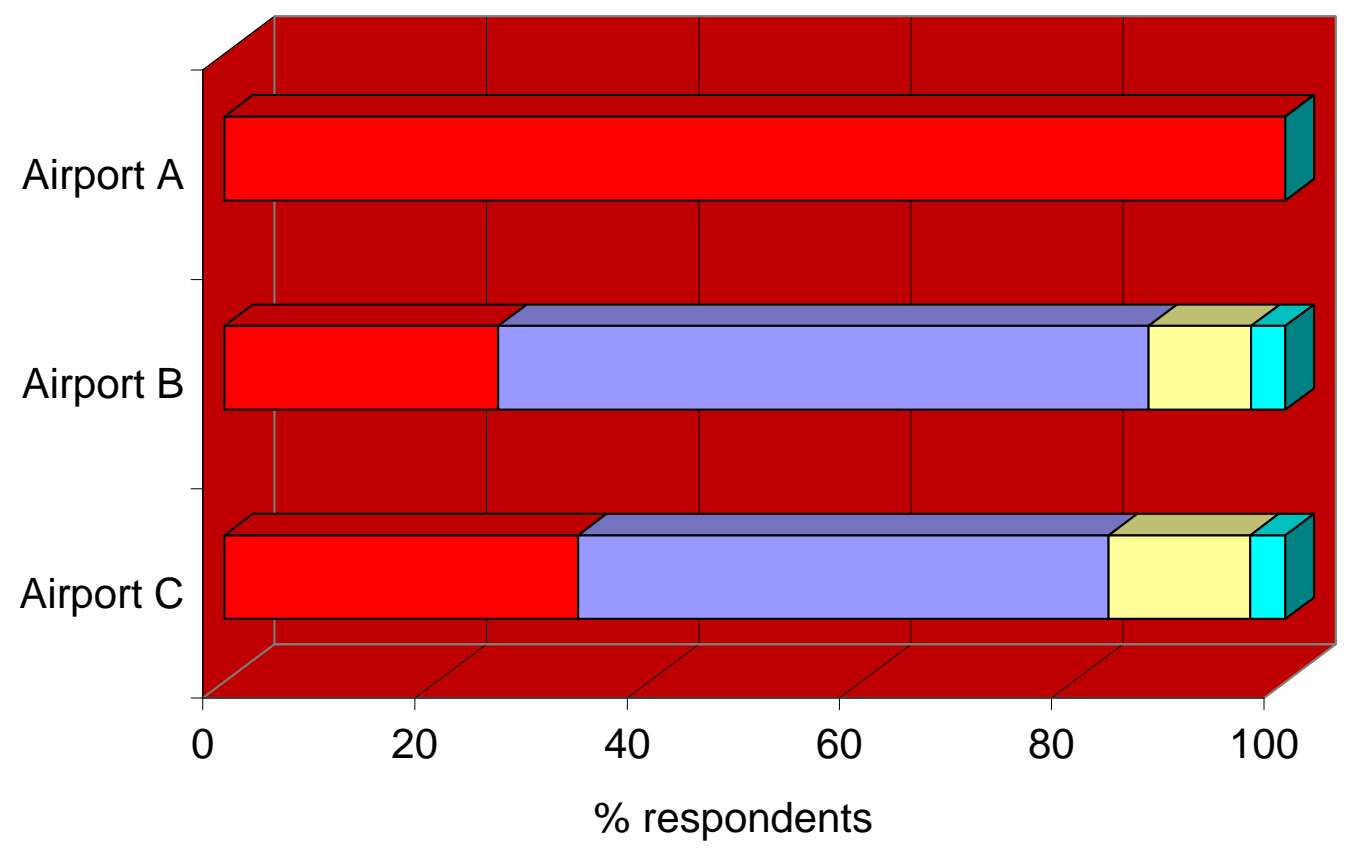

$\square$ Often $\square$ Sometimes $\square$ Almost Never $\square$ Never

$\mathrm{n}=129(8,31,90 ;$ Airport A, B, C respectively) 
Table 1: $\quad$ Number of Bags Handled per Day, per Person

\begin{tabular}{lccc}
\hline & Minimum & Average & Maximum \\
\hline Airport A & 160 & 418 & 600 \\
Airport B & 2 & 135 & 500 \\
Airport C & 0 & 97 & 650 \\
\hline
\end{tabular}

$\mathrm{n}=91(8,20,63$; Airport A, B, C respectively)

Handling of baggage takes place mainly at 3 locations: at the initial check-in, at the gate and at the special baggage area (Figure 14) (for overweight, oversized, unwieldy or awkward shape baggage, including skis and bicycles). Check-in workers' jobs include lifting, carrying, and generally handling special baggage, regardless of size or weight.

Figure 14: Areas Where Baggage is Handled (\% respondents dealing with specified areas)

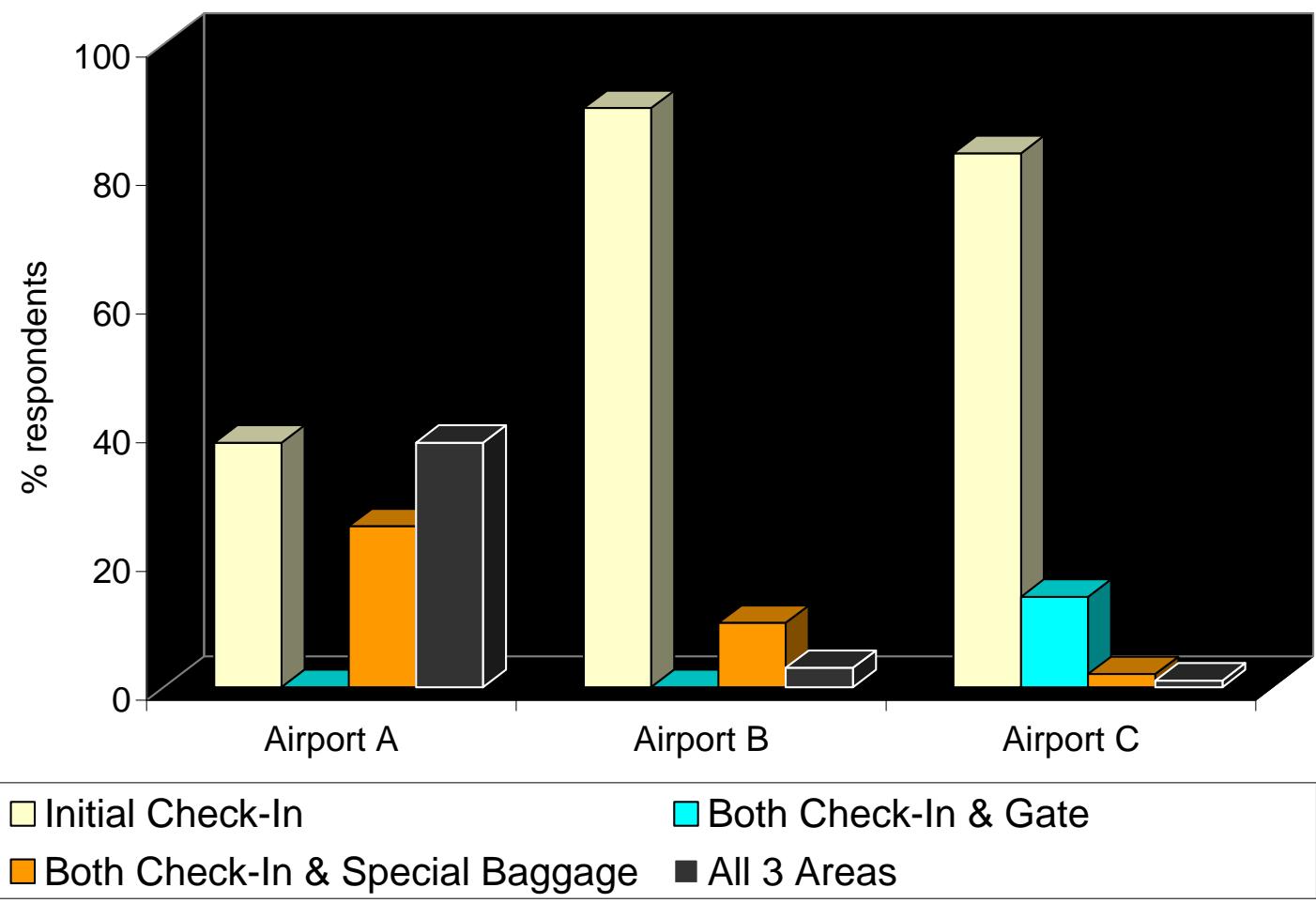

$\mathrm{n}=125(8,31,86$; Airport A, B, C respectively $)$

Workers at all three airports handle baggage at the initial check-in, where the greatest burden of work is performed. At Airport B, $10 \%$ also handle special baggage, 1 worker handles baggage at all 3 areas, and 1 worker handles only special baggage (this value does not appear in Figure 14 as it represents only 1 person among the 3 airports). At Airport C, $14 \%$ of workers handle baggage at both check-in and gate. Gate duties involve carrying baggage to the airplane directly, including lifting and carrying bags up and down stairs, with baggage weights not indicated.

No system is foolproof. Even where there is a fully mechanized baggage handling system, workers still end up lifting bags some of the time. 
"Last year I had 1 month off due to an accident at the check-in. I had a medical certificate and got paid. I slipped and fell off the step behind the desk and tore ankle ligaments. I don't want to hurt my back, so I only lift bags when they fall off, but bags fall off often. If a big one falls, I will call for help" (worker, Airport C).

Lifting such heavy loads exceeds by many times any existing recommendations for safe lifting limits, such as the NIOSH guide for manual lifting (Waters, 1994)). Failing to follow safe lifting limits is not without consequence: the high number of workers who live with back pain is a consequence of unsafe conditions for manual lifting.

Quick turnaround policies appear to be the root of the problem of work speed and work intensification, which directly affects the handling of baggage by check-in workers. The pressure, workload, and speed demanded of check-in workers contribute both physically and psychologically to negative health outcomes.

\subsubsection{Computer Use and Working Posture}

Fully computerized processing of passenger tickets involves health hazards similar to those faced by computer operators in clerical environments, notably fixed and constrained postures. An externally imposed pace of work, such as a high volume of passengers, the management of which is dictated by quick turnaround policies, and a high pace of work during peak periods, also present potential risks for MSDs in check-in workers, similar to computer operators in clerical environments.

With work shifts ranging in length from six and a half hours (Airport C) to twelve-hour shifts (Airport A) (Figure 15), check-in workers spend most of their working day in front of a computer. Close to $100 \%$ of check-in workers spend nearly their entire work shift in front of a computer $(92.4 \%, 93.6 \%$ and $94.5 \%$ of the work shifts at Airports A, B and C respectively) (Figure 16). Body load and potential damage result from static posture maintained over prolonged periods of time (Figures 17 and 18) (Airports $\mathrm{A}$ and $\mathrm{C}$ ), and conditions found at Airports $\mathrm{A}, \mathrm{B}$ and $\mathrm{C}$, including work at poorly designed, or non-adjustable workstations (including computer height and angle, table and chair), use of chairs that do not adequately support the back and legs, repetitive hand movements, glare from overhead lights or direct sun, lack of regular breaks, and pressure to work at a certain speed. "The fact that the VDU monitors cannot be adjusted is a problem. I get frequent eye strain" (worker, Airport B). Adjustability is particularly important for check-in workers, who work on shifts, thereby sharing workstations, invariably with workers of different sizes. 
Figure 15: Length of Work Shift

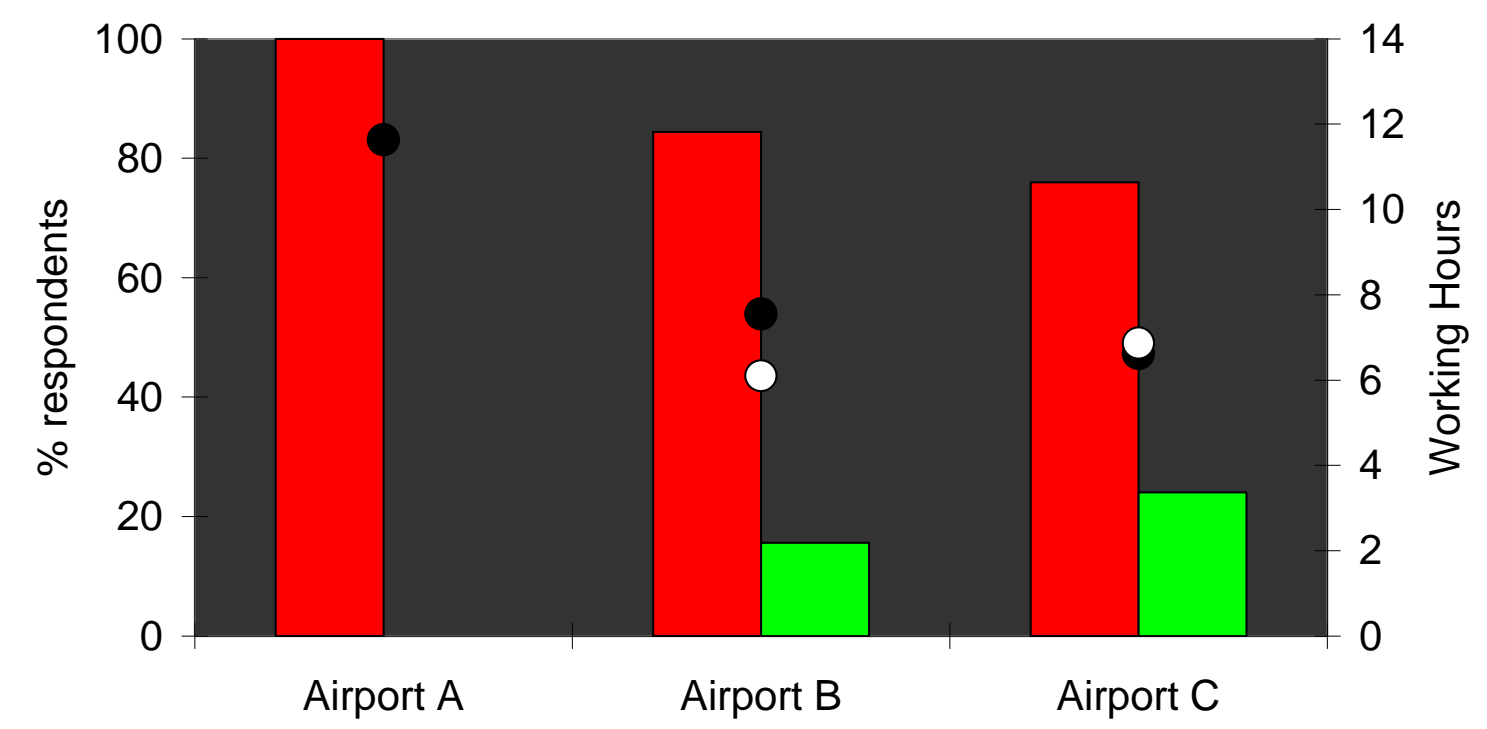

$\square \%$ Respondents With Symptoms

$\square \%$ Respondents Without Symptoms

- Length of Work Shift With Symptoms

O Length of Work Shift Without Symptoms

$\mathrm{n}=119(8,32,79 ;$ Airport A, B, C respectively $)$

Over $85 \%$ of Airport A workers said their computers could be adjusted, and roughly half of Airport B and C workers said they could adjust their computers, while the other half said they could not (Figure 19). Findings based on our workstation analysis do not concur with these reports of computer height-adjustability - in reality, none of the computers at any of the airports were adjustable in height, and only some were adjustable in tilt. Computers at Airport A were adjustable neither in angle nor in height. The high number of responses indicating that computers are adjustable seems to indicate that 'adjustability' was understood to mean brightness and contrast adjustability on the screen (standard features of most all computers), or simple tilt, rather than height adjustability.

Similarly, over $70 \%$ of workers at all three airports said they could adjust their workstation chair, while roughly $1 / 3$ at each airport said they could not adjust their chairs (Figure 19). Work observation revealed that chairs at Airport A are not adjustable, some chairs at Airports B and C are adjustable, while others are only partially adjustable (such as in seat height, but not back rest angle or height). Over half of workers who say they can adjust their chair still experience pain from MSDs, while over $20 \%$ of workers who say they cannot adjust their chair live with pain (Tables 2 and 3). 
Figure 16: Computer Use

(number of hours per day and percent shift spent on computer)

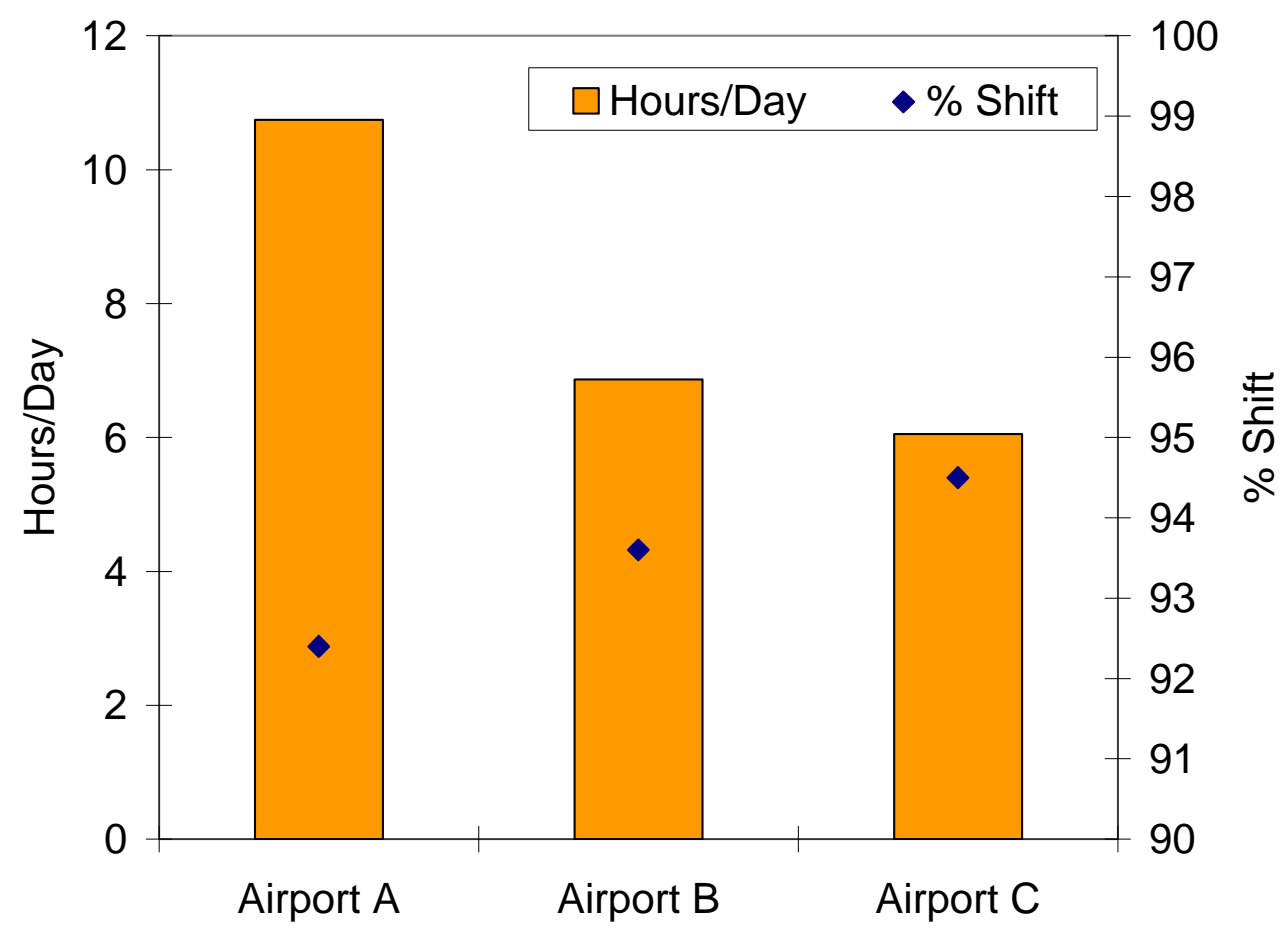

$\mathrm{n}=122(6,30,86$; Airport A, B, C respectively)

Check-in workers should be provided with fully adjustable chairs (adjustable in seat height and tilt, back rest height and angle, with a 5-wheel base for stability and ease of movement, and a fabric-covered seat pan to prevent sliding). Training should be provided to demonstrate how to adjust the furniture and how to determine appropriate chair height for each individual. Chairs should be easily adjustable from a sitting position.

Table 2: Can Adjust Computer

\begin{tabular}{lcc}
\hline & With Symptoms & Without Symptoms \\
\hline Yes & $40.0 \%$ & $10.8 \%$ \\
No & $35.4 \%$ & $10.0 \%$ \\
No Answer & $1.5 \%$ & $2.3 \%$ \\
\hline
\end{tabular}

$\mathrm{n}=130$

Table 3: Can Adjust Chair

\begin{tabular}{lcc}
\hline & With Symptoms & Without Symptoms \\
\hline Yes & $56.3 \%$ & $17.2 \%$ \\
No & $21.1 \%$ & $3.9 \%$ \\
No Answer & $0.0 \%$ & $1.6 \%$ \\
\hline
\end{tabular}

$\mathrm{n}=128$ 
Figure 17: Working Posture

(\% working time spent in specified posture)

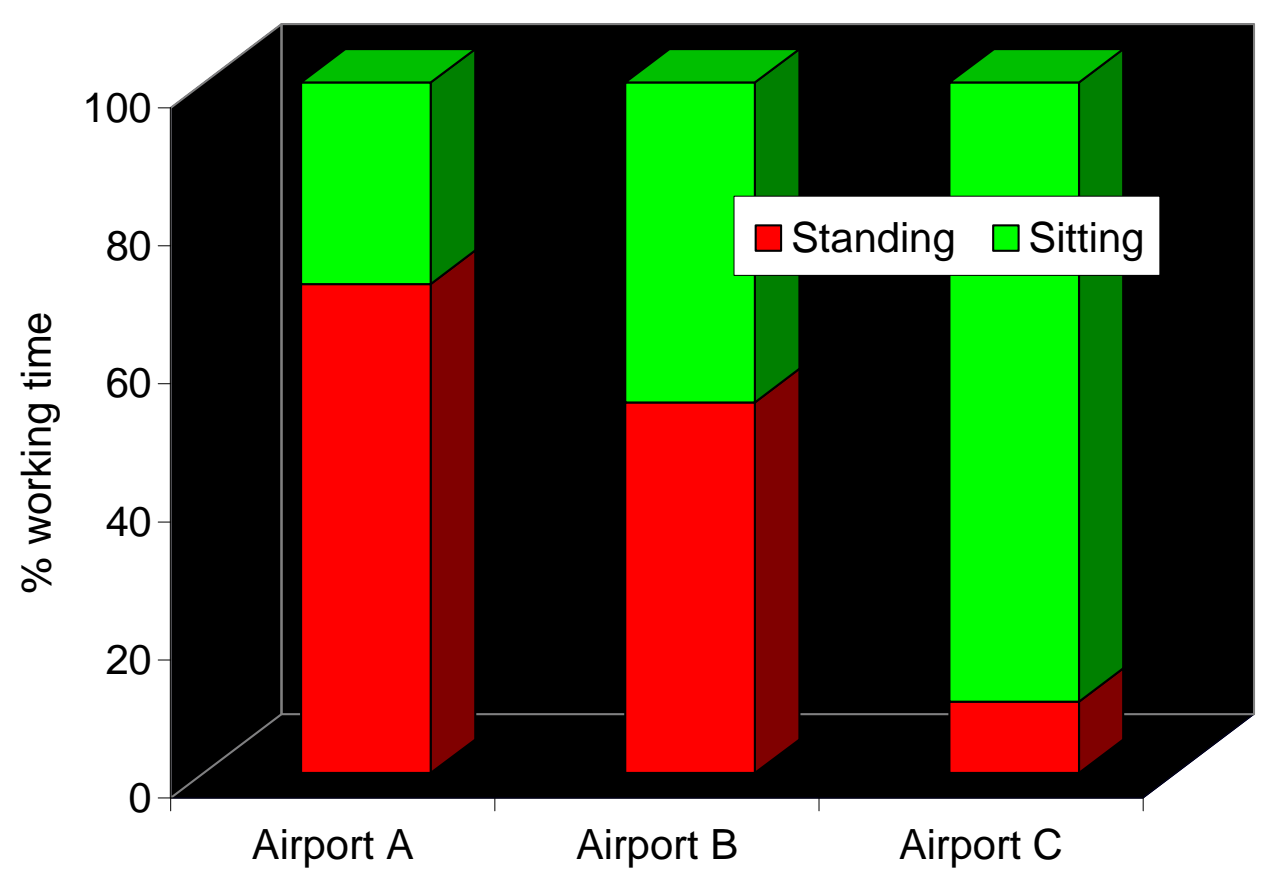

$\mathrm{n}=100(6,23,71$; Airport A, B, C respectively)

Figure 18: Spending Too Much Time in One Working Posture (\% workers responding "Yes")

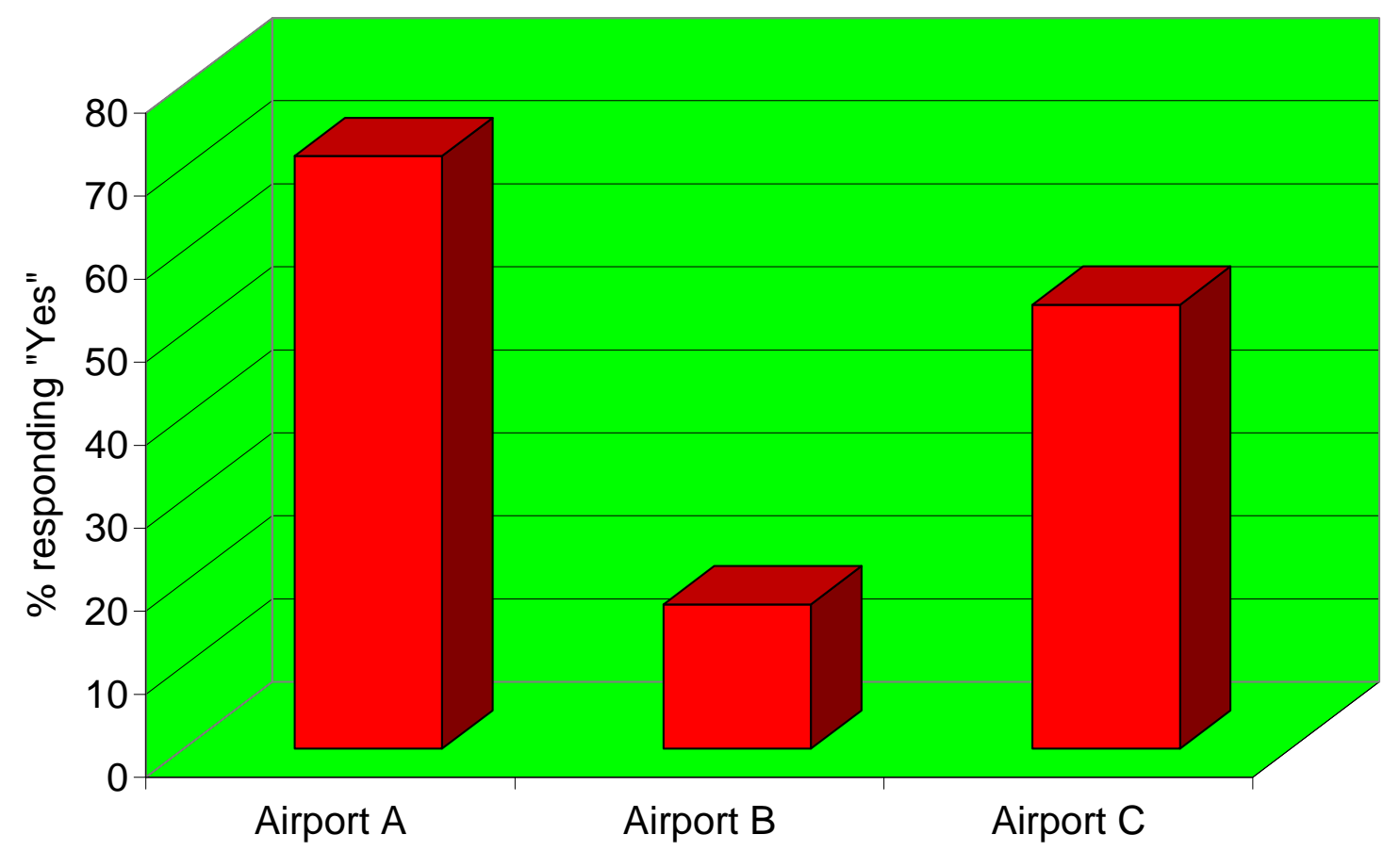

$\mathrm{n}=116(7,23,86$; Airport A, B, C respectively) 
Figure 15 shows the number of respondents having pain and those not having pain, crosstabulated with the length of the average work shifts for each airport. Results reveal that all workers at Airport A had symptoms of MSD pain, at Airport B many more workers on a 7.5 hour work shift reported having MSD-related pain than those workers on a 6 hour shift. At Airport C, the number of workers having MSD-related symptoms was slightly more than three times the number of workers not having symptoms, while there was no significant difference in the workshift length between the two groups.

\section{Figure 19: Computer and Chair Adjustability}

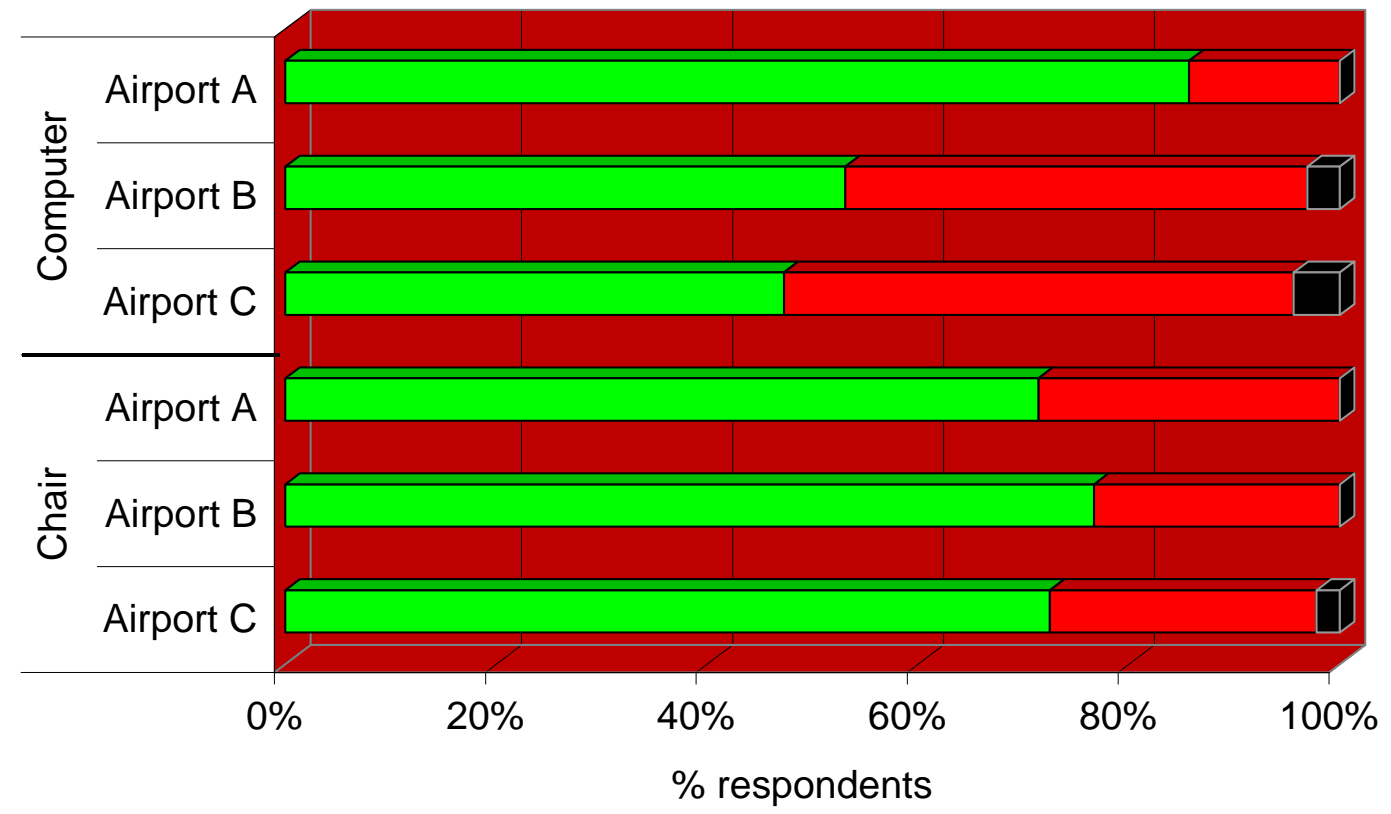

$\square$ Yes $\quad \square$ No $\quad$ No Answer

$\mathrm{n}=130(7,32,91 ;$ Airport A, B, C respectively)

As length of employment increases, so too does the ratio between the number of workers with and without MSD symptoms. In other words, under the present conditions at Airports A, B and $\mathrm{C}$, more time spent on the job appears to lead to a higher prevalence of workers with MSDrelated symptoms (Figure 20). It appears that the symptomatic category of workers begins to increase significantly after 3 years on the job under present conditions, although MSDs are shown to exist even among workers employed as little as 6 months or less. 
Figure 20: Distribution of Symptoms by Years on the Job

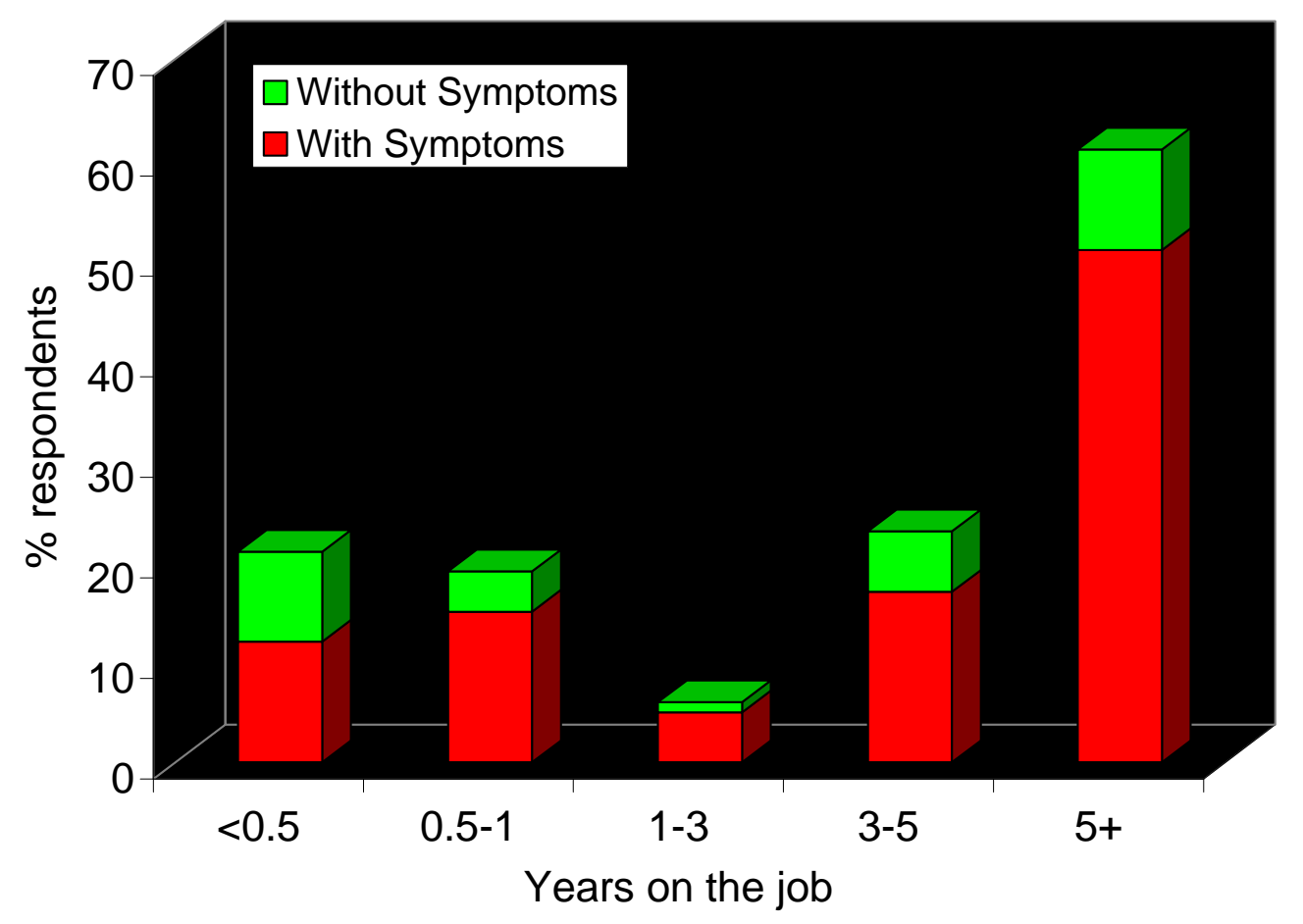

$\mathrm{n}=130$

\subsection{Examining Compensation Records}

The employer injury records obtained from employers at Airports B and C (including both employers at Airport C) did not allow us to identify what type of injury caused recorded lost workdays. The employers do not keep this information, indicating a rather lax attitude toward worker health. A proactive management approach to worker health requires more involvement in detailed information collection and dissemination. The employer injury and lost work time records compared with worker self-reports of MSDs signals a significant gap in communication and information, both top-down, and bottom-up.

Check-in workers do not appear to be losing much work time paid by workers' compensation, resulting from MSDs, but they are living in pain that is very likely work-induced. The low official injury reports indicate that employers externalize the costs associated with work design, working conditions, and management policies, particularly those associated with work intensification and quick turnaround policies. It appears that check-in workers themselves are bearing these hidden costs. While there may be a short-term gain in such a business strategy, there is long-term loss at the levels of the enterprise, individual, and society. While some employers may accept a labour market approach of paying the lowest wage possible, and investing as little as possible in 'the job,' we question whether the rapid turnover of workers, such as seen at Airport C, is cost-effective in the long-term. Searching for employees, initial training, and time spent in a learning curve also have associated costs.

Of no less importance are the issues of ethics and corporate responsibility. Is it either ethical or responsible to actively, or subtly, discourage reporting of work-related MSDs? The fact that MSDs are not recognized as an occupational injury category in Canada and Switzerland facilitates externalizing the costs of doing business. 


\subsection{Cost of Fully Mechanized Baggage System}

Information on the cost of installing and maintaining a fully mechanized baggage system for check-in work was difficult to obtain in a precisely comparable manner for the three airports. At Airport C, the installation cost is estimated at between US\$15-19 million (SFR28-31 million) for the entire airport, comprising 94 check-in workstations. The maintenance cost is estimated at between US\$1.8-2.7 million per year (SFR1-1.5 million), which is approximately 2-3\% of the purchase price of the whole mechanized baggage check-in system. These costs include the entire system from check-in to container loading for the airplanes, including the mechanics, electronics, software, hardware, labour costs, and installation. The cost also includes a bag sorter machine that sorts bags by flight number.

In order to fully mechanize one workstation at Airports A and B in Canada, the cost of redesigning one check-in workstation was estimated at between US\$16,250-22,750 (C $\$ 25,000$ $35,000)$. 


\section{Conclusions}

\subsection{General Conclusions: Violence and MSDs}

Probably the two most important findings of this study are the existence and degree of workrelated violence faced by check-in workers, and the prevalence and severity of MSDs. During their employment as a check-in worker, 1 in 20 workers in the study has been physically assaulted on the job by aggressive passengers, and $80 \%$ exposed to verbal abuse from passengers. The level of perceived risk of violence is also substantial in this occupation, with nearly half of the workers reporting that they see violence as a substantial risk factor at their jobs. These findings indicate the need for empowerment-based training for check-in workers and managers, to deal with aggressive or unruly passengers. Such findings highlight as well the need for management systems to be put into place in every airport to protect workers, passengers and crew from potentially violent passengers.

MSDs are prevalent and severe among airport check-in workers and may lead to temporary or permanent disability. An important number of workers live with pain from musculoskeletal disorders in various parts of the body. Some workers have lost work time due to pain or disability, a substantial number of check-in workers experience pain that interferes with their job performance, while many perform their job functions despite living with significant pain. Checkin workers lose sleep due to musculoskeletal pain, and MSDs cause significant disruption to activities outside of work.

These findings indicate airport check-in work as having clear hazards associated with the job, an occupation likely to cause severe MSDs. None of the workers in the study received training on proper lifting technique, even though lifting, carrying, or generally handling baggage would appear to be sufficient to cause MSDs, even at fully mechanized check-in workstations. The awkward twisting and bending involved in baggage tagging also appears to cause MSDs.

The findings from this study indicate that MSDs are much more prevalent, and far more severe among check-in workers than what appears in official work-related injury data obtained from employers' records. It is indeed a cause for concern when 24 workers report living with pain in four different body points at once, and when only $23 \%$ of workers reported not having any musculoskeletal pain.

The costs to employers from lost work time due to sickness absence and decreased productivity can be measured directly. Indirect costs to both workers and employers, however, are more difficult to measure, more hidden than direct, and are borne mainly by the workers (and their families). But these costs should be of cause to management given that productivity, alertness on the job, customer satisfaction, and efficiency can be reduced when workers are sleep deprived, or where muscular pain causes restriction in freedom of movement. There is inadequate statistical information available due to a lack of consistent framework for classifying injury and illness data. To establish the extent of occupational injuries and diseases and their cost among check-in workers, it would be necessary to approach all airlines and ground handling companies individually, as they are the only ones having reliable statistical data.

The impact of the check-in workers' job on the individuals performing it can vary depending on the design of the check-in counter and baggage handling system at any given airport. The 
resulting workload and risk for MSDs from these exposures, especially low back pain, can be likened to the MSD risks found in industrial workplaces where heavy manual lifting is involved.

The higher prevalence of upper and lower back pain at Airport A, compared with Airports B and $\mathrm{C}$, provides evidence supporting the need for fully mechanizing baggage check-in systems. Eliminating the need for workers to lift and carry each and every checked bag is an important first step toward preventing work-related MSDs among check-in workers. However, the check-in job in its entirety needs to be re-examined, including all associated management policies. Additional factors that need to receive equal attention include unequal work load throughout a shift, lack of training, high levels of stress due to high work demand with a low level of worker control, daily tension from potentially aggressive passengers with a lack of empowerment-based worker training and management systems to protect workers, lack of management recognition of check in workers' skill contribution for passenger, crew, and aircraft safety, the need for adjustable workstations designed for workers' requirements, and the basic need for worker participation in decision-making.

Because many work-related MSDs are never reported as such, employers often believe that the rates of MSDs experienced by their employees are far lower than they are in reality (Morse et al 1998). Our findings suggest that there are hidden costs associated with work-related MSDs. The physical and psychosocial stressors inherent in check-in work have a direct, negative impact on workers' personal lives as well as on their productivity and efficiency at work, besides causing absenteeism from work. All of these demonstrated results have hidden yet real costs to both workers and employers.

\section{Check-in workers: safety professionals on the ground}

We have suggested that check-in workers' skills and occupational niche be expanded and enhanced so that check-in workers can play a recognized role as safety professionals in civil aviation. The check-in worker's job naturally lends itself to being combined with that of safety professional on the ground. In expanding the job, it is important that check-in workers have the confidence, commitment and authority to deal with aggressive and disruptive passengers. Checkin workers are the logical choice to assess a variety of passenger factors associated with ground and air rage (assessing the weight of bags, ensuring that carry-on baggage is of the correct weight, size and number, identifying passengers who are under the influence of alcohol or exhibiting mood problems at time of check-in). Skills development and role enhancement also can offset the repetitive and cyclical nature of some of the job tasks, an important additional benefit.

Given the necessary training to empower them to take on this critical role with management support, check-in workers are well placed to identify potentially aggressive or threatening passengers and to catalyse a chain of actions aimed at preventing disasters, or aggressive behaviour towards check-in and other air transport workers.

\subsection{Suggested Solutions}

We have tried to show how various conditions and exposures can be damaging to check-in workers and costly to their employers, as well as how such hazards can be prevented or alleviated. The primary focus for the prevention of MSD-related problems is through ergonomic and engineering design efforts, with the involvement of workers in the process. 
Of the major groups of risk factors identified for work-related MSDs summarized by the US National Institute for Occupational Safety and Health (NIOSH, 1995), a number of solutions, presented by risk factor group could be applied to improving check-in workers' jobs:

\section{$\underline{\text { Repetitiveness }}$}

Solutions:

?? Use mechanical aids (such as installing roller bars at semi-mechanized systems to connect baggage weigh scale to conveyor, to eliminate repeated lifting/carrying of bags)

?? Enlarge work content by adding more diverse activities (such as gate duties, providing assistance for passengers with special needs, possibly training to carry out other functions in airports, such as security checks, safety professional role)

?? Rotate workers (such as ensuring workers do not carry out exclusively check-in duties for more than 4 hours per work shift, giving workers the possibility to organize own shifts, ensuring same workers do not work repeatedly the shifts with the greatest number of flights)

?? Increase rest allowances (such as 10 minutes break for every 2 hours computer work, providing training so workers learn the benefits of alternating sitting and standing on the job, and encouraging such postural change every 2 hours after a short break)

\section{Force/mechanical stress}

Solutions:

?? Decrease weight of tools/containers and parts (such as $20 \mathrm{~kg}$. universal maximum baggage limits)

?? Improve mechanical advantage (such as zig/zag surface on all mechanized conveyors and addition of barriers to prevent bags falling off)

?? Use pads and cushions (such as for standing work at the check-in counter)

\section{$\underline{\text { Posture }}$}

Solutions:

?? Locate work to reduce awkward postures (such as locating the baggage scale so it can be viewed without twisting)

?? Alter position of tool (such as computer keyboard) to avoid bending of wrist

?? Provide adjustable tables and chairs, designed for work to be alternated between sitting and standing

?? Provide training on how to properly adjust workstation furniture for individual size 


\section{$\underline{\text { Psycho-social stresses }}$}

Solutions:

?? Enlarge workers' task duties (such as combining check-in work with duties at departure gates, safety professional responsibilities, client service, and special services for passengers with special needs)

?? Allow more worker control over pattern of work (such as allowing workers to establish schedules together, rather than imposing schedules)

?? Provide micro work pauses (in addition to regular breaks of 10 minutes every 2 hours)

?? Allow workers to participate in workstation and task design, as well as in work organization planning

\section{$\underline{\text { Violence }}$}

Solutions:

?? Establish a high check-in counter as the design standard to protect check-in workers against aggressive passengers

?? Provide obligatory training for both worker and managers on dealing with aggressive passengers

?? Establish a system and structure at airports to enable and empower check-in workers to use their position as a first line of defence for passenger, crew and aircraft safety.

To protect check-in workers against aggressive passengers, a coordinated industry wide approach, involving governments, regulators, airlines, airports and ground handling agents is needed. The ITF has issued guidelines recommending actions focusing on:

?? preventive policies for airports, ground agents and airlines aimed at minimising the risks of disruptive passengers boarding an aircraft;

?? strategies and training for both crews and ground staff for managing incidents;

?? passenger information and service improvements;

?? sanctions against offenders;

?? post-incident support for staff and passengers who are victims of aggression;

?? changes in law to ensure law enforcement jurisdiction extends to all aircraft;

?? stronger laws covering these offences;

?? an international treaty covering offences in the air.

We suggest that addressing other key factors as well, such as work organization and job content, is necessary to develop preventive strategies against workplace violence. Actions could include ensuring appropriate staffing levels, task assignment based on experience and competence, clearly defined tasks, working hours and shifts that are not excessive, and modifying work practices - including airline marketing practices - to limit client dissatisfaction. 


\subsubsection{Suggestions for Workers and Trade Unions}

This study has revealed that MSDs among check-in workers increase with time on the job; i.e. the more years one works at the check-in, the more MSD symptoms seem to appear. These findings are not surprising given that MSDs are cumulative over time. This is not to suggest that the number of years employed at airport check-in work should be limited as a preventive measure. On the contrary, the findings of this study support the need to use a systems approach to examine the entire concept and job tasks involved in check-in work in order to ensure that workers can perform a check-in job safely for many years. With training and recognition of the hazards inherent in the check-in job, preventive measures can be built in to protect workers' health.

Findings revealed a significant number of workers having an adjustable chair at the check-in yet still suffering from MDSs. This indicates that various causal factors appear to interact, resulting in MSD symptoms. It is, therefore, insufficient to address only one single item when considering work improvements.

The effectiveness of joint health and safety committees should be examined at all airports. Obstacles should be addressed if committees do not function effectively, if they do not address and resolve priority issues, or if committee members are not in regular contact with the workers they represent, to solicit information on a regular basis.

A final suggestion for future trade union action aimed at using the results of the study would be to consider applying skills objectives. These can range from individual, technical skills, such as how to lift properly, to group action skills, such as how to advocate for re-design of the workplace. Skills objectives could be useful in analysing check-in jobs in airports not included in the present study, and in proposing ergonomic modifications where social action is needed to initiate and implement changes in work organization through labour-management cooperation.

Research may or may not facilitate change. Some degree of "buy in" or "ownership" from those in power is needed for change to take place based on research. Through this study, we hope that the participatory research process has helped to produce new, directly applicable knowledge for both workers and managers.

"We need not more highly trained and sophisticated researchers operating with ever more esoteric techniques, but whole neighbourhoods, communities, and nations of 'researchers'." (Hall, 1975 in Elden, 1981).

\subsubsection{Suggestions for Management}

Based on the findings of this study, simple yet obvious preventive actions could be taken by management in any airport, to protect the health, safety, and well-being of airport check-in workers. The findings on MSDs, and the levels of pain and suffering experienced by these workers should give rise for concern among managers. The results would support the recommendation to install a fully mechanized conveyor system, or at least a roller bar, to obviate, as far as possible, the need for workers to lift and carry bags.

Preventive measures could begin with simple workstation and work organization adjustments, which do not necessarily require high investment costs for employers. Introducing wrist supports to the computer workstation may be a reasonable first step to prevent the wrist from resting on the hard table surface. Regular rest breaks away from computer work should be respected, by performing other tasks. 
The study has revealed that foot pain was experienced less often than other types of self-reported MSDs, but where foot pain was reported it was more severe among workers at Airport A where workers stand much more than workers at Airports B and C. The results associated with foot pain provide further evidence to support the recommendation that check-in workers be provided with sit/stand options during a work shift. Where chairs provided are uncomfortable, not sturdy, or where there is a lack of legroom while sitting, workers are more likely to stand, which can lead to foot pain. Adding a cushioned mat on the standing surface is a simple, low cost means of increasing comfort while workers stand. The issue of shoe allowance should be addressed where relevant.

The benefits of worker participation in the design of workstations, work process, work organization and in identifying and solving problems are cost effective in the long-term. A first step toward this end would be for management to promote and help establish a joint workermanagement health and safety committee in every airport, and to ensure that regular meetings of the committee are held, with identified problems addressed rapidly. Joint worker/management design and implementation of recommended changes have been shown to prevent MSDs caused by prolonged computer work (Smith et al, 1981; Smith, 1997; Statham and Bravo, 1990). Benefits of worker participation are also seen in developing coping and management strategies against work-related violence (Chappell and Di Martino, 2000). Joint strategies have been shown to protect workers' health and well-being, reduce costs to management from lost work time and sickness absence, as well as increase efficiency and productivity.

Lack of management attention to workplace psychosocial factors and MSDs, combined with a lack of worker voice and involvement is not a recipe for improved worker health and productivity. The psychosocial work environment has been linked to the occurrence of MSDs, particularly for the neck and shoulder region. Workers, like anyone else, appear to tense up their neck and shoulders when under stress (Hales et al, 1994).

The discrepancy shown in this study between workers' self-reported MSDs and injury rates recorded by employers demonstrates a gap in communication and participation between check-in workers and management in the three airports. Increased communication, dialogue and information exchange is recommended, with channels for upward as well as downward communication, and including attention given to feedback received from workers.

Management policies need to be examined with regard to their impact on check-in workers. The "quick turnaround" policies practiced by airlines increase the stress, pressure and workload for workers, without an accompanying increase in worker control over the organization of work or on any other aspect of the check-in job. What appears to be an important lack of training and skills development available to check-in workers also may contribute to high rates of MSDs and worker turnover.

Work-related violence is a human issue requiring organizational human resources departments to play a leading role in prevention, intervention and rehabilitation. Organizational commitment to the problem is essential, through policies and procedures, security, crisis management teams and employee assistance programmes, as well as education for workers and managers about workrelated violence. Training should consist of:

?? developing interpersonal and communication skills that diffuse and prevent potentially threatening situations;

?? developing competence in the particular function to be performed; 
?? improving the ability to identify potentially violent situations and people;

?? preparing a "core group" of mature and specially competent staff who can take responsibility for more complicated interactions;

?? developing violence-prevention strategies which include training managers and workers on how to recognise and handle violent behaviours or threats. Strategies should include the development of mutual support among staff members and assistance from supervisors and co-workers.

Source: Chappell and Di Martino, 2000, pp. 113-114.

We include these suggestions in addition to the coordinated industry wide approach and guidelines recommended by the ITF (see "Suggested Solutions" in Section 4.2 above).

In the immediate future, employers could pay close attention to the physical environment and design of check-in workstations as a measure for protecting workers against violent passengers. Findings demonstrate that a higher counter serves as a protective barrier against potentially aggressive passengers.

Employers of airport check-in workers may wish to consider the relevancy of a standards-based approach to health and safety at the check-in workplace, to ensure that workers' health is protected and that employers do not bear the financial burden related to poor, or ill-adapted working conditions. An example of a flexible and innovative standards-based approach was proposed through the Workers' Compensation Board of British Columbia, Canada, which proposed a forward-looking draft ergonomics regulation that included no specific standards. The focus was for employers to identify factors that might expose workers to a risk of adverse health effect. The employer would then have been required to eliminate or minimize the risk of adverse health effect to workers. Such an approach could be used in place of fixed weight limits for lifting, for example, which may not be protective for workers of all sizes and strength levels (Messing, 1998). A similar approach could be particularly useful in airports in developing countries where national health and safety legislation may not exist, and where awareness of ergonomics may be limited, or non-existent. A checklist of potential risk factors in the hands of both managers and workers could be useful where legislation does not exist, or where it is not protective for check-in workers.

Use of internationally recognized criteria for selecting or designing computer equipment and systems for check-in work is also suggested, as for computers used in any other type of workplace. Design and performance standards, such as those established by the International Organization for Standardization (ISO) provide managers with confidence that systems and equipment acquired can be used productively, safely, efficiently, and comfortably, and give workers a benchmark for judging their working conditions (Stewart, 1998).

Finally, adoption of a universal policy on maximum allowable weight of checked baggage may be worth considering. North and South America allow baggage to be checked up to 33 kilos per bag for all passengers, while many other countries limit checked baggage to 20 kilos total per passenger, for economy class passengers (which constitute the majority of travellers). The 33 kilogram per bag limit means a higher load on the musculoskeletal system of check-in workers. 



\section{References}

1. Boyd, C. and Bain, P., A summary of the findings from the cabin crew health and working environment survey, University of Strathclyde, United Kingdom in collaboration with Transport and General Workers Union and BASSA, 1999.

2. Chanlat, J-F., "Stress, psychopathologie du travail et gestion," in L'individu dans l'organisation: Les dimensions oubliées, Chanlat, J-F. (ed.), Sainte Foy, Paris, Presses de l'université Laval/Eska, 1990, pp. 709-721.

3. Chappell, D. and Di Martino, V., Violence at work, International Labour Office, Geneva, 2000.

4. Chenier, E., “The workplace: A battleground for violence," Public Personnel Management, vol. 27, no. 4, 1998, pp. 557-568.

5. De Koning, K. and Martin, M. (eds.), Participatory research in health: Issues and experiences, Zed Books, London, 1996.

6. Dickson, R., et al, "Intervention strategies to manage workplace violence," Occupational Health Review, vol. 50, 1994, pp. 15-18.

7. Dickson, R., et al, "Violence at work", Occupational Health Review, vol. 46, 1993, pp. 22-24.

8. Hales, T.R. et al., "Musculoskeletal disorders among visual display terminal users in a telecommunication company," Ergonomics, vol. 37, no. 10, 1994, pp. 16031621.

9. Hall, 1975 in Elden, M., "Sharing the research work: Participative research and its role demands," in Human Inquiry: A sourcebook of new paradigm research, Reason, P. and Rowan, J. (eds.), John Wiley \& Sons, Chichester, 1981, pp. 253266.

10. Hoel, H., et al., The costs of violence/stress at work and the benefits of a violence/stress-free working environment, International Labour Office, Geneva, 2000.

11. International Air Transport Association, Guidelines for handling disruptive/unruly passengers, Geneva, 1998.

12. International Transport Workers' Federation, “Air rage: The prevention and management of disruptive passenger behaviour" Safety in Practice, no.1, London, May 2000.

13. Leather, P., et al, "Exposure to occupational violence and the buffering effects of intra-organizational support," Work and Stress, vol. 12, no. 2, 1998, pp. 161-178. 
14. Messing, K., One-eyed science: occupational health and women workers, Temple University Press, Philadelphia, 1998.

15. Morse, T.C., et al, "The economic and social consequences of work-related musculoskeletal disorders," The Connecticut Upper Extremity Surveillance Project (CUSP), International Journal of Occupational and Environmental Health, vol. 4, 1998, pp.209-216.

16. National Institute for Occupational Safety and Health, Cumulative trauma disorders in the workplace, NIOSH, US Department of Health and Human Services, NIOSH Publication No. 95-119, 1995.

17. Smith, M., "Psychosocial aspects of working with video display terminals (VDTs) and employee physical and mental health," Ergonomics, vol. 40, no. 10, 1997, pp. 1002-1015.

18. Smith, M.J., et al., "An investigation of health complaints and job stress in video display operations," Human Factors, vol. 23, no. 4, 1981, pp. 387-400.

19. Statham, A. and Bravo, E., "The introduction of new technology: Health implications for workers," Women \& Health, vol. 16, no. 2, 1990, pp. 105-129.

20. Stewart, T.F.M. (ed.), "Ergonomics standards," Encyclopaedia of Occupational Health and Safety, $4^{\text {th }}$ Edition, International Labour Office, Geneva, 1998, vol. 2, ch. 52, pp. 31-34.

21. Waters, T.R., et al, "Applications manual for the revised NIOSH lifting equation," National Institute for Occupational Safety and Health, Division of Biomedical and Behavioral Science, Publication No. 94-110, 1994. 


\section{Appendix A: Use of the Study Results to Date}

To date, various channels have been used to disseminate the findings of the present study:

?? Focus group workshop held at ITF Health and Safety Conference, 1999, Amsterdam

?? Presentation of preliminary findings at ITF Health and Safety Conference, May, 2001, Stockholm

?? Article published in ITF Civil Aviation magazine, May, 2001

?? Article published on ITF website, May, 2001

?? Preliminary study results published as featured news story on ILO Washington, DC Office website, including hyperlink to the article on the ITF website page, September, 2001

?? Presentation of preliminary findings at American Public Health Association Annual Conference, November, 2001, Atlanta

?? Preliminary findings presented in seminar for Women in Development/Society in Development subgroup of US Agency for International Development and InterAmerican Development Bank, February, 2002, Washington, DC

?? Preliminary findings published in quarterly newsletter of ILO's Programme on Social and economic security, 2001, Geneva

?? Preliminary findings published in the ILO journal Labour Education, special issue for Workers' Memorial Day April 28, 2002, Geneva

?? Study results accepted for presentation at the XVI ${ }^{\text {th }}$ World Congress on Occupational Safety and Health, May, 2002, Vienna

?? Article published in Le Courrier, August 26, 2002, Geneva

?? Feature article published in the ILO's magazine World of Work, No. 44, September/October, 2002, Geneva, pp. 8-11

?? A three-minute video was produced, on CD-ROM, showing the conditions of work among check-in workers at the three study sites. The CD can be requested for free from Ellen Rosskam (Rosskam@ilo.org) or from the ITF, Civil Aviation Section

?? Conclusions from the ILO Tripartite Meeting on the Civil Aviation Industry, January 2002, Geneva, call for the ILO to continue research and follow-up work related to the present study of check-in workers

?? Study results accepted for presentation at the International Commission on Occupational Health, February 2003, Iguassu Falls, Brazil 
?? Study results accepted for presentation at the International Ergonomics Association Conference, August 2003, Seoul Korea

?? Feature article in Daily Times of Nigeria, March 2003

?? Article published by LO Sweden, in Swedish, April 2003

?? Article published by LO Denmark, in Danish, April 2003

?? Article published by the Labour Inspectorate of the Czech Republic, in Czech, April 2003

?? Joint seminar: ILO Programme on Social and economic security and Labour Inspectorate of the Canton of Geneva, October 23, 2003, at ILO Geneva, with management, union representatives, and check-in workers from Geneva International Airport

?? The CCOHS, ITF, CAW, CLC, and ILO will disseminate the report of this study through its appropriate channels. Management at all three study sites will be provided with copies of the report

?? This research served as the basis of a doctoral thesis by Ellen Rosskam, at the University of Lausanne, Management School, Lausanne, Switzerland, Doctorate in Economic Sciences: Management, January, 2003. 